\title{
NATURALEZA DE LOS RADICALES LIBRES DE ALANINA
}

\author{
TESIS QUE PRESENTA
}

M. en C. AGUSTIN CABRAL PRIETO

PARA OBTENER EL GRADO DE DOCTOR EN CIENCIAS

México D. F. , febrero del 2000.

UNIVERSIDAD AUTÓNOMA METROPOLITANA, UNIDAD IZTAPALAPA, División de Ciencias Básicas e Ingenieria. 


\section{DIRECTOR DE LA PRESENTE TESIS DOCTORAL \\ Dr. Julio Rubio Oca}




\section{ÍNDICE}

Pag.

RESUMEN 1

INTRODUCCION 4

A. Los dosimetros de alanina y la intercomparación 7 dosimétrica

B. Medición dosimétrica en el ámbito clínico 8

C. Naturaleza de los radicales libres de alanina $\quad 10$

CAPÍTULO I. CONVOLUCIÓN Y DECONVOLUCIÓN NUMÉRICA

$\begin{array}{ll}\text { A. El perfil de Voigt } & 17\end{array}$

B. El método de deconvolución

CAPÍTULO II. PARTE EXPERIMENTAL 29

A. Preparación de muestras y su irradiación con rayos $\gamma$

B. Tratamientos con luz UV y temperatura 29

C. Mediciones de RPE $\quad 30$

D. Tratamientos numéricos de los espectros de RPE 31

1. Uso del perfil de Voigt. Cambios de intensidad 31 relativa y de los anchos de línea.

2. Método de deconvolución. Estudio de la 32 superposición de líneas.

3. Líneas satélite 
CAPÍTULO III. LÍNEAS SATÉLITE Y NATURALEZA DE LOS RADICALES LIBRES DE ALANINA

A. Líneas satélite 33

B. Tratamiento con luz UV

C. Tratamiento térmico a $423 \mathrm{~K}$ y con luz UV

D. Tratamiento térmicu \& $473 \mathrm{~K} \quad 60$

E. Efecto de la dosis 61

CAPÍTULO IV. EFECTO DEL SILICON SOBRE LA 67 PRODUCCIÓN DE RADICALES LIBRES AL IRRADIAR ALANINA CON RAYOS $\gamma$

A. Alanina pura tratada con luz UV y a $423 \mathrm{~K} \quad 69$

1). Alanina pura irradiada y tratada con luz UV 69

2). Alanina pura irradiada y tratada a $423 \mathrm{~K} \quad 71$

B. Alanina con silicón tratada con luz UV y con 73 temperatura . 
APÉNDICE A. ESPECTRO DE RPE DE LA ALANINA IRRADIADA

A. 1 El radical libre $\left({ }_{\beta} H_{3} \dot{C}_{\alpha} H R,\left(\mathbf{R}=\mathrm{CO}_{2} \mathrm{H}\right)\right.$.

A. 2 Patrón de RPE de la alanina a $77 \mathrm{~K}$

A.3. Transiciones prohibidas en el radical libre $\mathrm{C}_{\beta} H_{3} \dot{\mathrm{C}}_{\alpha} H R$

APÉNDICE B. DECONVOLUCHÓN DE ESPECTROS

B.1 Deconvolución usando el método aproximado

B.2 Comparación entre métodos de deconvolución 


\section{AGRADECIMIENTOS}

Dedico este trabajo de estudios a mis padres, la Sra. $M^{a}$ de Jesús Prieto Magallanes y al Sr. Pedro Cabral Avila, quienes en vida, siempre me mostraron que una de las cosas importantes en la vida era poder realizar todo aquello que uno mismo se plantea. Esta enseñanza siempre esta conmigo.

Quiero agradecer también a mi hermana Carmen Llamas Prieto y a mi hermano Francisco Cabral Prieto, quienes sin ellos, yo no hubiera podido realizar mis estudios de licenciatura.

De igual forma quiero dar las gracias a mi asesor, el "Dr. Julio Rubio Oca", por permitirme realizar este trabajo de doctorado bajo su dirección. Agradezco sobre manera su disposición a dejarme desarrollar y concluir este trabajo de tesis con mis propias ideas.

Finalmente también dar las gracias al Instituto Nacional de Investigaciones Nucleares por brindarme su apoyo y darme las facilidades para realizar estos estudios. 


\section{RESUMEN}

En la actualidad la Resonancia Paramagnética Electrónica (RPE) de la alanina $\left(\mathrm{CH}_{3} \mathrm{CH}\left(\mathrm{NH}_{2}\right) \mathrm{COOH}\right)$ irradiada, es la base del sistema dosimétrico Alanina/RPE que se utiliza para controlar procesos de irradiación a nivel industrial y a nivel terapéutico.

En este sistema dosimétrico generalmente se mide la intensidad de la línea central del patrón de polvos de RPE de los radicales libres de alanina $\left(e l \mathrm{CH}_{3} \dot{\mathrm{C}}\right.$. $\mathrm{HCOOH}$ y posiblemente otras especies), inducidos previamente por radiación ionizante, para luego relacionar esta intensidad con la dosis absorbida.

El origen del patrón de polvos de RPE de la alanina irradiada, base de este sistema dosimétrico hasta ahora, sin embargo, no ha sido perfectamente interpretado. En este trabajo se analizan su estructura y su origen.

Como antecedentes se puede mencionar que, en general, se acepta que algunas de las señales de resonancia que aparecen en el espectro de RPE son debidas a la especie de radical libre $\mathrm{CH}_{3} \dot{\mathrm{C}} \mathrm{HR}\left(\mathrm{R}=\mathrm{CO}_{2}\right)$, en donde el grupo amino $\mathrm{NH}_{2}$ de la alanina $\mathrm{CH}_{3} \mathrm{CH}\left(\mathrm{NH}_{2}\right) \mathrm{R}$ es eliminado por el efecto de la radiación (Miyagawa and Gordy, 1960, 1962 ; Morton et al., 1961).

Por otra parte, también existen evidencias experimentales de que se pueden inducir especies secundarias de radicales libres (Brustad et al., 1964 ; Samskog et 
al., 1980 ; Kuroda et al., 1982 ; Matsuki et al., 1982 ; Cabral Prieto et al., 1994 ; Pilbrow et al., 1996 ; Vitaly et al., 1996) y/o defectos cristalinos (Kuroda et al., 1982 ; Höfer et al., 1989 ; Nakagawa et al., 1993 ; Brustolon et al., 1994) al irradiar alanina con radiación ionizante.

Un rasgo espectral adicional del patrón de polvos de RPE de los radicales libres de alanina son las denominadas líneas satélite, debidas a transiciones de baja probabilidad (prohibidas por la regla de selección de espin, . $I m_{1}= \pm 1$ ), que aparecen en el espectro (Miyagawa and Gordy, 1960 ; Höfer et al., 1989 ; Arber et al., 1991 ; Barnard et al., 1996 ; presente trabajo). Si bien estas lineas satélite ya fueron identificadas, a partir de su medición surge una señalización mas sistemática de ellas. La asignación de estas líneas como satélite aún, sin embargo, presenta controversias.

A partir del estudio de esas líneas satélite en este trabajo, se muestran evidencias adicionales sobre la generación de al menos cuatro especies secundarias de radicales libres al irradiar, a temperatura ambiente, muestras de alanina policristalina. Esto último, como resultado del análisis numérico de convolución y deconvolución que se realiza a los espectrcs de RPE que se observan después de tratar a los radicales de alanina con luz UV y calor. 
Por otra parte, cuando se analiza el efecto que tiene el silicón (II.aterial aglutinante que se utiliza para producir el dosimetro de alanina del LFAM cel ININ') sobre la generación de los radicales libres al irradiar alanina, se obtienen evidencias de que este material aglutinante (el silicón) inhibe la formación de al menos (i) una especie secundaria de radicales libres y/o (ii) de defectos cristalinos. Como parte de este trabajo y en el contexto de los datos experimentales sobre el efecto del aglutinante (silicón), el efecto de otros aglutinantes (como parafina y otros polimeros, etc.) podrá también estudiarse para ampliar el estudio de la naturaleza de los radicales libres que se inducen al irradiar muestras de ala nina aglutinada.

Dado que la técnica de deconvolución, para aumentar la resolu:ción espectral, es una herramienta básica de este trabajo, se reporta la comparación entre dos métodos numéricos de deconvolución (uno aproximado y otro no aproximado), mostrando la utilidad de dichas técnicas de análisis para los casos en donde existe una gran superposición de señales espectrales. Adicionalmente a esta comparación, entre métodos de deconvolución (Cabral Prieto ett al., 1991, 1993, 1994 ; Hedberg y Ehrnberg, 1968), la técnica de deconvolución es mejorada al poder eliminar señales de alta frecuencia que pueden aparecer en los espectros deconvolucionados; esto es, como resultado del proceso numérico de deconvolución.

\footnotetext{
' LFAM del ININ significa Laboratorio de Fisica Atómica y Molecular de Instituto Nacional de Investigaciones Nucleares.
} 


\section{INTRODUCCIÓN}

Los radicales libres que se producen al irradiar alanina $\left(\mathrm{CH}_{3} \mathrm{CH}\left(\mathrm{NH}_{2}\right) \mathrm{COOH}\right)$, uno de los aminoácidos mas simples de la naturaleza, han sido objeto de estudio desde hace aproximadamente cuatro décadas (Bradshaw et al., 1962, Haskell et al., 1998). Su estudio aún continua. Debido a la naturaleza paramagnética de esos radicales libres, la Resonancia Paramagnética Electrónica (RPE) ha sido la técnica que más se ha utilizado para su estudio. Debido a la gran estabilidad de estos radicales libres a la temperatura ambiente, y su respuesta casi lineal de producción en cierto intervalo de dosis, ha permitido el uso de la alanina como dosímetro el cual es ampliamente conocido (Appl. Radiat Isot., Vol. 44, No. (1/2), (1993). Por ejemplo, desde los años 60 se planteó la posibilidad de medir con la señal de RPE de estos radicales libres, las dosis que se reciben de la radiación proveniente de una ráfaga solar. Mas tarde, en 1982, se promueve también el uso del sistema dosimétrico Alanina/RPE para emplearlo en el monitoreo de diversos procesos de irradiación, como el del esterilizado de materiales por radiación, en irradiación de alimentos, en irradiaciones terapéuticas, como un sistema secundario de referencia, etc. En estos procesos de irradiación se emplean dosis que fluctúan entre 0.001 y $100 \mathrm{kGy}$, intervalo de dosis para el cual el sistema Alanina/RPE es lineal (Sarpe et al., 1996). No es sino hasta 1988 cuando el sistema dosimétrico Alanina/RPE es adoptado formalmente por algunos paises asociados a la Agencia Internacional de Energía Atómica (AlEA) (Appl. Radiat Isot., Vol. 44, No. (1/2), (1993) y ibid, Vol.47, No. (11/12), (1996)), (3). En los 
últimos años, este sistema dosimétrico se ha estado estudiando cuidadosamente para controlar procesos de irradiación terapéutica. cuyas dosis de irradiación están entre 0.05 y $10 \mathrm{~Gy}$ (Haskell et al., 1998). Este aspecto por si solo bastaría para justificar un estudio sistemático y más profundo del espectrio de RPE de los radicales libres de alanina, ya que el espectro de RPE de los radicales de alanina, obtenidos con estas dosis bajas no esta bien definido

En términos muy generales, se ha supuesto que el patrón de RPE de la alanina policristalina irradiada, proviene del radical libre $\mathrm{CH}_{3}\left(\dot{ } \mathrm{HR}\left(\mathrm{R}=\mathrm{COO}_{2} \mathrm{H}\right)\right.$, que queda atrapado en la red cristalina y en donde el electrón libre se sitủa preferentemente en el carbono del grupo $\mathrm{CH}$, e interactúa con los protones del gr'spo metilo $\left(\mathrm{CH}_{3}\right)$ y con aquel de grupo $\mathrm{CH}$, solamente. Evidencias experimentale:s que (Miyagawa and Gordy, 1960; Morton et al. 1961), muestran el protón del grupo R no interactúa con el electrón libre. La posible existencia de especies secundarias de radicales libres o de defectos cristalinos aparece mas claramente cuando se estudian los radicales libres inducidos al irradiar alanina policristalina. El espectro de polvos de RPE de estos radicales libres de alanina ha sido muy estudiado pero sin llegar a esciarecer las peculiaridades que se observan al soineter los radicales libes a ciertos tratamientos.

De estudios con monocristales de L-alanina irradiada se ha concluido que los protones de los grupos $\mathrm{CH}_{3}$ y del $\mathrm{CH}$ pueden interaccionar isotrópicamente con el electrón libre. Esto ocurre al orientar el eje cristalino [001] con la dirección del 
campo magnético aplicado, en donde se observa un patrón de cinco líneas con razones de intensidad muy próximas a $1: 4: 6: 4: 1$. Sin embargo, cuando el eje cristalino [100] se alinea con la dirección del campo magnéticc aplicado aparece un doble cuarteto con razones de intensidad cercanas a $1: 1: 3: 3: 3: 3: 1: 1$. De aqui se concluye que el acoplamiento del protón del grupo $\mathrm{CH}$ es diferente con respecto de aquellos del grupo metilo. Para otras direcciones, entre el campo magnético y los ejes cristalinos, aparece la superposición del quinteto y el doble cuarteto arriba mencionados.

Por otra parte, el patrón de RPE de la alanina policristalina irradiada consiste aproximadamente de un patrón de cinco lineas muy ensanchadas, y cuyas razones de intensidad son también muy próximas a $1: 4: 6: 4: 1$. Pareciera que se induce una sola especie de radical libre al irradiar alanina policristalina, esto es el $\mathrm{CH}_{3} \dot{\mathrm{C}}$ HR. Como se ha hecho notar en el resumen, varios estucios muestran que este podria no ser el caso.

Aunque la historia sobre la naturaleza de los radicales libres de alanina esta inconclusa, la mayor parte de los estudios sobre alanina policristalina irradiada han estado orientados a resolver el problema de dosimetria de las altas (industriales) y las bajas (clínicas) dosis, no importando mucho la naturaleza misma de los radicales libres que se inducen al irradiar alanina. La gran aceptación del sistema dosimétrico Alanina/RPE, que incluso ha reemplazado paulatiniạmente a otros, se debe al hecho de que los radicales libres de alanina, son muy estables a la 
temperatura ambiente; y además, es un sistema dosımétrico no destructible y de lectura fácil. En la actualidad hay gran interés por conocer la naturaleza de estos radicales libres. Es claro que el conocer rigurosamente la interacción radiaciónalanina seria benéfico en el aspecto biológico, en el de la dosimetria, y en general en el de la interacción de la radiación ionizante con substancias hidrocarbonadas.

Asi, las diversas investigaciones realizadas hasta ahora alrededor de este sistema dosimétrico, podrian agruparse en tres lineas principales de investigación : (a) La Intercomparación dosimétrica entre los distintos Laboratorios que usan este sistema dosimétrico, (b) La medición dosimétrica en el ámbito terapéutico y (c) El estudio de la Naturaleza de los radicales libres de alanina. A continuación se hace una descripción breve de estas líneas de investigación :

\section{A. Los dosímetros de alanina y la intercomparación dosimétrica}

La primera linea de investigación esta relacionada con la medición de la dosis de irradiación con el sistema dosimétrico Alanina/RPE, en Jonde desde su establecimiento como técnica dosimétrica por la IAEA, se realizan intercomparaciones entre los distintos laboratorios incorporados a este sistema. EI objetivo de estas intercomparaciones, es poder medir con ei mínimo error, la misma dosis absorbida de un dosímetro de alanina irradiado a cierta dosis, entre los distintos laboratorios asociados a este sistema dosimétrics. Actualmente el error minimo alcanzado entre algunos laboratorios llega al $1 \%$ (Wieser et al., 
1996). Esta intercomparación se ha hecho necesaria ya que prácticamente cada laboratorio tiene un dosimetro de alanina y un espectrómetro de RPE distintos. De esto se puede inferir que aún no se cuenta con un dosimetro tipo universal que supla, en el mejor de los casos, a dicha diversidad, pues cada iaboratorio apuesta a su propio dosimetro.

Por otra parte, es indudable que esta diversidad de dosimetros ha diversificado el número de estudios publicados alrededor de este sistema, y er, razón de esto se han reconocido varios aspectos relacionados con la estabilidad y la naturaleza de los radicales libres de alanina, pero en donde aún existen aspectos de tipo práctico y fundamental por conocer.

\section{B. Medición dosimétrica en el ámbito clínico}

La segunda línea de investigación está relacionada con la medición de irradiaciones a bajas dosis utilizando el sistema dosimétrico Alanina /RPE. Cuando se someten los dosimetros de alanina a dosis muy bajas (0.05-50 Gy), la medición entre el máximo y mínimo de la señal más intensa del espectro de RPE, debida a los radicales libres generados por la radiación, se involucra un error de lectura mayor que cuancio se realiza para altas dosis. Compare las Figs. 1 a) y b), en donde la distancia entre el máximo y el mínimo de la línea central del espectro de alanina irradiada con 50 Gy no está bien definida, i. e., hay cierto error debido al ruido instrumental de la señal ; por otra parte, la distancia entre el máximo y el 


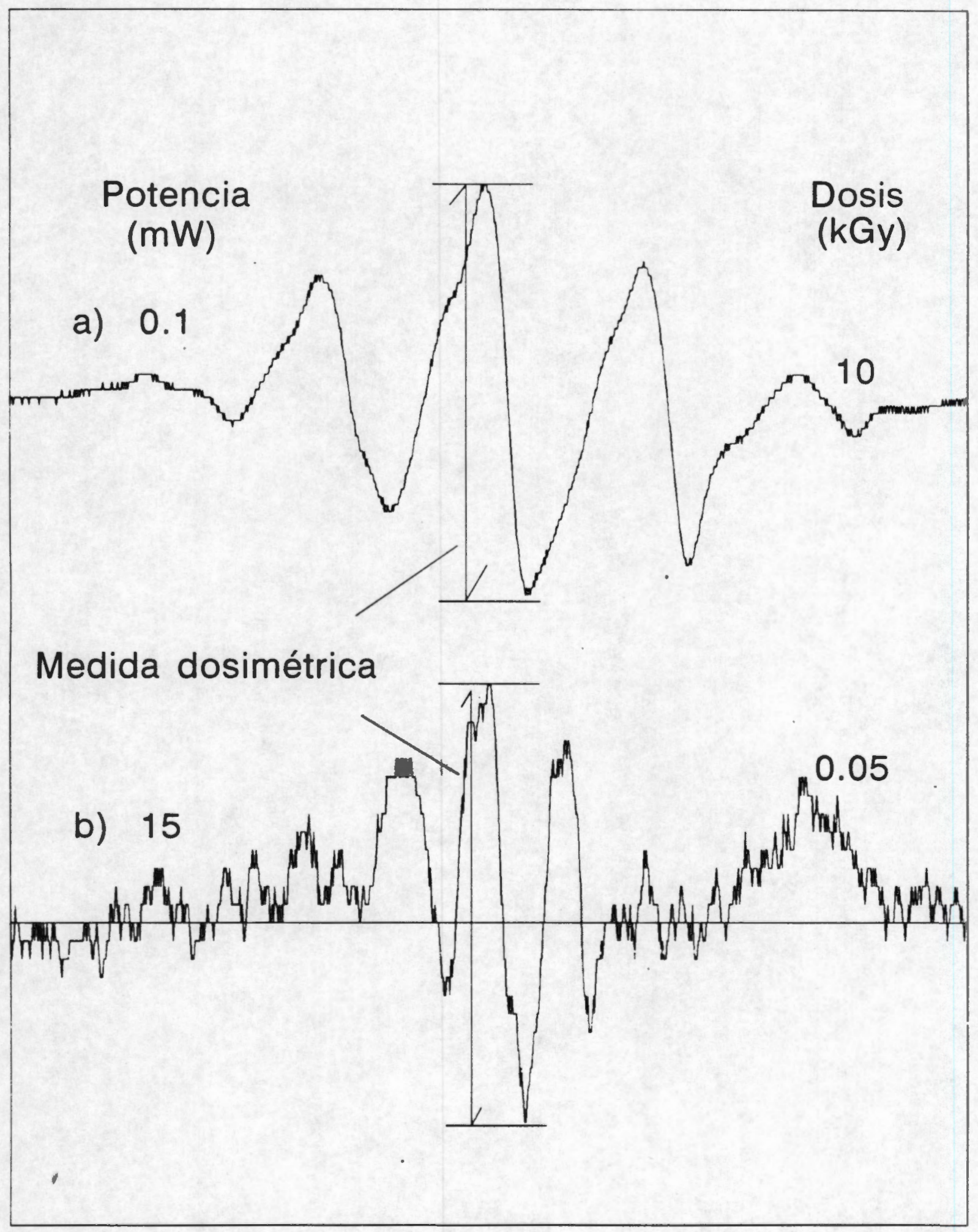

FIGURA 1. Comparación entre espectros obtenidos de muestras irradiadas a distinta dosis y potencias. El Grey $(G y)$ es la unidad para medir las dosis absorbidas por los materiales. 1 Gy $=10000 \mathrm{erg} / \mathrm{g}$. Mientras que el campo barrido en (a) fue 200 Gauss en (b) fue de 400 Gauss. 
minimo de la señal central del espectro de la alanina irradiada con 10 kGy está bastante bien definida, el ruido instrumental de la señal es mucho menor. Debe hacerse notar que el espectro de la alanina irradiada con 50 Gy, Fig. 1 b), fue registrado usando una potencia de las microondas de $15 \mathrm{~mW}$ para incrementar la razón señal-a-ruido. En el pasado se optó por emplear altas potencias para aumentar la razón señal-a-ruido de los espectros de RPE de los dosímetros irradiados con bajas dosis. Esta práctica se ha discutido someramente debido a la presencia de líneas satélite (Arber et al., 1991 ; Haskell et al. 1998). Algunas otras opciones han surgido para su medición. Por ejemplo, los tratamientos numéricos sobre los datos experimentales (Sharpe et al., 1996 ; Ruckerbauer et al., 1996 ; Haskell et al., 1998) ó las mediciones a $200 \mathrm{~K}$ (Rakvin et al., 1996), ó el registro de los espectros bajo diversas condiciones de operación ciel espectrómetro (Bartolotta et al., 1993; Wieser et al., 1993). Todo ello con el objeto de incrementar la razón señal-a-ruido del espectro de RPE de los :adicales libres de alanina. Este sigue siendo un problema de investigación abierto.

Aunque desde el origen del sistema dosimétrico Alanina/RPE, (Bradshaw et al., 1962), se usó la doble integración para evaluar el área del espectro de RPE y así evaluar el número total de radicales libres de alanina en conjunción con un patrón de referencia, ésta técnica se sustituyó posteriormente por la medición entre el máximo y mínimo de la señal mas intensa del espectro de RPE r'e estos radicales. Este última medida es mas simple y práctica de efectuar. Existe un método físicoquímico alterno para medir el número total de radicales lib:es de alanina, vía la medición del amoniaco atrapado en el dosímetro, por medio de un electrodo 
selectivo de iones (Van Laere et al., 1989). Este método aunque confiable es destructivo. Por otra parte, para medir el número de radicales libres de alanina con la técnica de RPE se necesitaria determinar : el radical libre o los radicales libres que se inducen por la radiación, los fenómenos de ensanchamiento del espectro de RPE y la forma de la línea base, aspectos que no se conocen del todo bien en el presente caso. Por ejemplo, hasta ahora no ha sido posible interpretar satisfactoriamente el espectro de polvos de RPE de la alanina irradiada. La posible existencia de radicales libres secundarios y/o defectos cristalinos, aun no caracterizados, dificultan esta tarea. Además, cada aglutinante usado para producir un dosimetro de alanina, produce generalmente una línea base diferente y cierto ensanchamiento en el espectro de RPE de los radicales de alanina o algún otro efecto, que aun no han sido considerados.

\section{Naturaleza de los radicales libres de alanina}

La tercera línea de investigación se concentra en estudiar la naturaleza de los radicales libres que se inducen al irradiar alanina $\left(\mathrm{CH}_{3} \mathrm{CH}\left[\mathrm{NH}_{2}\right] \mathrm{C} ; \mathrm{OOH}\right)$, ya sea en forma policristalina o en forma de monocristal.

Actualmente existe interés por interpretar correctamente el espectro de polvos de RPE de la aianina irradiada y por ende el de su origen. Como se mencionó antes, la falta de su interpretación, sin embargo, no ha detenido la apliçación práctica que 
se ha hecho de lo que hasta ahora se conoce de la interacción radiación ionizantealanina.

De un lado, se acepta que una de las especies de radical libre que se produce al irradiar alanina es el $\mathrm{CH}_{3} \dot{C} \mathrm{HR}$ (Morton et al., 1961 ; Miyagawa et al., 1960, 1962) y es la especie de radical libre que pudiera producirse en mayoi proporción, pero sin descartar la formación de especies secundarias de radicales libres, aún no identificadas claramente. Por ejemplo, de los diversos experin:entos usando las tres variantes de la RPE (de onda continua, pulsada y la doble resonancia nuclear y electrónica) y utilizando alanina policristalina o en forma de monocristal, se muestran evidencias de que al irradiar alanina se producen más de una especie de radicales libres y/o defectos cristalinos (Brustad et al., 1964; Samskog et al., 1980 ; Kuroda et al., 1982; Matsuky et al., 1982 ; Höfer et al., 1989; Nakagawa et al., 1993; Brustolon et al., 1993 ; Wieser et al., 1993 ; Cabral-Prieto et al., 1993, 1994 ; Vitaly et al., 1996, Pilbrow et al., 1996).

Es de interés mencionar el trabajo de Samskog et al., (1980), quienes llegan a sugerir a partir del análisis de las transiciones ópticas de la alanina irradiada y correlacionando estos resultados con las mediciones de RPE de onda continua (RPE-oc), que la segunda especie de radical libre de alanina pudiera ser el $\mathrm{CH}_{3} \mathrm{CHR},\left(\mathrm{R}=-\mathrm{NH}_{2}\right)$, en donde ahora el grupo carboxilo, $\left(\mathrm{CO}_{2} \mathrm{H}\right)$, es eliminado de la molécula de alanina por efecto de la radiación ionizante. Esta especie de radical no ha sido confirmada (Samskog et al., 1980). 
Al estudiar la naturaleza de los radicales libres que se inducen al irradiar alanina policristalina, utilizando su espectro de RPE, es necesario tornar en cuenta la presencia de señales satélite, resultado de transiciones de es?rín no permitidas. Estas señales han generado cierta controversia (Miyagawa et ol., 1960; Höfer et al., 1989 ; Arber et al., 1991 ; Barnard et al., 1996) debido a su origen no bien establecido. Estas líneas prohibidas o satélite se observan en los patrones de RPE de un monocristal de alanina irradiado cuando se usan micro-ondas de $24 \mathrm{GHz}$, (Miyagawa et al., 1960). En algún momento estas lineas satélite, que también aparecen en el patrón de polvos de RPE usando micro-ondas de $9 \mathrm{GHz}$ y altas potencias $(200 \mathrm{~mW})$, han estado asociadas a especies secuncarias de radicales libres (Wiessel et al., 1993, Pilbrow et al., 1996). Estas lineas satélite han complicado entonces la interpretación del patrón de polvos de RPE de los radicales libres de alanina. Mas recientemente parece contirmarse el origen prohibido de estas líneas satélite usando microondas de varias energías (Branrad et al., 1996). En el presente trabajo se hacen algunas observaciones sobre su identificación y su señalización debido a Arber et al., 1991 y Barnard et al., 1996; una señalización empleada por varios autores que de algún modə es incorrecta.

Asi, la naturaleza de los radicales libres inducidos al irradiar alanina, ya sea en forma de un monocristal o en forma policristalina, aun no se corıocen bien y tiene un interés general. Además de esto, el sistema dosimétrico Alénina/RPE esta ya inmerso dentro del comercio internacional, en donde la trasferensia de mercancias controladas con radiación es una realidad. Debido a esto, el mejoramiento del este 
sistema dosimétrico, tanto en el área industrial como en el área clínica, se hace cada día más necesario.

Entonces, existen varios aspectos fundamentales por entender : por un lado, la interpretación del espectro de polvos de RPE de la alanina irradiada y derivado de esto, la historia de los efectos inducidos por la radiación ionizarite en alanina aún esta incompleta. Hasta ahora no se ha reportado en la literatura una simulación satisfactoria de su patrón de RPE, aún asumiendo que una sola sspecie de radical libre esta presente, e. g. el $\mathrm{CH}_{3} \dot{\sim}$ HR. Por otra parte, aún no se cuenta con un dosímetro universal, y aún no se tiene un procedimiento completo para medir con este sistema dosimétrico las dosis de irradiación bajas (dosis clínicas).

Finalmente, el presente trabajo esta distribuido en la forma siguiente :

En el Capítulo I se describen las técnicas de convolución y deconvolución numéricas utilizadas para analizar la estructura de líneas de los espectros de RPE de los radicales libres de alanina.

En el Capitulo II se presenta la parte experimental del trabajo, en donde se describe la preparación de las muestras de alanina pura y aglutinada con silicón, el proceso de irradiación gama, los distintos tratamientos con lu.? UV y calor a que son sometidos los radicales libres de alanina inducidos por radięción, y finalmente 
se describe el análisis numérico realizado a los espectros de RPE observados. También se describe el equipo utilizado en el trabajo.

En el Capitulo III se reporta una parte de los resultados, particuiarmente, sobre el estudio de las líneas satélite que aparecen en el patrón de polvos de RPE de los radicales libres de alanina, sobre los resultados que se obtientn al tratar a esos radicales libres con luz UV y calor, y sobre el efecto de distintas dosis de irradiación, al irradiar alanina aglutinada con silicón, en la producción de los radicales libres.

En el Capitulo IV se reporta la otra parte de los resultados, y en particular sobre el efecto que tiene el silicón, el aglutinante para formar el dosimetro de alanina del LFAM del ININ, en relación al efecto que tiene este aglutinante al prevenir la formación de especies secundarias de radicales libres de alanira. Por su parte el Capitulo V reporta la conclusiones del trabajo.

Por su parte, en el Apéndice $\mathbf{A}$ se describen elementos básicos en relación al patrón de RPE del radical libre de alanina, el $\mathrm{CH}_{3} \dot{\mathrm{C}} \mathrm{HCOOH}$, oue se observa en un monocristal de L-alanina irradiado con rayos gama, tarto a temperatura ambiente como a $77 \mathrm{~K}$. Asi mismo, en este Apéndice A se dan elementos generales en relación al origen de las señales satélite que aparecen en el patrón de polvos de RPE de los radicales libres de alanina. 
Por otra parte, en el Apéndice B se reporta la comparación ent:e los métodos de deconvolución (aproximado y no aproximado) numéricos para incrementar la resolución espectral. En este Apéndice $\mathbf{B}$ también se reporta el método para eliminar señales de alta frecuencia que pueden aparecer en un espectro deconvolucionado.

En la parte final de este manuscrito se presenta la bibliografíe utilizada en este trabajo.

15 


\section{CAPITULO I}

\section{CONVOLUCIÓN Y DECONVOLUCIÓN NUMÉRICA}

En el presente trabajo se emplean las técnicas de convolución y deconvolución numéricas para estudiar la estructura de lineas de los espectros de polvos de RPE de los radicales libres que se inducen al irradiar alanina. Con este estudio se buscan evidencias espectrales sobre la posible existencia de mas de una especie de radical libre en alanina irradiada.

Básicamente, la alanina previamente irradiada con radiación $\gamma$ (en forma pura o aglutinada con silicón) será sometida a una serie de tratamientos con luz UV y térmicos para estudiar los procesos de decaimiento de los radicales libres utilizando los cambios espectrales de RPE. Algunos de estos carnbios espectrales se analizan haciendo uso del método de mínimos cuadrados y convolución, en donde los quintetos ensanchados de RPE observados, Fig. 2, son ajustados a un patrón de cinco Voigtianas. Con ello se analizan de manera cualitativa los cambios relativos en la intensidad y ensanchamiento de las líneas. Estos cambios de intensidad (o de áreas relativas) y de ancho de líneas, podrian relacionarse con la posible existencia de especies secundarias de radicales libres y/o defectos cristalinos al irradiar, a la temperatura ambiente, alanina pura o en forma aglutinada con silicón. 
La técnica de deconvolución numérica, por su parte, se utiliza para incrementar la resolución en energía de los espectros de polvos de RPE de los radicales libres de alanina. Con la deconvolución numérica se estudia la estructura de las líneas de los espectros, al variar la potencia de las microondas, debido a los tratamientos de los radicales libres con luz UV, por efecto del calor, por el efecto de diferentes dosis de irradiación, y por efecto del silicón como aglutinante del dosímetro de alanina. Con el incremento de resolución espectral simplemente se investigan distintas lineas espectrales para poder discernir entre líneas satólite y de aquellas permitidas de especies primarias y/o secundarias de radicales lit:res.

A continuación se hace una descripción de las técnicas numéricas por emplear :

\section{A. El perfil de Voigt}

La forma general de la integral de convolución de dos funciones $g(y)$ y $l(y)$ se expresa como:

$$
I(t)=\int_{\infty}^{\infty} g(y) l(t-y) d y .
$$

Si $g(y)$ y $l(y)$ representan perfiles de línea que se pueden describir analíticamente, entonces I $(t)$ es la convolución de ellas y puede ser usada para 
describir una línea espectral observada. Por ejemplo $I(v)$ puede representar a la función espectroscópica que representa al fenómeno de resonancia que se desea estudiar. En experimentos de absorción resonante, esta distribución es del tipo lorentziano (Abragam et al., 1970). Por otra parte, $g(y)$ puede ser cualquier distribución estadistica que describa algún fenómeno externo de perturbación al proceso de absorción (emisión) de energía por un átomo o núcleo. Esta perturbación provocará una modificación de la función espectroscópica original, modificación que dependerá del tipo de interacción entre el átomo o núcleo que absorbe (o emite) energía con el medio que lo rodea. Cuando la perturbación al proceso de absorción (emisión) de energia es del tipo aleatorio, $g(y)$ puede representarse por una distribución de tipo gausiano. Como resultado de esta perturbación aleatoria la función espectroscópica (lorentziaria) de absorción (emisión) se ensancha sin asimétrizarse. Esta perturbación de origen aleatorio puede representar también la imprecisión del sistema que mide al fenómeno ; esto es, a la resolución del propio sistema de observación. A la resoiución del sistema generalmente se le asocia una distribución de tipo gausiano.

En RPE este tipo de perturbaciones pueden tener su origen en las interacciones entre el centro de resonancia (electrón(s) desapareado (s)) y' el medio que lo circunda. Por ejemplo, un centro paramagnético puéde interaccionar isotrópicamente (espin-espin, $S_{1}=S_{2}$ ) 0 anisotrópicamente (espin-espin, $S_{1} \neq S_{2}$ ) (J. A. Mcmillan, 1967) dando origen a distintas distribuciones estadísticas que se convolucionan con la señal espectroscopica original. A la coinvolución de una 
lorentziana con una gausiana se le conoce como perfil de $V$ igt (Voigt, 1912; Posener, 1957). Al estudiar los mecanismos de relajamiento del centro paramagnético, el perfil de Voigt puede proporcionar información útil ya que el centro paramagnético puede interaccionar con el medio que lo rodea de forma isotrópica o homogénea (ensanchamiento lorentziano), o anisotrópica o heterogénea (ensanchamiento gausiano), de tal suerte que empleando el perfil de Voigt, uno puede estudiar esas interacciones vía la evaluación del ensanchamiento espectral de tipo gausiano y lorentziano.

Explícitamente el perfil de Voigt se puede escribir de la siguiente manera :

$$
H(a, v)=\frac{a}{\pi} \int_{x}^{\pi} \frac{d y e^{y^{2}}}{a+(v-y)^{2}}
$$

De acuerdo a la notación de Posener, (1959), $a$ y $v$ están dadas por

$$
a=\frac{\Gamma_{L} \sqrt{\ln 2}}{\Gamma_{G}},
$$

$y$

$$
v=\frac{t-t_{o}}{\sigma \sqrt{2}}
$$


donde $\Gamma_{L}$ es el ancho total a la mitad del pico (ATMP) de la distrilución lorentziana, $\sigma$ es la desviación estándar de la gausiana, que se relaciona con el ATMP por $\Gamma_{G}=$ $\sigma 2 \sqrt{2 \ln 2}, t_{0}$ representa al centro o la frecuencia media de la Voigtiana $H(a, v)$.

La integral [2] no tiene solución exacta pero puede escribirse en términos de la función compleja de error :

$$
H(a, v)=\operatorname{Re}\left[e r f c(z) e^{z^{2}}\right]
$$

donde la función compleja de error $w(z)$ esta definida por :

$$
w(z)=\operatorname{erfc}(-i z) e^{-z^{2}}
$$

por lo que

$$
H(a, v)=\operatorname{Re} w(i z)=\operatorname{Re}\left[\operatorname{erfc}\left(-i^{2} z\right) e^{z^{2}}\right]
$$

donde $z$ es un numero complejo y está dado por $z=a+i v$.

La evaluación numérica de $H(a, v)$ se realiza empleando el algoritmo de Gautschi, (1970 ; Flores Llamas et al., 1990, 1991), a partir del cual se pueden conocer tanto la componente homogénea como heterogénea de un espectro de RPE. 
Bajo estas consideraciones, es posible que el espectro de polvos de RPE de los radicales de alanina ${ }^{2}$ pueda aproximarse a un patrón de cinco líneas, Fig. 2. Esta aproximación es posible debido al gran ensanchamiento espectral observado, en donde la razón de intensidades relativas se aproxima a los valores 1:4.6:4:1 ya antes señalado. Por ejemplo, los valores obtenidos del ajuste de la Fig. 2 fueron $(0.99: 4.02: 6.00: 3.80: 0.90)$. De esta manera, mediante la minimización del cuadrado de las diferencias entre los datos experimentales y os calculados, se pueden estudiar algunos cambios espectrales (áreas relativas y el ensanchamiento de líneas) del espectro de RPE de los radicales de alanina. Así el criterio de ajuste es:

$$
\bar{\chi}^{2}=\left(\left(Y_{\text {exp }}-Y_{\text {calc }}\right)^{2} \quad / Y_{\text {exp }}\right) /(N-n p),
$$

en donde

$$
Y_{\text {calc }}=\sum_{n=1}^{5} H_{n}\left(a_{n}, v\right)
$$

$H(a, v)$ esta dada por la expresión [7], de tal suerte que lo que se busca son los anchos gausiano y lorentziano (expresiones [3] y [4]) para cada línea ensanchada del espectro. Las letras $N$ y $n p$ de la expresión [8] representa al número de datos experimentales y al número de variables a ajustar, respectivamente.

\footnotetext{
2A menos de que otra cosa sẹ indique. se escribirá radicales de alanina en lugar de rudicales libres de alanina.
} 


$$
M
$$


Aparte de las posibles variaciones en las intensidades relativas del patrón de polvos de RPE de los radicales de alanina, también se intenta encontrar alguna dependencia de los anchos de línea con los distintos tratamientos físicos de los radicales de alanina aqui efectuados. Dado que cada una de las líneas del patrón de polvos de RPE de los radicales de alanina no son únicas, el procedimiento que se siguió para estimar su ancho lorentziano, fue el de mantenerlo constante e igual para todas las lineas; este ancho se varió desde cero militeslas (mT) (caso para el cual se ajustan gausianas puras a los datos) hasta un valor máximo encontrado (caso en que se adaptan a los datos lorentzinas puras). En el proceso de ajuste el ancho lorentziano $\left(\Gamma_{L}\right)$ se estima hasta encontrar un mínimo global. En el Capítulo IV se muestra la evaluación de este mínimo que puede tener algún interés al caracterizar el dosimetro de alanina a base de silicón. Así, la Fig. 2 muestra un resultado típico de ajuste, en donde se observa que el modelo de cinco Voigtianas se adapta bastante bien a los datos experimentales, por lo que podria ser posible obtener información útil a partir de estos ajustes.

\section{B. El método de deconvolución}

Debido al gran ensanchamiento y al traslape de líneas obsevado en el espectro de polvos de RPE de la alanina irradiada, Fig. 2, un análisis de su estructura de lineas es adecuado para continuar su estudio (Ureña-Nuñez et al., 1993). Esto se realiza a partir de los espectros resueltos numéricamente. El incremento de 
resolución espectral se obtiene mediante la eliminación de algún tipo de función (lorentziano y/o gausiano) del espectro observado ; esto es, la función a eliminar puede ser la espectroscópica $l(t)$ y/o la función perturbadora $g\left(y_{t}\right.$.

Para este análisis se puede partir de la transformada de Fourier de la expresión [1]

$$
I(\alpha)=(2 \pi)^{1 / 2} G(\alpha) L(\alpha)
$$

donde $I(\alpha), G(\alpha)$ y $L(\alpha)$ son las transformadas de Fourier del espectro observado $I(t)$, de la gausiana $g(t)$ y de la lorentziana $I(t)$, respectivamente. Esto es, la integral en [1] se reduce a un simple producto de las transformadas de Fourier de las funciones que se convolucionan (Brigham, 1974). De la expres:ón [10] se puede despejar ya sea la transformada de Fourier de la lorentziana

$$
L(\alpha)=(2 \pi)^{1 / 2} I(\alpha) / G(\alpha),
$$

ó la transformada de Fourier de la gausiana

$$
G(\alpha)=(2 \pi)^{1 / 2} I(\alpha) \Omega(\alpha)
$$

dependiendo de lá función que uno desee estudiar o eliminar. Si el ancho de un espectro es esencialmente de tipo lorentziano entonces la expresión [12] debe ser 
usada. Caso contrario, si el ancho del espectro es de tipo gausiano la expresión [11] debe ser usada. Existen casos en que ambos tipos dé ensanchamiento contribuyen al ensanchamiento de un espectro por lo que un análisis previo debe realizarse para decidir que tipo de expresión debe usarse. Existe un trabajo previo (Hedberg and Ehrenberg, 1968) en donde se usan directamente las expresiones [11] y [12] sin usar aproximaciones para incrementar la resolución espectral. Debido a que en este método directo se requieren datos experimentales extremadamente bien comportados, esto es, con muy poca fluct sación entre ellos, este método no se utilizará en este trabajo. En el Apéndice E se compara este método directo con el aproximado que a continuación se describa:

Así, el lado izquierdo de la expresión [11] puede ser expresado como

$$
l(t)=(2 \pi)^{-1 / 2} \int_{-\infty}^{\infty} e^{i a t} L(\alpha) d \alpha .
$$

0 , substituyendo [11] en [13]

$$
l(t)=(2 \pi)^{-1} \int_{-\infty}^{\infty} e^{i a t} I(\alpha) / G(\alpha) d \alpha .
$$

Análogamente se obtiene : 


$$
g(1)=(2 \pi)^{-1} \int_{-\infty}^{\alpha} e^{s a t} I(\alpha) / L(\alpha) d \alpha
$$

En los trabajos de SjØntof et al., (1979), y Cabral-Prieto et al. . (1991, 1994), se obtienen las expresiones, en el espacio real, en forma de series de potencias en $\rho$, $\Gamma_{L}$ and $H$; esto es, de la desviación estándar de la distribución gausiana, el ATMP de la lorentizana y la intensidad del campo magnético, respectivamente. La expresión [14] puede expresarse en el espacio real como :

$$
l(H)=\sum_{n=0}^{\infty} \frac{(-1)^{n}}{n !}\left(\frac{\rho^{2}}{2}\right)^{n} a^{2 n}(H)
$$

y la expresión [15] como:

$$
g(H)=\sum_{n=0}^{\infty}(-1)^{n} \frac{\left(\Gamma_{L}\right)^{2 n}}{(2 n) !} a^{2 n}(H)
$$

respectivamente. $a^{2 n}(H)$ representa las derivadas pares con respecto al campo magnérico del espectro de RPE observado, en modo absorción. La derivación completa de estas fórmulas ha sido descrita anteriormente (Cabral-Prieto et al, 1991, 1994). Es apropiado mencionar aqui que este método para incrementar la resolución espectral resulta muy útil cuando se tiene espectros muy ensanchados 
y su interpretación inconclusa. El espectro de la alanina policris’alina irradiada es un muy buen ejemplo.

Estas expresiones están dadas en términos de los datos del espectro observado, los parámetros que dependen de la distribución a eliminar y del número de términos necesarios $n$ para deconvolucionar un espectro; esto es, de $\Gamma_{L} \circ \Gamma_{G}$ y $n$. Debido a la aproximación utilizada con series de Maclaurin (Sjøntof et al., 1979, Cabral Prieto et al., 1991), se tiene una restricción en el sentido de que los anchos de línea a eliminar de un espectro observado, ya sea $\Gamma_{L}[17]$ o $\Gamma_{G}[16]$ deben ser menor o igual al ancho medio a la mitad del pico (AMMP) del espectro observado.

Por otra parte, las derivadas pares pueden evaluarse empleandi la fórmula de las diferencias finitas centrada :

$$
a^{2}(i)=\left[Y(i-m)-2^{*} Y(i)+Y(i+m)\right] / m^{2}
$$

en donde $\boldsymbol{m}$ es un número a determinar en forma empírica en el proceso de deconvolución. El valor de $\boldsymbol{m}$ determina el tamaño de paso entre dato y dato de un espectro dado. El valor de $\boldsymbol{m}$ dependerá de la calidad de los datos; entre mas fluctuaciones estadísticas tengan los datos experimentales mas grande será el valor de $\boldsymbol{m}$. $Y(I)$ es algún punto discreto de los datos experirnentales en modo abscrción. Existen otras formas numéricas para evaluar estas derivadas, aunque no será necesario discutirlas en este trabajo. 
Con el empleo de estas expresiones, uno puede eliminar del espectro observado, ya sea una distribución de tipo lorentziana, expresión [17], usar,do únicamente el espectro de RPE observado, un valor de $\Gamma_{L}$, un número $(n)$ de términos de la serie y $\boldsymbol{m}$. Los valores $\Gamma_{L}, \boldsymbol{n}$ y $\boldsymbol{m}$ se estiman en el proceso de deconvolución. También se puede eliminar del espectro observado, una distribución gàusiana, expresión [16], usando el espectro observado y los valores $\sigma, \boldsymbol{n}$ y $\boldsymbol{m}$, todo ellos a determinar.

El efecto que se obtiene al eliminar cualesquiera de estas funciones de un espectro observado, es el de incrementar su resolución en energía. Esta operación de deconvolución es muy útil al analizar espectros experimentales que presenten un ensanchamiento muy pronunciado. El caso del espectro de polvos de RPE de los radicales de alanina es un muy buen ejemplo.

En el Apéndice B se muestra un procedimiento para deconvolucionar uno de los espectros de polvos de RPE de los radicales de la alanina. Adicionalmente al uso de las expresiones [16] y [17], en ocasiones es necesario eliminar señales espurias o de alta frecuencia que resultan del proceso de deconvolución. Para esto, se emplea la técnica de poda del espectro observadc que también se describe en al Apéndice B. Este procedimiento para eliminar esas señales no deseadas y la comparación de este método aproximado con el método directo de Hedberg and Ehrenberg (1968), forman parte de este trabajo. Esto es, con la eliminación de señales espurias, y con la obtención de mejores iesultados usando 
el método aproximado (Cabral-Prieto et al., 1991), se muestra los avances en la parte de manipulación numérica de datos. 


\section{CAPITULO II}

\section{PARTE EXPERIMENTAL}

\section{A. Preparación de muestras y su irradiación con rayos $\gamma$}

En el presente trabajo se utilizó DL-alanina, grado reactivo de MERCK. Se prepararon dosímetros de alanina pura y en forma aglutinada con silicón (transparente y para uso general de Dow Corning, Co.). Los dosimetros a base de alanina y silicón tienen forma de cilindros con $30 \mathrm{~mm}$ de largo y $3 \mathrm{~mm}$ de diámetro. Aproximadamente se usan $140 \mathrm{mg}$ de DL-alanina en cada dosímetro. La cantidad porcentual en peso entre el silicón y alanina es de 60:40 P/P \%, respectivamente. Se realizaron irradiaciones con una fuente de ${ }^{60} \mathrm{Co}$ del GAMACEL de ININ usando dosis absorbidas desde 0.05 kGy hasta $150 \mathrm{kGy}$.

\section{B. Tratamientos con luz UV y calor}

La alanina pura y los dosimetros de alanina, previamente irradiados con rayos $\gamma$, fueron expuestos a la luz UV utilizando una lampara de luz UV de banda ancha de la General Electric G8T5 con una potencia de $20 \mathrm{~mW}$. Los tiempos de exposición variaron desde 5 minutos hasta dias. Los tratamientos con calor, a 423 K y a $473 \mathrm{~K}$, se realizaron utilizando un plato caliente típico de laboratorio de Dow Corning Co. La temperatura se controló con un termómetro, en donde se observó una variación de $\pm 1^{\circ} \mathrm{C}$. 


\section{Mediciones de RPE}

La mediciones de RPE se realizaron utilizando el espectrómetro Varian E15 operando en la banda $X$. Las condiciones de operación ciel espectrómetro variaron dependiendo del tipo de experimento. Se emplearon putencias de microondas desde 0.1 a $200 \mathrm{~mW}$. La constante de tiempo y la moduración de amplitud fueron siempre de 3 s y de $0.2 \mathrm{mT}$, respectivamente. La frecuencia de modulación del campo fue de $10 \mathrm{kHz}$ y el campo barrido de $20 \mathrm{mT}$. El espectrómetro cuenta con un digitizador de señal en donde 7681 ordenadas se graban en un archivo en formato ASCII. 


\section{Tratamientos numérico de los espectros de RPE}

1. Uso del perfil de Voigt. Cambios de intensidad relativa y de los anchos de linea.

El perfil de Voigt, descrito en la Sección A del Capitulo I, se emplea para analizar cambios de intensidad relativa y anchos de linea debidos a los efectos producidos por:

i) la exposición de los radicales de alanina a la luz UV,

ii) los tratamientos térmicos a $423 \mathrm{~K}$ y $473 \mathrm{~K}$.

iii) las distintas dosis de irradiación con rayos $\gamma$,

iv) y por el efecto del material aglutinante (el silicón) para estudiar la producción de radicales libres y/o defectos cristalinos

En esta parte del análisis se asumió que cada una de las línȩs del quinteto de RPE de los radicales de alanina policristalina son únicas, Fig. 2. En realidad cada línea ensanchada es el resultado de una compleja superposición de líneas. Tanto esta superposición como el propio ensanchamiento hacen parecer a cada línea como única. 
2. Método de deconvolución. Estudio de la superposición cie lineas.

El análisis de la superposición de líneas que aparece en los espectros de polvos de RPE de los radicales de alanina se realiza utilizando el método de deconvolución descrito en la Sección B del Capítulo I y Apéridice B. Con este análisis de superposición de líneas se estudia la posible existẹncia de especies secundarias de radicales de alanina y/o defectos cristalinos que se pueden inducir al irradiar alanina. Los espectros que se analizan son aquellos que se obtienen antes y después de someter a la alanina irradiacia a los distintos tratamientos ya mencionados

\section{Líneas Satélite}

Finalmente, se hace un estudio de las líneas satélite que aparecen en el patrón de polvos de RPE de los radicales de alanina. 


\section{CAPITULO III}

\section{LINEAS LATÉLITE Y \\ NATURALEZA DE LOS RADICALES LIBRES DE ALANINA}

En este capitulo se presentan los resultados y la discusión sobre el estudio de las líneas satélite que aparecen en el patrón de polvos de RPE de los radicales. de alanina ; sobre el tratamiento de estos radicales con luz UV, con calor (a 423 K y a $473 \mathrm{~K}$ ) y sobre el efecto producido al irradiar alanina policristalina con distintas dosis de radiación $\gamma$. El efecto del material aglutinante, el silicón, será analizado en el Capitulo IV.

\section{A. Lineas satélite}

Debido a la gran superposición y ensanchamiento de líneas que aparece en el espectro de RPE de los radicales de alanina, Figs. 1 y 2 el estudio de su origen has sido complejo hasta ahora. Aun mas, deben tomarse en cuenta a las líneas satélite que aparecen en su espectro si se usan altas potencias de microondas para su registro. Estas lineas satélite fueron previstas por algunos autores (Miyagawa et al., 1962; Höfer et al., 1989), y posteriormente identificadas (Arber et al., 1991) al analizar su comportamiento en intensidad al incrementar la potencia de las microondas. En el Apéndice A se presenta información adicional sobre el origen de estas transiciones de espín electrónico no 
permitidas $\left(\Delta m_{1}= \pm 1\right)$ o lineas satélite. Mas recientemente otros autores, (Barnard et al., 1996), confirman su origen prohibido, no sin dəjar de mencionar la controversia que han suscitado para definir su origen (Pilb, ow et al., 1996, y el presente trabajo), ya que se les ha confundido con líneas de resonancia permitidas de ya sea especies primarias o secundarias de radicales libres.

Por otra parte, debido a que varios autores usan la señalización de Arber et al., (1991), incluyendo a Barnard et al., (1996), para identificar dichas líneas satélite, estos autores solo hacen referencia a dos líneas satélite, de las 8 líneas que deben aparecer en el patrón de polvos si es que uria sola especie de radical libre se forma durante el proceso de irradiación $\gamma$. En la primera parte de este trabajo se hacen algunas reconsideraciones acerca de su posición, surgiendo de esto una señalización mas consistente y sistemática de ellas. Por tanto, de su identificación y estudio se puede obtener infc:rmación adicional sobre la naturaleza de los radicales libres que se inducen al irradiar alanina y algunos otros aspectos relacionados con las distancias entre el electrón libre y sus protones vecinos (Arber et al., 1991, Trammell et al., 195').

Asi, la Fig. 3 muestra una serie de espectros de RPE en piimera derivada, de la alanina pura irradiada, en donde se observa el efecto de la potencia de las micro-ondas (de 0.1 a $200 \mathrm{~mW}$ ) sobre la forma del espectro. En esta Fig. 3 se indica a las líneas satélite (indicadas con flechas y próximas a la línea central) de acuerdo a la señalización de Arber et al., (1991). Las otras lineas indicadas 
en esta figura se ha hecho simplemente observando el incremento en la intensidad de líneas como en el caso de la linea central. Su discusión se hará mas adelante. La potencia de las microondas empleadas para registrar cada espectro se muestra en la parte izquierda de la Fig. 3. Un comportamiento análogo del incremento en la intensidad de las lineas satélite, en función de la potencia de las microondas, es el observado por Zeldes and Livingston, (1954), al estudiar hidrogeno atómico.

Arber et al., (1991) han asumido que las lineas marcadas a ambos lados de la linea central, Fig. 3, corresponden a líneas satélite. Según Ba nard et al, (1996), esta señalización se puede extender para cada linea principal del quinteto, en donde sus líneas satélite también se indican en la Fig. 3.

Como se menciona en el Apéndice A dichas señales satélite 0 prohibidas resultan de un cambio simultáneo de los estados de espín c'el electrón libre y protones vecinos, (Trammell et al., 1958). Esta condición se da siempre y cliaride exista anisotropía en el acoplamiento del electrón libre con los protones del radical libre bajo estudio. En este caso, el acoplamiento dt:l protón del grupo $\dot{\mathrm{C}} \mathrm{H}$ del radical libre de alanina $\left(\mathrm{CH}_{3} \dot{\mathrm{C}} \mathrm{HR}\right)$ tiene una comrconente isotrópica (interacción de Fermi) y una parte anisotrópica (interacción Jipolo-dipolo). De acuerdo a varios autores (Zeldes and Livingston, 1954, Trariımell et al., 1954, Arber et al., 1991) las líneas satélite resultantes de esta i.tteracción, deben 


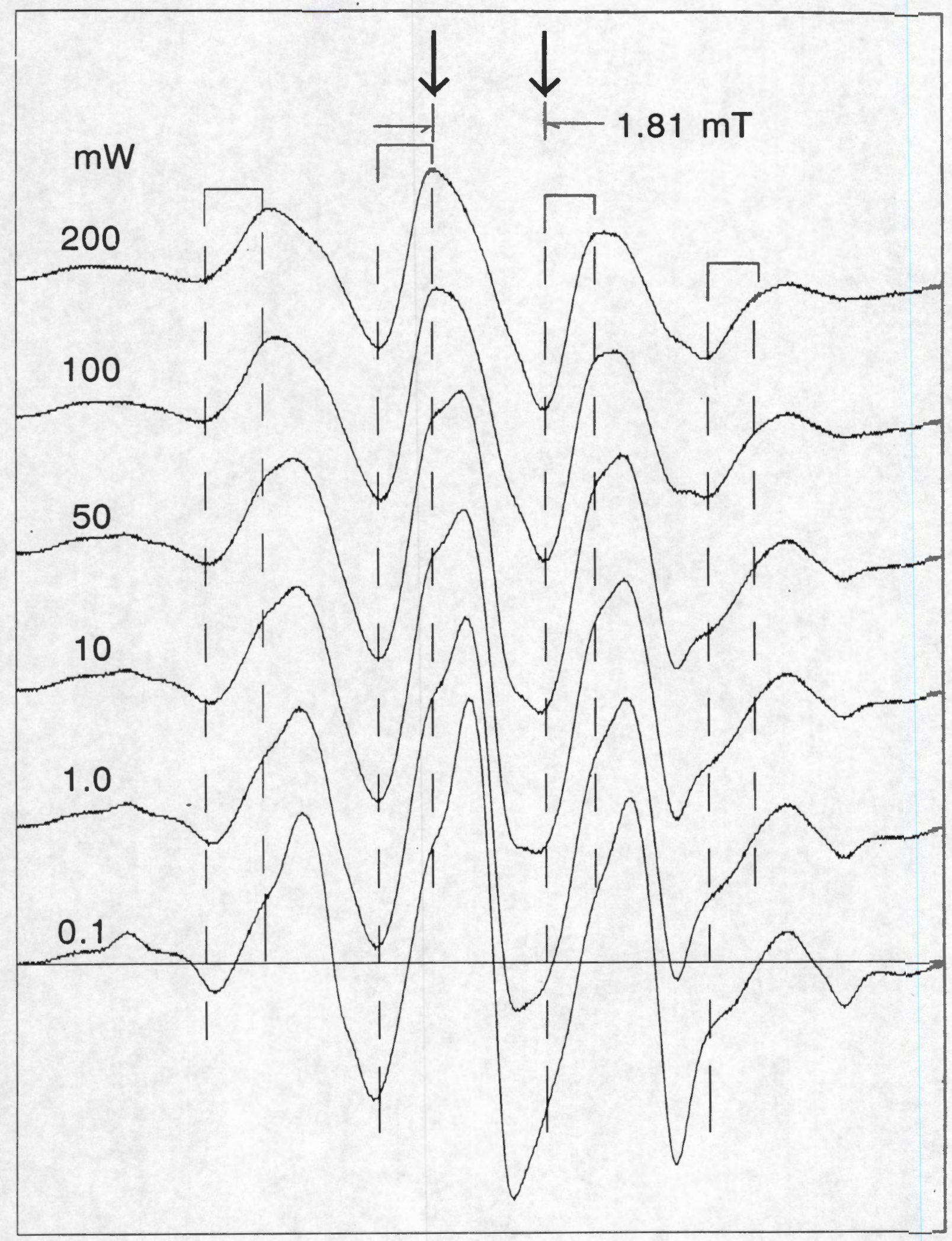

FIGURA 3. La señalización de las líneas satélite de Arber et al. (1991) esta indicada for flechas. 
aparecer a una distancia de $\pm g_{n} \beta_{n} H( \pm 0.5 \mathrm{mT}$ ) con respects alguna posición determinada, como resultado de la interacción hiperfina entre el electrón y los protones involucrados del radical libre; esto es, los protones de los grupos $\mathrm{CH}_{3}$ y del $\dot{c} \mathrm{H}$, en donde el acoplamiento entre el electrón libre y los protones del grupo $\mathrm{CH}_{3}$ es isotrópica, pero con aquel del grupo $i \mathrm{H}$ no lo es del todo.

De acuerdo a este esquema de interacción, las líneas satélite (transiciones de espin electrónico con $\Delta m_{1}= \pm 1$ ) deben aparecer en $g_{\mathrm{e}} \beta_{\mathrm{e}} \mathrm{H} \pm 3 / 2 \mathrm{~A}\left(\mathrm{CH}_{3}\right) \pm g_{\mathrm{N}} \beta_{\mathrm{N}} \mathrm{H}$ $y$ en $g_{\mathrm{e}} \beta_{\mathrm{e}} \mathrm{H} \pm 1 / 2 \mathrm{~A}\left(\mathrm{CH}_{3}\right) \pm g_{\mathrm{N}} \beta_{\mathrm{N}} \mathrm{H} . \mathrm{A}\left(\mathrm{CH}_{3}\right)=2.5 \mathrm{mT}$ es la constante de acoplamiento hiperfina de los protones del grupo $\mathrm{CH}_{3} . g_{N} \beta_{N} \mathrm{H}=0.5 \mathrm{mT}$ es la separación entre una línea permitida y una satélite, en doride $g_{N}$ y $\beta_{N}$ son el factor g y magnetón de Bohir nuclear, $\mathrm{H}$ es el campo magnético aplicado, que es del orden de $300 \mathrm{mT}$. $g_{\mathrm{e}}$ y $\beta_{\mathrm{e}}$ son el factor $g$ y magnetón de Bohr del electrón. Debido a que la constante de acoplamiento hiperfina del protóin del grupo $A(C H)$ $=2.0 \mathrm{mT}$ (Miyagawa y Gordy, 1060), las líneas satélite deber: aparecer $0.5 \mathrm{mT}$ separadas de las líneas del doble cuarteto que aparece como resultado de la interacción entre el electrón libre y los cuatro protones del radical libre considerado, Fig. 4.

De acuerdo a estos cálculos, las líneas satélite pertenecientes a un mismo par $\left({ }_{ \pm} g_{N} \beta_{N} H\right)$ deben estas espaciadas $1.0 \mathrm{mT}, y$ aquellas líneas satélite contiguas pertenecientes a distintos pares deben estar separadas $1.5 \mathrm{~m}$. 
En la señalización de Arber et al., (1991), las señales indicadas con flechas corresponden a pares distintos y no a un solo par como lo suyieren Arber et al., y como se verá mas claramente usando la Fig. 5. Para recilizar la Fig. 5 se utilizaron los valores g observados (Miyagawa and Gordy, 196:J).

Así, si uno asume que el $\mathrm{CH}_{3} \dot{\mathrm{C}} \mathrm{HR},\left(\mathrm{R}=\mathrm{CO}_{2}{ }^{\circ}\right)$, es la única especie de radical libre que se forma en el proceso de irradiación de la alanina, y que los protones del grupo metilo de este radical libre se comportan magnéticamente iguales y el del grupo $\mathrm{CH}$ se comporta distinto a ellos, entonces uno esperaria observar algo como lo que se muestra en la Fig. 4 y parte de la Fig. 5.

Como se ha mencionado anteriormente, las líneas satélite deben aparecer separadas de algún rasgo espectral característico del especitro por $\pm g_{n} \beta_{n} \boldsymbol{H}$ ( \pm $0.5 \mathrm{mT}$ ), ó unas de otras por aproximadamente $1.0 \mathrm{mT}$ (Tran:mell et al., 1958 ; Seldes et al., 1959 ; Weltner, 1984 ; Höfer et al., 1989 ; Arbel et. al., 1991). En la Fig. 5 se muestran las líneas satélite que pueden aparecer en el patrón de RPE de los radicales libres de alanina tomando en cuenta solamente una especie de radical, el $\mathrm{CH}_{3} \dot{\mathrm{C}} \mathrm{HR}$ y el efecto anisotrópico del prctón del grupo $\mathrm{CH}$. En esta Fig. 5 se muestra adicionalmente el quinteto que se cibserva al analizar un monocristal de alanina irradiado al orientar el eje cristalino [001] con respecto al campo aplicado. Esto es, bajo esta situación de orientación los 


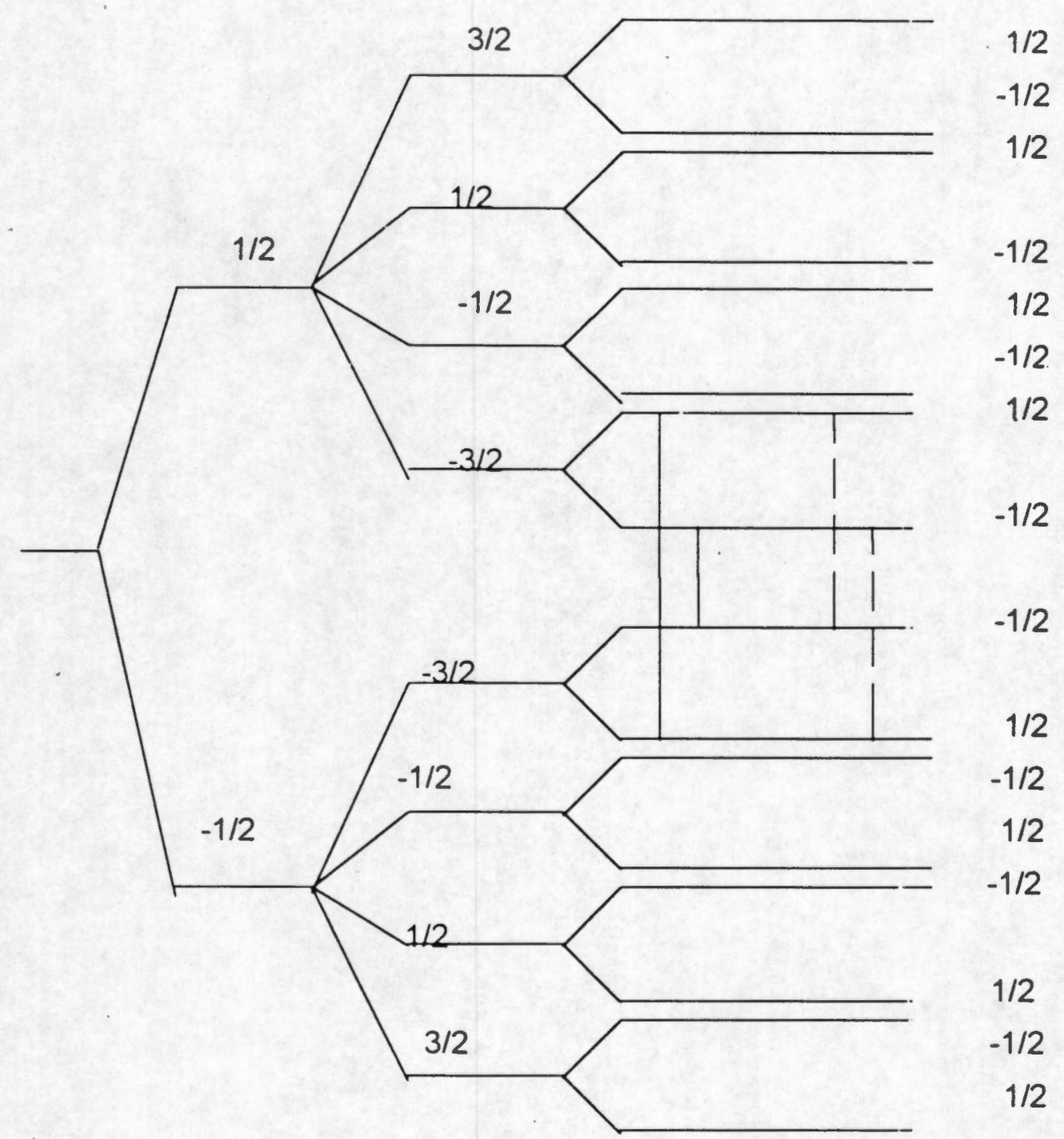

FIGURA 4. Niveles de energia esperados para el caso de tres protones magnéticamente iguales $\left(\mathrm{CH}_{3}\right)$ y un protón distinto $(\mathrm{CH})$ a ellos. Solo se muestran dos líneas permitidas, (líneas continuas, $\Delta m_{1}=0$ ) y tos líneas satélite, (líneas a rayas, $\Delta m_{1}= \pm 1$ ). Estas lineas satélite aparecerán a $0.5 \mathrm{mT}$ del punto central con relación al doblete producido por el protón del grupo CH, ver Fig. 5 . 


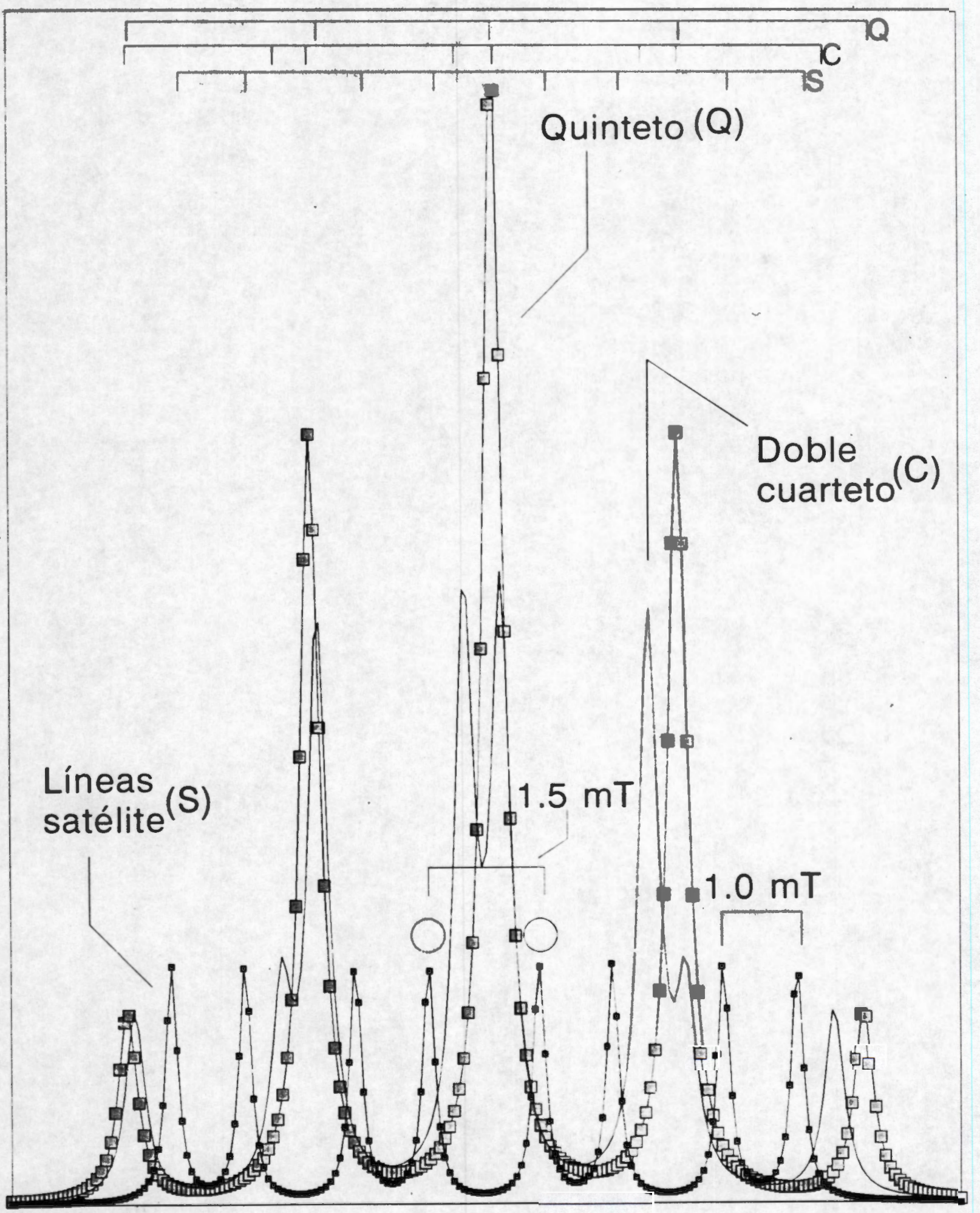

FIGURA 5. Patrones simulados usando los factores g de Miyagawa y Gordy, (1960). Las líneas satélite son simuladas de acuerdo a este trabajo. Las señales satélite indicadas por círculos son las referidas por Arber et al., (1991). 
cuatro protones, los del grupo $\mathrm{CH}_{3}$ y del $\mathrm{CH}$ interactúan isotr jpicamente con el electrón libre.

Cuando uno analiza los patrones de RPE mostrados en la Fig. 3, pero ahora en su modo absorción y resueltos en energía (espectros deconvolucionados y filtrados de señales espurias usando la función rectangular en el proceso de poda), Fig. 6. b, encontramos lo siguiente: En esta forma de peesentación de los espectros de RPE, se puede identificar y medir mas fácilr,ente a la líneas satélite utilizando la separación eritre ellas de $1.0 \mathrm{mT}$. En la frig. 6 b se indican los pares de líneas satélite que podrian corresponder a aquellas indicadas tanto en la Fig. 3 como en la Fig. 5.

Cabria resaltar aqui que en dos trabajos previos de Cabral Frieto et al., (1993, 1994), la última publicación formando parte de este trabajo ductoral, se emplẹ́ el método de deconvolución para incrementar la resolución de estos espectros y para estudiar un poco la estructura de lineas (Cabral-Prieto et al. 1994), pero sin haber hectio un análisis de las lineas satélite, sirio haste er, Esta parte da! trabajo de tesis. Algunos resultados ya fueron publicados (Cabral-Prieto et al. 1999 a). En este segundo trabajc de Cabral.-Prieto et al. (199:) a) se hace ver el error en que varios autores incurren al tratar de identificar i:as lineas satélites (Áarber et al., 1991; Barnard et al., 1996) usando la linea central del espectro que incidentalmente corresponde a la superposición de al menos dos señales ; la línea central del quinteto y una debida al doble cuarteto, verr Figs. 5 y 6 . Esto 
es, intentar identificar las líneas satélite a $0.5 \mathrm{mT}$ de la línea zentral y a ambos lados de ella se incurre en un error. En general, la distancia de las líneas satélites con respecto a las lineas del quinteto difieren de $0.5 \mathrm{mT}$ como lo sugieren Arber et al., (1991), y Barnard et al., (1996) y no son las señales adecuadas para definir la posición de las lineas satélite en el espectro de polvos de RPE de los radicales de alanina.

La señalización mostrada en la Fig. 6, aunque prácticamente: igual en su parte central a la de Arber et al., (1991), difiere en su interpretación con respecto a su posición. Esta sénalización extendida de las señales satélite, Figs. 3 y 6 , puede ayudarnos a estudiar de una manera más sistemática el patrón de RPE de los radicales libres inducidos al irradiar alanina para estudiar su nüturaleza.

Por otra parte, para identificar a estas señales satélite y para estudiar su origen, Barnard et al., (1996), emplean distintas energias de microondas (bandas $L(1.8$ $\mathrm{GHz}), \mathrm{S}(3.2 \mathrm{GHz}), \mathrm{C}(4.9 \mathrm{GHz}), \mathrm{X}(9.1 \mathrm{GHz}), \mathrm{K}(19.4 \mathrm{GHz})$. Estos autores estudian las dependencias de las intensidades de las líneas satélite con la energía y la separación entre las líneas satélite y la permitida con el campo magnético aplicado, (Trammell et al., 1958). Mostrando cualitativamente los corrimientos de las líneas satélite en función de la banda de la microonda usada, Barnard et al., (1996) confirman de esta manera el origen de transicione; del tipo spin-flip, pero preservando la notación de Arber et al., (1991), Fig. 3, esto es, sin presentar un análisis cuantitativo adicional de sus observaciones. Igualmente 


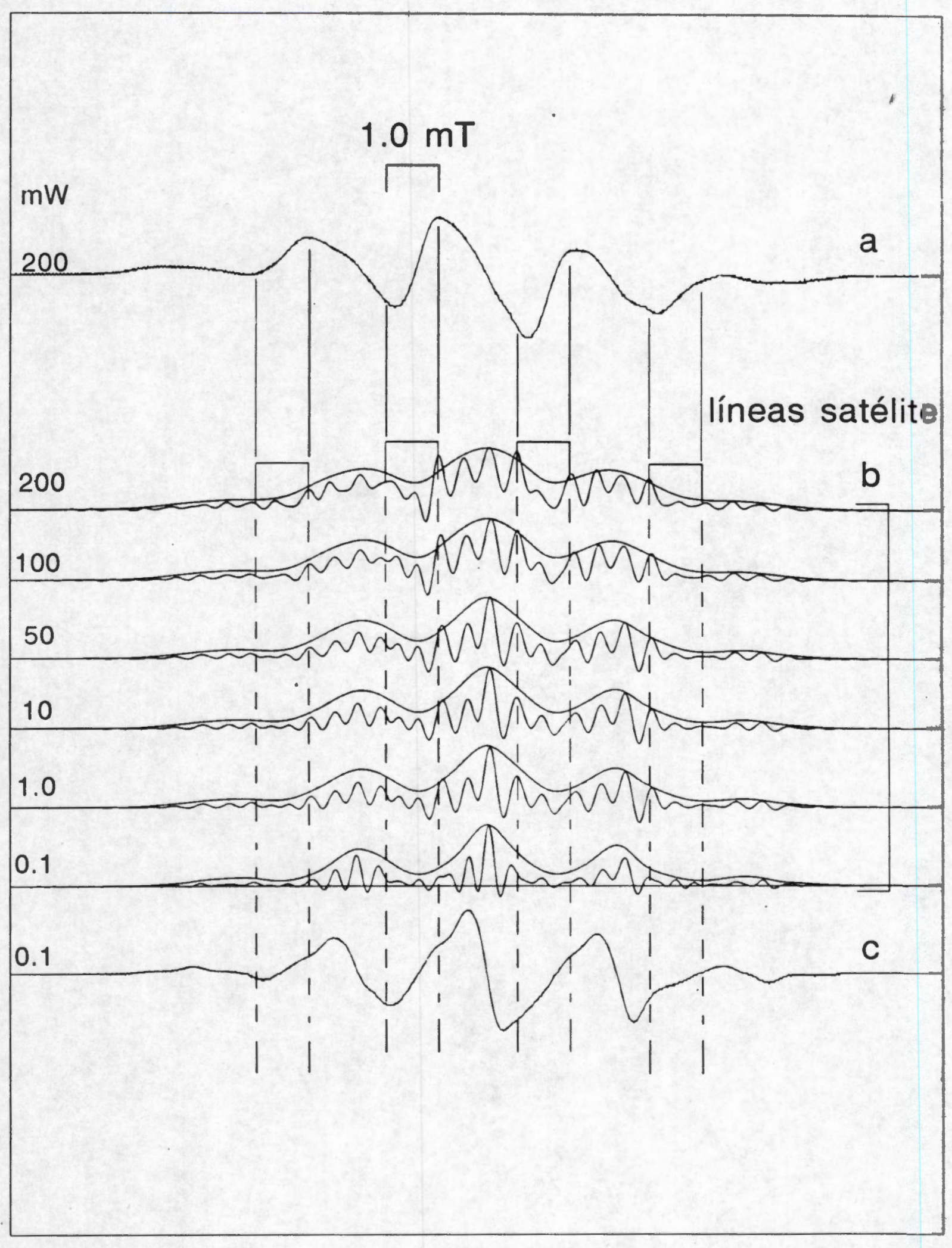

FIGURA 6. Señalización de las líneas satélite de acuerdo a este trabajo 
incurre en el error al indicar que las líneas satélite están a $0.5 \mathrm{mT}$ de la línea central. Si uno hace esto, la distancia de la línea satélite, al ledo izquierdo de la linea central, es mucho mayor a $0.5 \mathrm{mT}$.

Así pues, con la señalización de todas las lineas satélite indicadas en las Figs. 3 y 6 b se pueden describir otros rasgos espectrales que tienen interés para el estudio de la naturaleza de los radicales libres que se inducen al irradiar alanina. Por ejemplo, Arber et al., (1991), usa la razón de intensidades de la línea central con respecto a una de las intensidades de la linea satélite supuesta. De esta manera estima la distancia del electrón libre con uno y tres protones vecinos usando la relación de Trammell et al., (1958, :

$$
\left.\langle r(n)\rangle=0.73\left(g_{e} \beta_{e} / B_{0}\right)^{1 / 3}\left[n 2 I_{p} / s\right]_{s}\right]^{1 / 6}
$$

donde $\langle r(n)\rangle$ es la distancia esperada del electrón libre con respecto a $n$ protones, $g_{e}$ y $\beta_{e}$ son la razón giromagnética y el magnıtón de Bohr del electrón, respectivamente. $B_{0}$ es el campo magnético exterro aplicado y $\left[I_{p} / I_{S}\right]$ es la razón de intensidades de la línea permitida a la línea sa'élite. De acuerdo a Arber et al., (1991) la razón encontrada fue de $\left[2 I_{p} / I_{s}\right]=7$ por lo que para $n=$ 1. $\langle r(n)>=0.20 \mathrm{~nm}$ y para $n=3<r(n)>=0.25 \mathrm{~nm}$. De acuerdo a la nueva ser̃alización de la Fig. 6 la razón $\left[2 \mathrm{I}_{\mathrm{p}} / \mathrm{I}_{\mathrm{s}}\right]=6.66$ por lo que para $n=1,\langle r(n)\rangle=$ $0.18 \mathrm{~nm}$ y para $n=3\langle\mathrm{r}(n)\rangle=0.21 \mathrm{~nm}$. Estas dos nuevas estimaciones están 
más dentro de lo esperado (Kuroda and Miyagawa, 1982). F'or ejemplo para $n$ $=3\langle\mathrm{r}(n)\rangle=0.23 \mathrm{~nm}$ (Kuroda y Miyagawa, 1982). A'unque en ambas mediciones (Arber et al., 1991 y presente trabajo) el error es el mismo con respecto al valor reportado por Kuroda y Miyagawa, en el presente trabajo no existen dudas sobre la elección de las señales involucradés para evaluar la razón de intensidades $I_{p} / I_{s}$ a partir de la Fig. 6 b. Particular nente, usando el espectro registrado con una potencia de $0.1 \mathrm{~mW}$. Ambas líneas difieren de las de Arber et al., (1991), aparte de que en este último caso no es muy claro como se estimó dicha razón de intensidades por el gran ensanchemiento que existe en el espectro.

Por otra parte, cuando se analizan las lineas de resonancia inas próximas a la linea central se observa lo siguiente: Tómese de refer'ncia el espectro obtenido a una potencia de $0.1 \mathrm{~mW}$, Fig. 6. Por un lado, cuéndo se registra el espectro con una potencia de $200 \mathrm{~mW}$, la línea satélite del lado derecho de la línea central predomina en la parte indicada, mientras que ¿̇ una potencia de $0.1 \mathrm{~mW}$, dichas señal casi no se observa. Esto mismo ocurre para el caso de la línea satélite del lado izquierdo de la línea central. Esto e.;, además de las líneas satélite, aparecen otras líneas vecinas a las satélite, a ambos lados de la línea central que se comportan peculiarmente cuando $s a$ someten a los radicales de alanina algun tratamiento. Como se verá inas adelante, es probable que a partir de estas observaciones cercanas a lia línea central, se 
puedan dar mas evidencias sobre la posible existencia de especies secundarias de radicales libres de alanina.

Entonces, para estudiar el origen del patrón de polvos de R.PE de la alanina irradiada es apropiado analizar espectros registrados a una potencia por debajo de $0.5 \mathrm{~mW}$ (Arber et al., 1991; Wieser et al., 1996) en donde los efectos de saturación son mínimos, y las señales satélite casi no aparecen en el espectro. De otra manera, habrá de tomarse en cuenta la presencia de esas lineas satélite en el análisis como se hace en el presente trabajo, en donde algunos experimentos se realizaron usando una potencia de $15 \mathrm{~mW}$.

Tomando en cuenta estas consideraciones a continuación se describen los resultados de los tratamientos de los radicales libres de ala-ina con luź UV y con calor (Cabral-Prieto et al., 1999 b).

\section{B. Tratamiento con luz. UV}

En este tratamiento se empleó alanina pura y fue irradiada con rayos $\gamma$ a una dosis absorbida de $14 \mathrm{kGy}$. Con esta dosis absorbida de $14 \mathrm{kGy}$ se obtienen espectros de RPE bastante bien definidos. Los radicale; de alanina asi generados fueron posteriormente expuestos a la luz. UV durante distintos 
intervalos de tiempo. Algunos resultados de este tratarniento ya fueron publicados, (Cabral Prieto et al., 1994), por lo que aqui se presentan resultados adicionales de este tratamiento (Cabral Prieto et al., 1999 b).

Así, la Fig. 7 muestra la curva de decaimiento que resulta de exponer a los radicales de alanina a la luz UV, desde cero hasta 2335 minu:os. En esta Fig. 7 se grafica la pérdida de intensidad de la señal central del espectro de RPE de los radicales de alanina en función del tiempo de exposición a la luz UV (Cabral Prieto et al., 1994, 1999 b). Esta curva se puede adaptar con cos exponenciales por lo que se pueden estimar dos constantes de decaimiznto o dos vidas medias ; una de 50 minutos (con una intensidad relativa de $33 \%$ ), y la otra de tres días (con una intensidad relativa de $67 \%$ ), para la piimera y segunda componentes, respectivamente. Los valores de las vidas medias difieren ligeramente de los reportados por Brustad et. al., (1964), quien trabajó bajo condiciones de vacío. La vida medias reportadas por estos autores son de tres hrs y de cinco días, para la vidas medias corta y larga, respectivamente. En el presente caso la exposición de luz UV se realizó a presió. atmosférica, en donde los componentes del aire pueden modificar el proceso de decaimiento de los radicales de alanina. Sin embargo, tanto de los experimentos de Brustad et al., (1964), como de los del presente trabajo, se pueden Jeducir dos vidas medias a partir de las curvas de decaimiento resultantes. Estas dos vidas medias o constantes de decaimiento no se han asociado tácitamente a especies distintas de radicales libres. La posibilidad de que se formen dos 


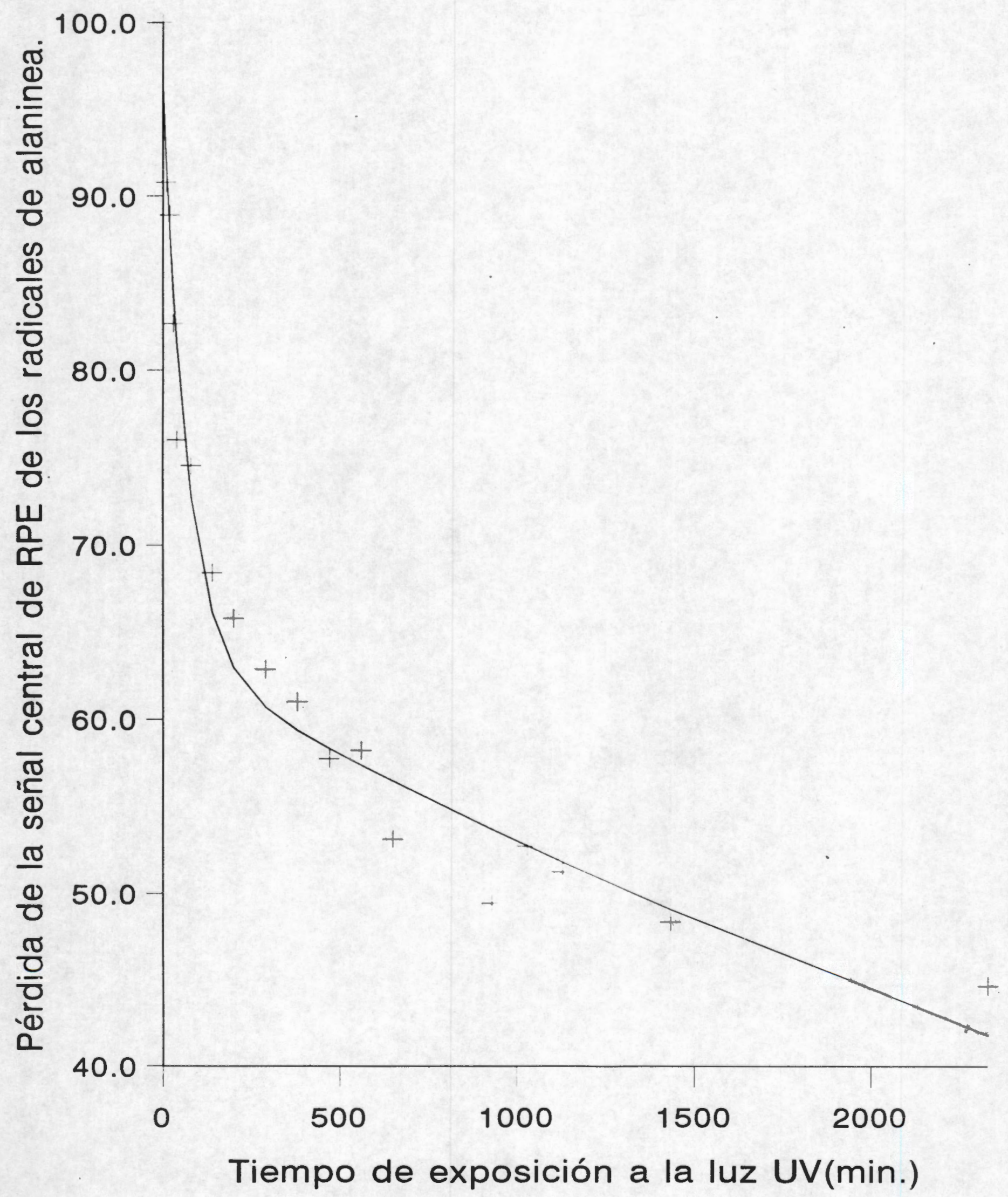

FIGURA 7. Decaimiento de los radicales libres de alanina por el efecto de luz UV 
especies de radicales libres de alanina no está comprobado todavia, ya que también existe la posibilidad de que se formen defectos cristalinos que aglutinen a una sola especie de radical libre (Höfer et al., 1989). Derivado de esto, el fenómeno de decaimiento de radicales libres con luz UV tampoco ha sido bien interpretado. En este trabajo se hace un análisis mas c'etallado de este fenómeno de transformación de radicales libres por efecto de ia luz UV, Fig. 7.

Asi, la Fig. 8 muestra algunos espectros de RPE, en primera derivada, Fig. 8 b, y en modo absorción, Fig. 8 a, de los radicales de alanina tratados con la luz UV. De los espectros en primera derivada se aprecia que la intensidad de la linea central disminuye conforme el tiempo de exposición de l'sz UV aumenta.

A partir del análisis de la curva de decaimiento, Fig. 7, uno podria suponer con cierta certeza que hay más de una especie de radicales libres, como lo sugieren Brustad et al., (1964). Esta conclusión, sin embargo, no se scporta claramente a partir de los cambios espectrales mostrados en la Fig. 8 b, yzi que las líneas de resonancia, antes y después del tratamiento, son prácticamente las mismas. EI ensanchamiento y superposición de líneas es muy pronunciado antes y después del experimento de tal suerte que no se tiene much. 1 certeza sobre la presencia de especies secundarias. De los espectros integriados, Fig. 8 a, se alcanza a distinguir, sin embargo, que hay una variación considerable de intensidades relativas entre las cinco lineas ensanchacas del espectro. 


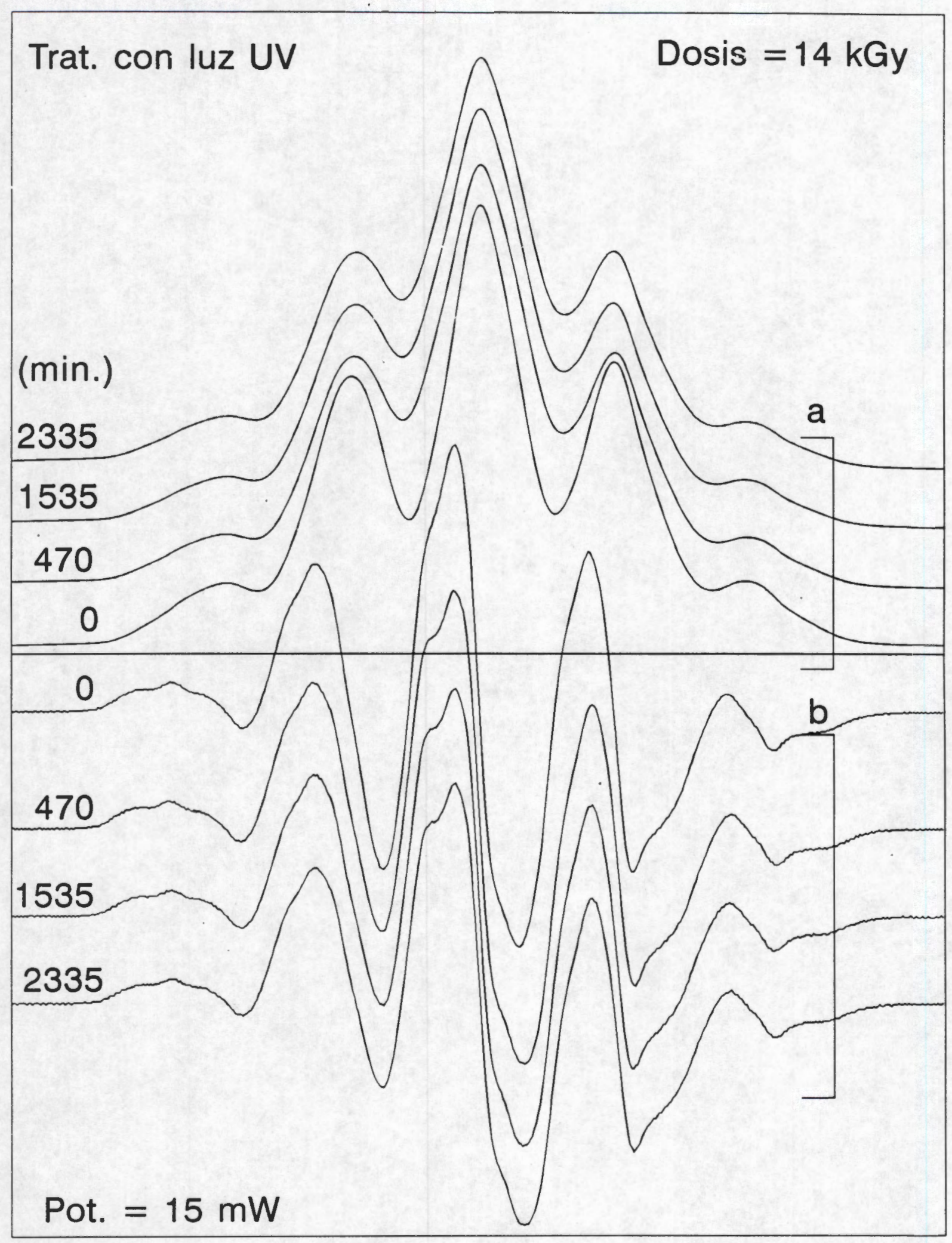

FIGURA 8. Espectros de RPE de la alanina irradiada y tratada con luz UV 
También se aprecia un ensanchamiento del espectro desfués de tratar los radicales de alanina con luz UV, Fig. 8 a.

La Tabla 1 y la Fig. 9 muestran algunos de estos cambics espectrales del patrón de cinco líneas de la Fig. 8 a. El área de la línea central se normalizó siempre a un valor de seis, y las áreas de las lineas restantes están referidas a ese valor normalizado. Este análisis de áreas relativas se realizó como se describió en la Sección A del Capitulo I, usando el perfil de Loigt.

Tabla 1

Areas relativas de los espectros de RPE de ios radicales de alanina tratados con luz UV.

\begin{tabular}{|c|l|l|l|l|l|}
\hline Min Linea & 1 & 2 & 3 & 4 & 5 \\
\hline 0 & 1.03 & 3.61 & 6.00 & 4.00 & 1.68 \\
\hline 470 & 0.74 & 3.16 & 6.00 & 3.08 & 0.66 \\
\hline 1635 & 0.67 & 2.95 & 6.00 & 2.79 & 0.56 \\
\hline 2335 & 0.68 & 2.98 & 6.00 & 2.73 & 0.55 \\
\hline
\end{tabular}

Ahora bien, si se analiza el comportamiento del área de la línea 3, o central, en relación a las otras líneas, Fig. 9, se observa que esta aumerta mientras que el área de sus líneas vecınas disminuyen sistemáticamente $a$ medida que el tiempo de exposición de los radicales a la luz UV se incrementa. Asociado a estos cambios de intensidades relativas, también está el de ، a variación de los anchos de línea. Para simplificar el análisis, solamente el ancho de la línea central del espectro de RPE de los radicales de alanina tratados con luz UV, se muestra en la Tabla 2. (Cabral Prieto et al., 1994), en donde se reporta su ancho Voigtiano y en paréntesis su ancho homogéneo. En ambos casos los 
anchos, Voigtiano y homogéneo (lorentziano), aumentan al incrementar el tiempo de exposición a la luz UV, mientras que el ancho gausiano, no reportado en la Tabla 2, disminuye.

Tabla 2

Semiancho de la linea central del espectro de RPE de los radicales de alanina tratados con la luz UV.

\begin{tabular}{|c|c|c|c|c|c|}
\hline$\frac{\text { Linea }}{\text { Min }}$ & $\overline{1}$ & 2 & $\begin{array}{c}3 \\
\Gamma_{V}\left(\Gamma_{L}\right)(\mathrm{mT})\end{array}$ & 4 & 5 \\
\hline 0 & $\ldots$ & $=$ & $1.59(0.02)$ & $\overline{---}$ & -- \\
\hline 470 & --- & $\overline{---}$ & $1.88(0.71)$ & $\overline{-\cdots}$ & $-\cdots$ \\
\hline 1635 & $-\ldots$ & $\cdots$ & $1.90(0.85)$ & $\cdots$ & -- \\
\hline 2335 & $\cdots$ & --- & $1.92(0.81)$ & $\overline{-\cdots}$ & -- \\
\hline
\end{tabular}

La Fig. 10 muestra, por su parte, la variación de los anchos de las cinco líneas de los patrones de RPE de los radicales de alanina en función del tiempo de exposición a la luz UV, en donde en términos generales los anchos de las líneas 1 y 5 disminuyen, y los anchos de las líneas 2,3 y 4 aurnentan.

Aun con la medición de estos cambios espectrales es difícil inferir la existencia de una segunda especie de radical libre, pero tampoco se pueden asociar simplemente a una sola especie de radical libre como se hará ver mas adelante. Quizás la curva de decaimiento de la Fig. 7 sea la evidencia mas clara de la existencia de dos especies de radicales libres, ya que de ella se pueden estimar con confianza dos constantes de decaimiento (Brustad et al., 1964, Cabral Prieto et al., 1994). Sin embargo, estas dos constantes de decaimiento también se pueden asociar a otras causas. Por ejemplo, (1) a la presencia de dos tipos 


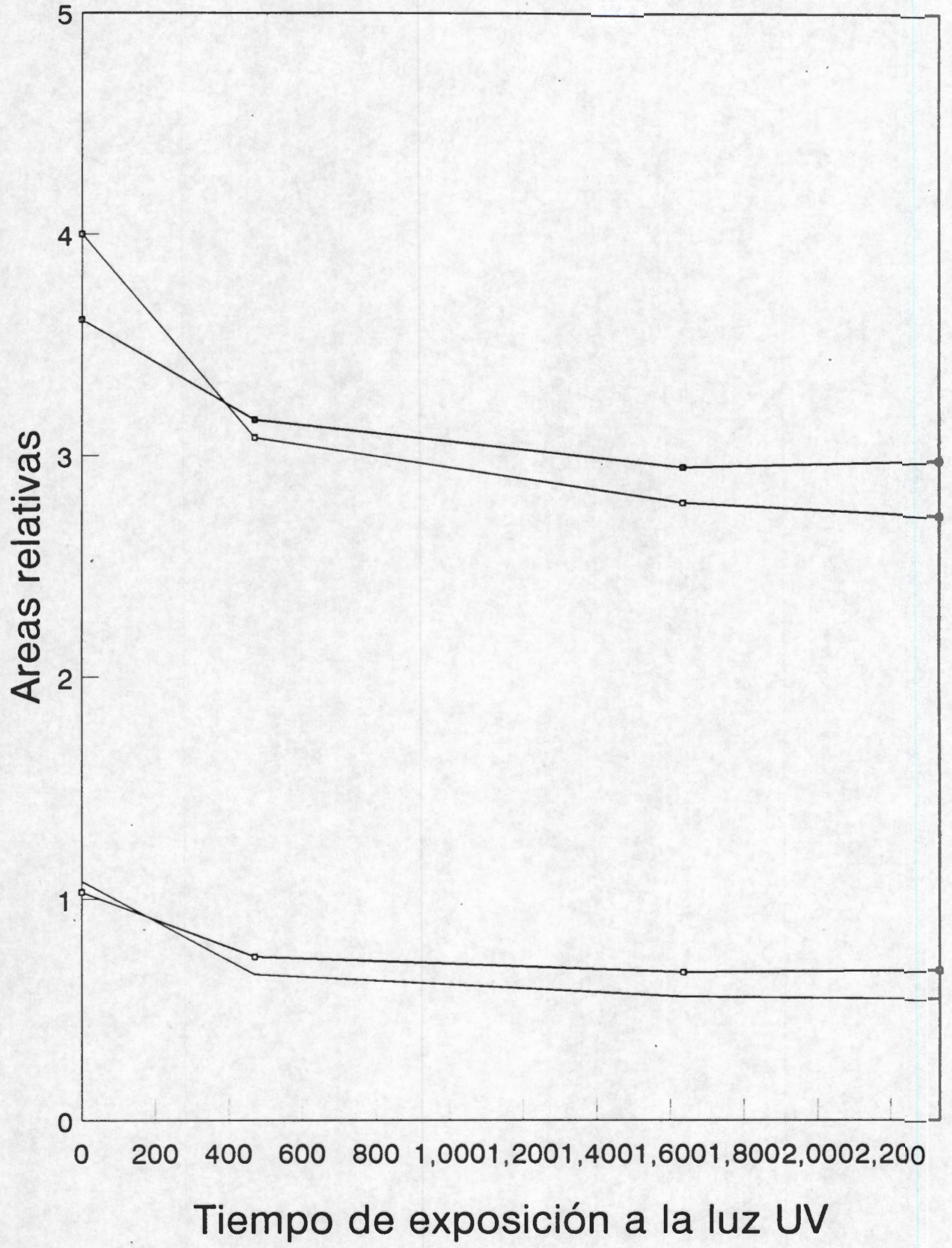

FIGURA 9.Variación de las areas de las líneas $1,2,4$ y 5 de los patrones de RPE de los radicales de alanina tratados con luz UV. 
defectos cristalinos que aglutinen a una sola especie de radical libre y que bajo las condiciones del tratamiento con luz UV este radical libre se transforma con dos constantes de tiempo o vidas medias dependiendo en que defecto cristalino se encuentre (Höfer et al., 1989). Estos defectos cristalinos ya han sido considerados en la literatura, aunque un estudio detallado de ellos aun no se ha realizado. La técrica de aniquilación del positronio (Ps) pedría utilizarse para investigar este aspecto de los defectos cristalinos. Por otra parte, la curva de decaimiento de la Fig. 7 también se puede asociar (2) a la existencia de mas de una especie de radicales libres (Brustad et al., 1964). Estas dos posibilidades se han estudiado a través de diversos trabajos de investigación (Samskog et al. 1980 ; Kuroda et al., 1982 ; Nakagawa et al., 1993 ; Pilbıw et al., 1996 ; Desrosiers et al., 1996). En ninguno de estos trabajos, sin embargo, se obtienen datos concluyentes, aunque predomina la idea de la existencia de mas de una especie de radical libre de alanina.

Para estudiar con más detalle los cambios espectrales medidos a partir de la Figs. 7,9 y 10 , y las Tablas 1 y 2 , a continuación se analizan los patrones de RPE de los radicales de alanina tratados con luz UV aumentando su resolución para ver si es posible discernir entre uno y otro casos. Esto es, el primer caso es suponer que una sola especie de radical libre y dos tipos de defectos cristalinos coexisten. La curva de decaimiento de la Fi!y. 7 admite esta suposición. Si este fuera el caso, entonces el espectro de polvos de RPE de esta especie única de radicales libres, deberia de ser el mismo antes y después 


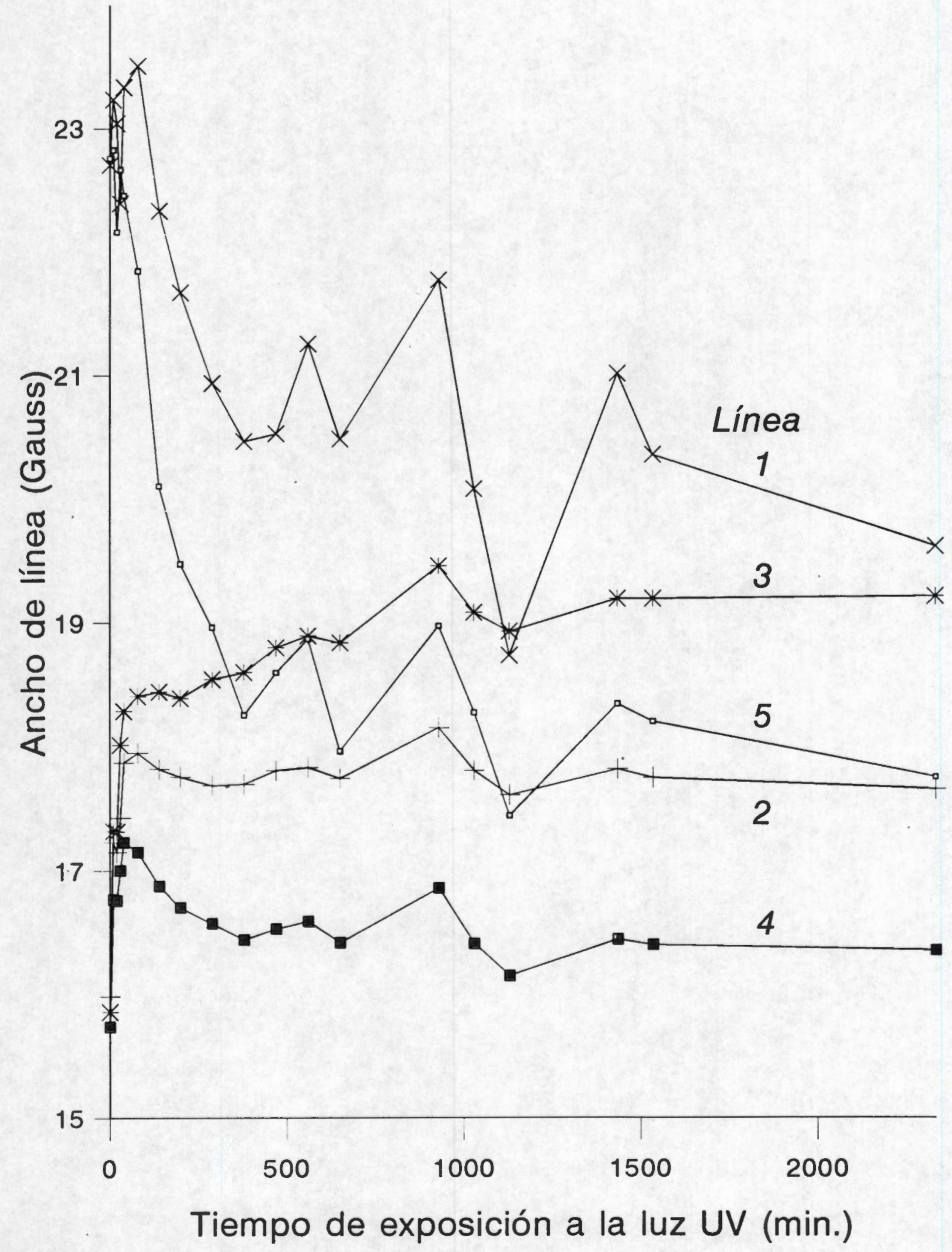

FIGURA 10. Variación de los anchos de línea de los espectros de RPE de la alanina tratada con luz UV 
de dicho tratamiento sin ocurrir una variación considerable tanto de anchos de línea como de razones de área relativas. En el segundo caso es suponer que coexisten mas de una especie de radicales de alanina. La curva de decaimiento de la Fig. 7 también admite esta suposición. Si se considera este segundo caso, entonces el espectro de polvos de RPE de estas dos especius de radicales de alanina, deberia ser distinto antes y después de dicho tratamiento, y podria haber cambios tanto en los anchos de línea como en las razones de área relativas.

De acuerdo con los espectros de RPE mostrados en primera jerivada, Fig. 8 b, el espectro prácticamente es el mismo antes y después del tratamiento, por lo que el primer caso podría ser el correcto, aunque los cambios en las razones de área reportados en la Tabla 1 y Fig. 9 podrian no coilcordar con esta conclusión, i. e. no debería haber cambios ni en los anchos ni an las razones de área o de intensidad, o al menos no tan drásticos como los reportados en la Tabla 1, e indicados en la Fig. 8 a con líneas horizontales.

Por tanto, si se consideran los resultados anteriores, i. e. , la curva de decaimiento, Fig. 7, los cambios de área, Tabla 1, y los camibios de ancho de línea, Tabla 2, estos resultados tienden a favorecer mas al segundo caso. Se podria argüir que los cambios espectrales medidos pueden explicarse en términos de algún efecto de orientación preferente de los ẹes cristalinos con respecto a la dirección del campo externo, en donde aigunas lineas de 
resonancia aparecen con mayor intensidad que otras debido a la dependencia angular. Esta posibilidad es poco probable ya que se esta estudiando una muestra policristalina en donde los ejes cristalinos están orientados aleatoriamente con respecto a la dirección del campo magnético externo. La otra y única posibilidad que pudiera explicar la variación de áreas espectrales y anchos de línea es suponer que existen dos o mas especies ce radicales libres, pero en donde sus señales se traslapan considerablemente. Algunos autores coinciden mas con esta posibilidad (Samskog et al., 1980 ; Kuroda et al., 1982).

Según lo anterior, el segundo caso entonces prevalece sobre el primero, en donde más de una especie de radicales libres de alanina pueden coexistir y sus señales de resonancia se traslapan considerablemente. Para estudiar esta posibilidad de traslape de líneas, los espectros integrados de la Fig. 8 a se resolvieron en energia, usando el procedimiento de deconvclución descrito en el Apéndice B para analizar con mas detalle la estructura de líneas de resonancia antes y después del tratamiento de los radicales de alanina con luz UV y dilucidar algo mas sobre la discusión anterior.

Entonces, si hubiera mas de una especie de radicales ibres de alanina deberian desaparecer lineas de resonancia debidas a la especie del radical libre con la vida media corta y de menor abundancia $\left(\tau_{1 / 2}=50 \mathrm{~min}\right.$. y $33 \%$ de abundancia) después del tratamiento de los radicales de alanina con luz UV por $38 \mathrm{hrs}$; esto es, después de haber transcurrido aproximadamente 47 vidas 
medias. La deconvolución numérica de los espectros se muestra en la Fig. 11, en donde los patrones de cinco líneas, originalmente ensanchadas, se transforman ahora en una compleja superposición de líneas. Si se observa en detalle a estos espectros deconvolucionados, Fig. 11, el número de líneas de resonancia no es el mismo antes y después del tratamiento. Otros cambios, en términos de intensidades relativas, se aprecian como se indica con flechas apuntando hacia arriba o hacia abajo, según aumentan つ disminuyen las intensidades de esas señales. Aunque de los espectros decrnvolucionados de la Fig. 11 se aprecian varios cambios, solo se señalarán alçunos de ellos. En particular, las señales próximas a la linea central. Como se puede observar, la intensidad de la linea de bajo campo, marcada con un aste-isco y una flecha apuntando hacia arriba y a la izquierda de la línea central, aumenta con el tratamiento. Este efecto puede ser realmente producido por la disminución en intensidad de la linea central. Por otra parte, la intensidad c'e la línea de alto campo, marcada con otro asterisco y una flecha apuntando hacia abajo y a la derecha de la linea central, disminuye. Al final del tratamiento prácticamente no se observa. En su lugar, resurge una linea, un poco mas a la derecha marcada ahora con un círculo y flecha apuntando hacia arriba, con major intensidad que antes del tratamiento. La posición de esta línea coincide corı la posición de la línea satélite a la derecha de la línea central, Fig. 6. Finalmente, si se observan los demás cambios señalados en la Fig. 11, como aquel indicado con una gran línea vertical y un signo mayor que para la linea cuatro, la línea indicada desaparece al final del tratamiento. Un poco a su derechà surge otra línea. 


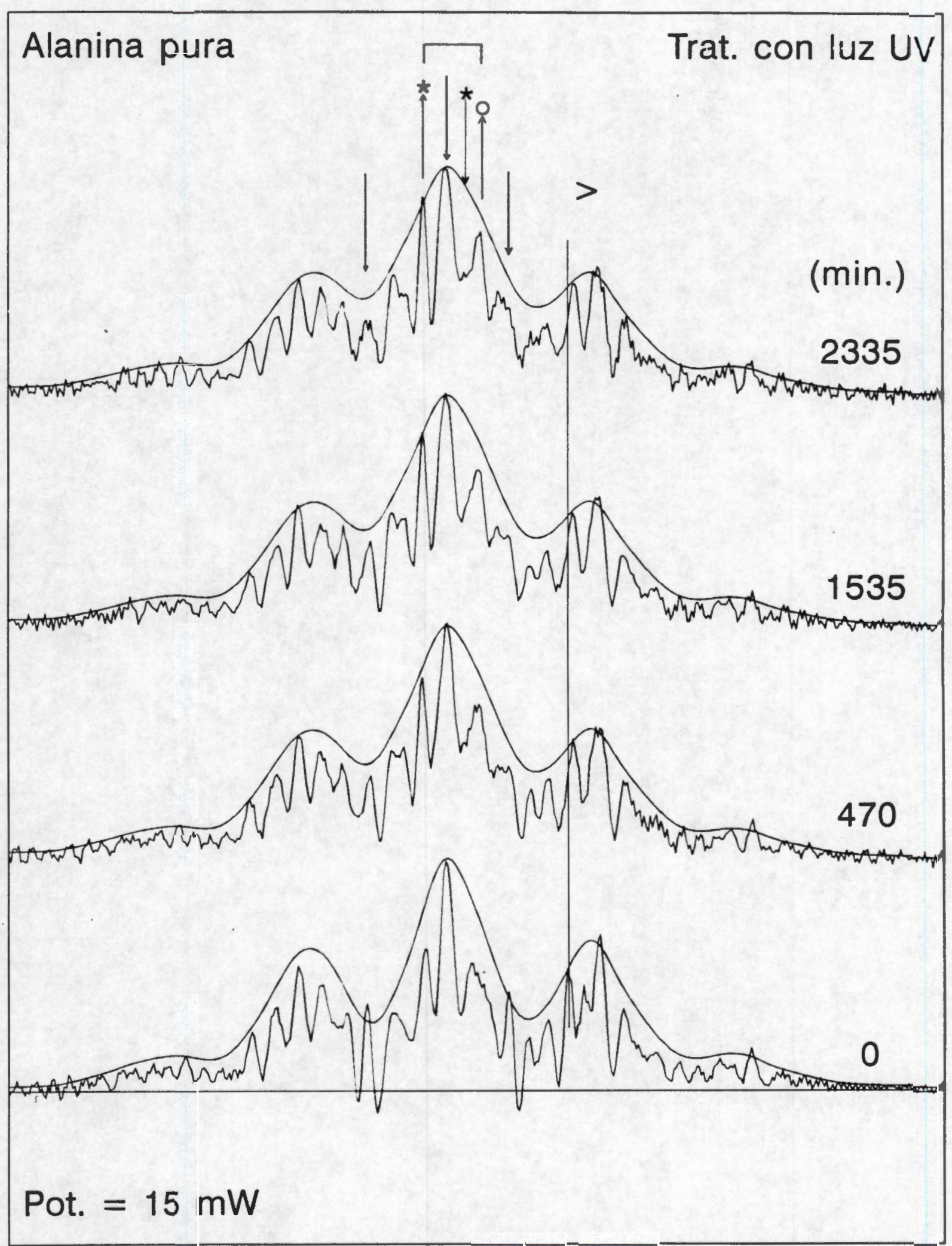

FIGURA 11. Deconvolución espectral del tratamiento de radicales libres con luz UV 
Estos son pues algunos de los resultados esperados pero no observados al analizar los espectros en primera derivada o en su forma integrada, Fig. 8 a y b.

A partir de estos resultados y aunque las líneas satélite están presentes y contribuyen al espectro, el incremento en la intensidad re!ativa de algunas líneas o la disminución de otras con el tratamiento, Fig. 11, son ineludibles. Esto es, concuerdan con los cambios espectrales esperados para el caso en que más de una especie de radical libre se transforman con constantes de tiempo distintas por efecto de la luz UV.

Por otra parte, el ensanchamiento de linea reportado en la Tabla 2, ahora se puede explicar mas fácilmente con los resultados de deconvolución, en donde las líneas centrales de cada pico ensanchado disminuyer: en intensidad y algunas de sus vecinas aumentan. Este ensanchamiento no se puede explicar si se asume el primer caso, descrito arriba, en donde ningún ensanchamiento apreciable debiera ocurrir y solo una disminución simultánea en intensidades de todas las lineas debiera observarse. Esto no ocurre.

La pregunta que surge aqui es la de que si los cambios espectrales medidos de la Fig. 7, a través de las Tablas 1 y 2 , y a partir de las observisciones de las Fig. 9, 10 y 11 son concluyentes como para asociarlos a mas cee una especie de radicales libres que se generen al irradiar alanina. 
Cualquiera que sea la conclusión por ahora, es necesario decir que a partir de los espectros resueltos en energía, obtenidos vía el método de deconvolución (Cabral-Prieto et al., 1991, 1994), es posible observar nue:vos cambios que pueden a ayudar a esclarecer aun mas la naturaleza de los radicales de alanina. Esto es, hasta ahora solo se lograba ver líneas superpuestas, pertenecientes posiblemente a distintas especies de radicales de alaniria usando RDNE y midiendo a $77 \mathrm{~K}$ (Kuroda y Miyagawa, 1982). Como se muestra en la Fig. 11, existe un gran traslape de líneas pero es posible analizar algunas líneas ligeramente desplazadas de otras, en donde su intensidad cambia de acuerdo a ciertas tendencias esperadas.

Ahora bien, si se acepta a partir de los cambios espectrales medidos y observados (Fig. 7, Tablas 1, 2 y Fig. 11) que existe más de una especie de radicales libres, y que se transforman con constantes de tiempo diferentes por el efecto de la luz UV, en donde muchas de sus señales de resonancia se traslapan, entonces se podria pensar que el espectro resultante, después del tratamiento de 2335 minutos con luz UV, deberia deberse a uila sola especie de radical libre. Es decir, después de haber transcurrido apr Jximadamente 47 vidas medias de la especie con vida media mas corta, (50 min.) su contribución al espectro debería ser minima. Mientras que la especie cori vida media larga, pudiera ser el $\mathrm{CH}_{3} \mathrm{CHR}\left(\mathrm{R}=-\mathrm{CO}_{2}{ }^{-}\right.$) (Miyagawa et al., 1960, 1961, Kuroda y Miyagawa, 1982), la otra especie de radical libre, con la vida media corta, aún por definir. 
La posibilidad de que realmente dos o mas especies de radicales libres se generen en el proceso de irradiación de la alanina policristalina, como lo han sugerido otros autores (Samskog et al., 1980 ; Kuroda et al., 1982; Nakagawa et al., 1993; Pilbrow et al., 1996) se estudia aun mas en este trabajo, pero ahora los radicales de alanina son tratados con energias térmicas.

\section{Tratamiento a $423 \mathrm{~K}$ y con luz UV}

Brustad et al., (1964), también obtienen a partir de un tratamiento térmico a 423 $\mathrm{K}$, pero bajo condiciones de vacío, otra doble curva de decaimiento, muy parecida a la que se obtiene con el tratamiento de los radicales de alanina con luz UV. De esa doble curva esos autores estiman dos constantes de decaimiento y sugieren que posiblemente más de una especie de radical libre se podrian inducir al irradiar alanina policristalina con rayos $X$.

En el presente tratamiento a $423 \mathrm{~K}$ se usó alanina pura y fue irradiada con una dosis de $10 \mathrm{kGy}$ de radiación $\gamma$. A esta dosis se obtienen también espectros bien definidos. Al tratar los radicales de alanina a $423 \mathrm{~K}$, y a presión atmosférica, también se obtiene una doble curva, a partir de la cual se pueden estimar dos vidas medias : una de 25 minutos (con una inte 7 sidad relativa de aproximadamente $25 \%$ ), y la otra de aproximadamente $14 \mathrm{hrs}$. (con una intensidad relativa de $75 \%$ ). Mientras que las vidas medi،as difieren de las obtenidas con el tratamiento de luz UV, las intensidades relativas no cambian 
mucho con respecto aquellas del tratamiento de los radicales libres con luz UV. La diferencia en las vidas medias se podria justificar en térmiíıs de que ambos procesos de decaimiento fueron efectuados de manera distinta, i. e., la energía suministrada en cada caso difiere, por lo que el mecanismo dz recombinación o destrucción del radical libre es distinto.

Se hace notar que en esta serie de experimentos a $423 \mathrm{~K}$ los espectros fueron registrados usando una potencia de las microondas de $C 1 \mathrm{~mW}$; esto es, cuando la presencia de las líneas satélites y el efecto de saturación en el espectro son minimos.

Así, la Fig. 12 muestra algunos espectros de RPE de los raficales de alanina tratados a $423 \mathrm{~K}$ (desde 0 a $717 \mathrm{~min}$.). Con este tiempc de $717 \mathrm{~min}$. de tratamiento a $423 \mathrm{~K}$ se obtuvo la misma pérdida de señal de RPE que para el caso del tratamiento de luz UV ; esto es, la intensidad final clespués de ambos tratamiento fue de un $40 \%$ del total.

A pesar de que no se puede hacer una comparación directa entre los espectros del tratamiento con luz UV y con los del tratamiento a $423 \mathrm{~K}$, por haber sido registrados a distintas potencias, ciertas observaciones comb'nes se derivan de estos tratamientos. Particularmente lo que aqui interesa son los resultados de deconvolución. 
Por una parte, de los espectros en primera derivada de la Fig. 12 b, se pueden observar cambios espectrales similares a los observados de aquellos espectros resultantes del tratamiento de los radicales de alanina con luz UV, Fig. 8 b; esto es, principalmente hay una disminución en la intensidad de la línea central. En este caso se observan, sin embargo, cambios mas claros eา las intensidades relativas de las líneas que con el caso del tratamiento con luz UV. Ahora bien, si se observa a los espectros en modo absorción, Fig. 12 a, da este tratamiento térmico, hay una disminución en la intensidad de la línea central con respecto a las otras líneas (lineas 1, 2, 4 y 5). Esta disminución se indica con líneas horizontales entre los espectros obtenidos antes y después del tratamiento térmico. Este resultado difiere un poco de aquel que aparece con el tratamiento de los radicales de alanina con luz UV, Fig. 8 a.

Estas diferencias observadas, entre los espectros de las Fig̈. 8 y 12, pueden deberse a que en unos espectros contribuyen las líneas satélite, Fig. 8, y en los otros, Fig. 12, no. La ausencia de las líneas satélite, Fig. 12, permite, sin embargo, analizar con mas detalle la estructura de lineas de los espectros de RPE de estos radicales. Por ejemplo, al comparar los espectros de RPE en su modo absorción de ambos tratamientos, los de la Fig. 12 a presentan mas estructura que aquellos que se muestran en la Fig. 8 a.

De igual forma, cuando se comparan las razones de áre:a relativas de los espectros resultantes de este tratamiento a $423 \mathrm{~K}$ con aquellas obtenidas del 


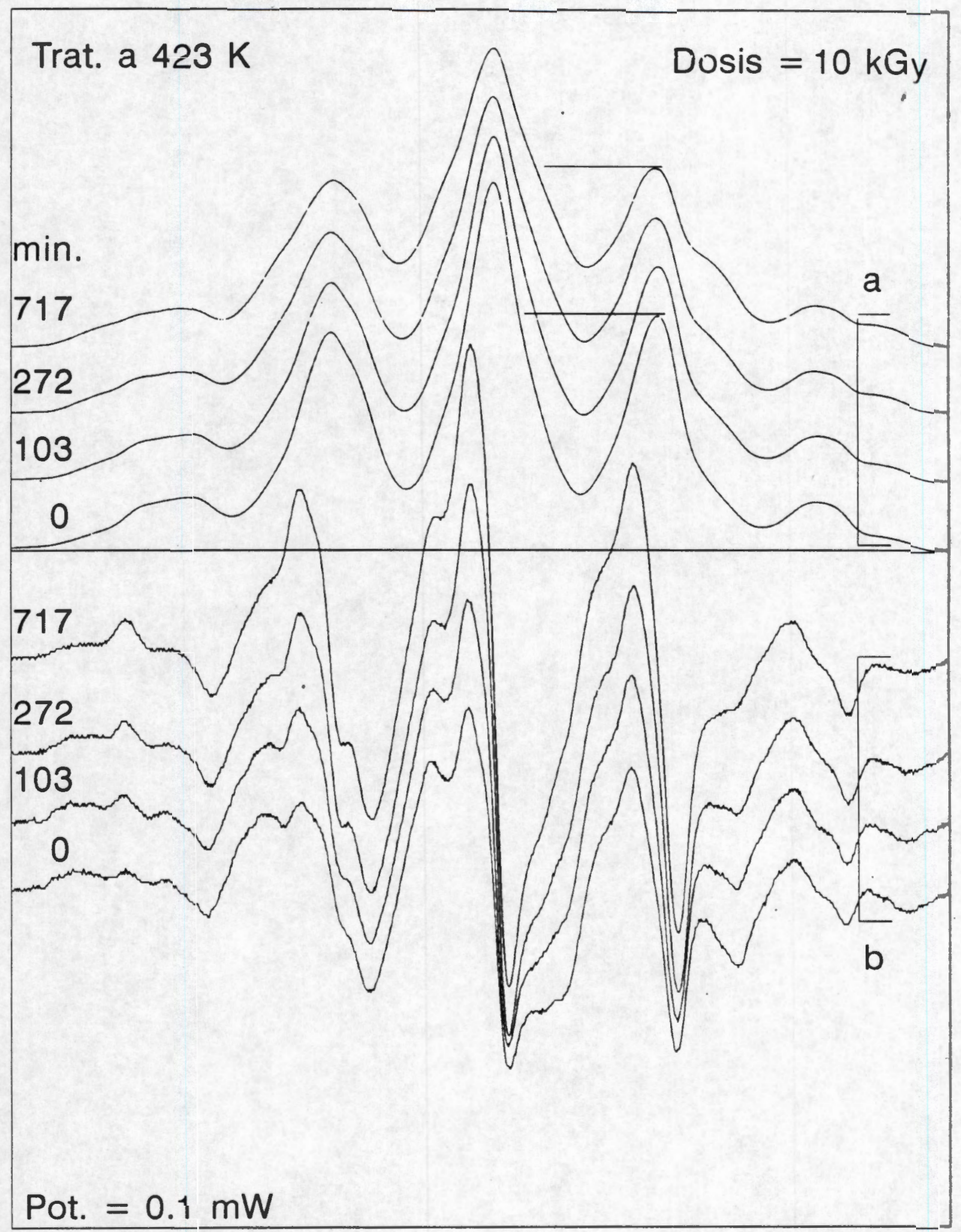

FIGURA 12. Tratamiento térmico de los radicales libres a $423 \mathrm{~K}$ 
tratamiento con luz UV, Tablas 1 y 3 , dichas áreas relativas son también distintas. Con el tratamiento de luz UV uno estima sistemáticamente un incremento en la razón de área de la línea central (línea 3) con respecto a la otras líneas (líneas 1, 2, 4 y 5). Este incremento no es tan sistemático para el caso de los espectros resultantes del tratamiento de los radi zales de alanina a $423 \mathrm{~K}$, Tabla 3 y Fig. 13. Aunque las líneas satélite influyen eri el espectro, esta diferencia probablemente es muy particular del tratamiento térmico.

Como se verá mas adelante, la luz UV y el tratamiento a $4 z 3 \mathrm{~K}$ afectan a los radicales de alanina de una manera distinta. Esto es, el mecanismo de recombinación o destrucción del radical libre es distinto para cada caso. Por otra parte, con el tratamiento a $423 \mathrm{~K}$ también se estima un er.sanchamiento del espectro como se muestra en la Tabla 4. Y Fig. 14.

Todos estos cambios espectrales se pueden analizar mas de cerca observando los espectros resueltos en energia. Por ejemplo, en la Fig. 15 se indica con flechas apuntando hacia arriba y hacia abajo, al igual que er la Fig. 11, según un aumento o una disminución en intensidad de las líneas a medida que aumenta el tiempo de calentamiento de los radicales a $423 \mathrm{~K}$. Esto es, ocurren cosas similares al tratamiento de los radicales de alanina con luz UV. Si analizamos de nueva cuenta las lineas vecinas a la linea central del espectro, obtenemos lo siguiente Por ejemplo, la intensidad de la línea de bajo campo, marcada con asterisco y flecha apuntando hacia arriba, termina con una inten- 


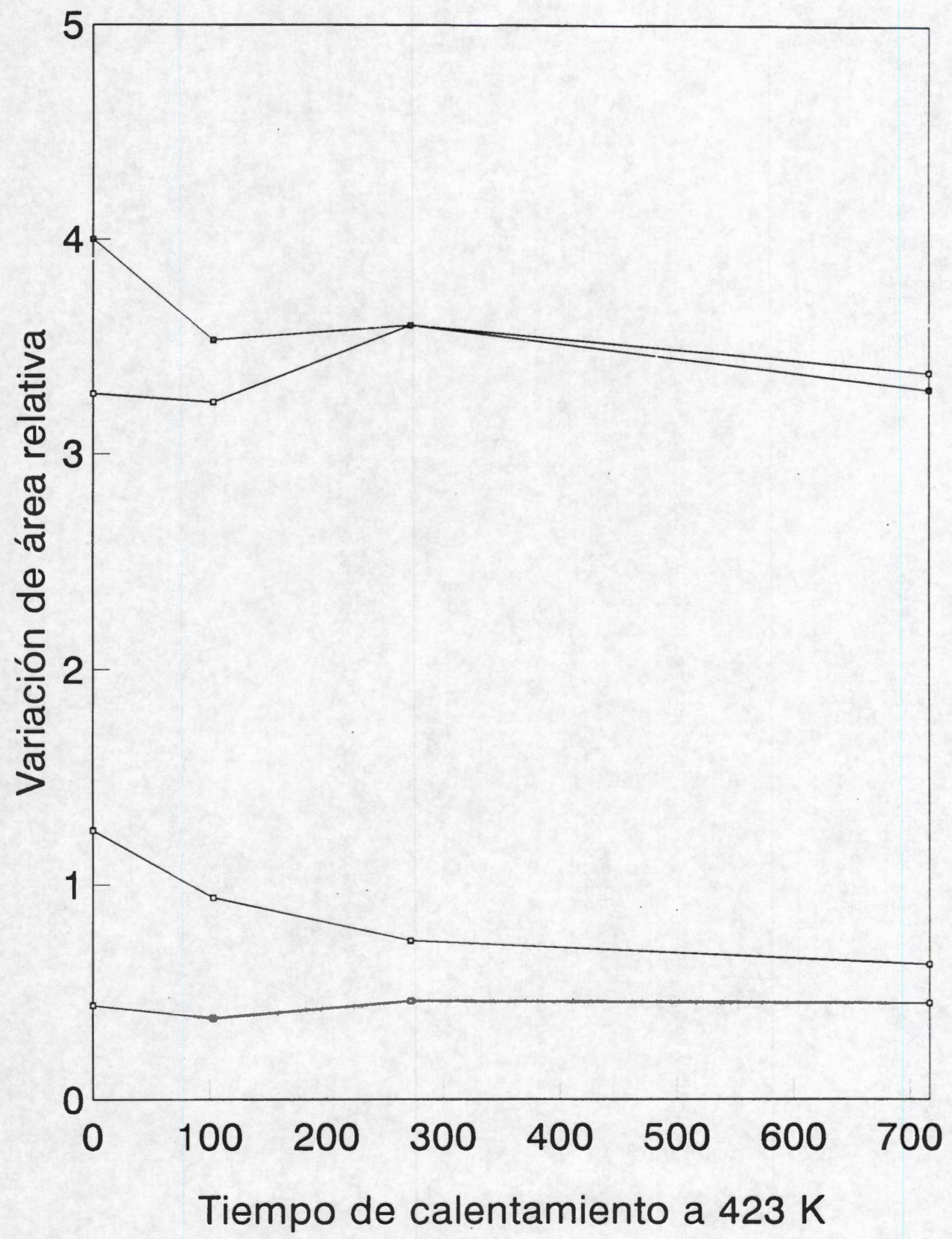

FIGURA 13. Variacion de áreas espectrales por efecto del tratamiento dérmico de los radicale de alanina a $423 \mathrm{~K}$. 


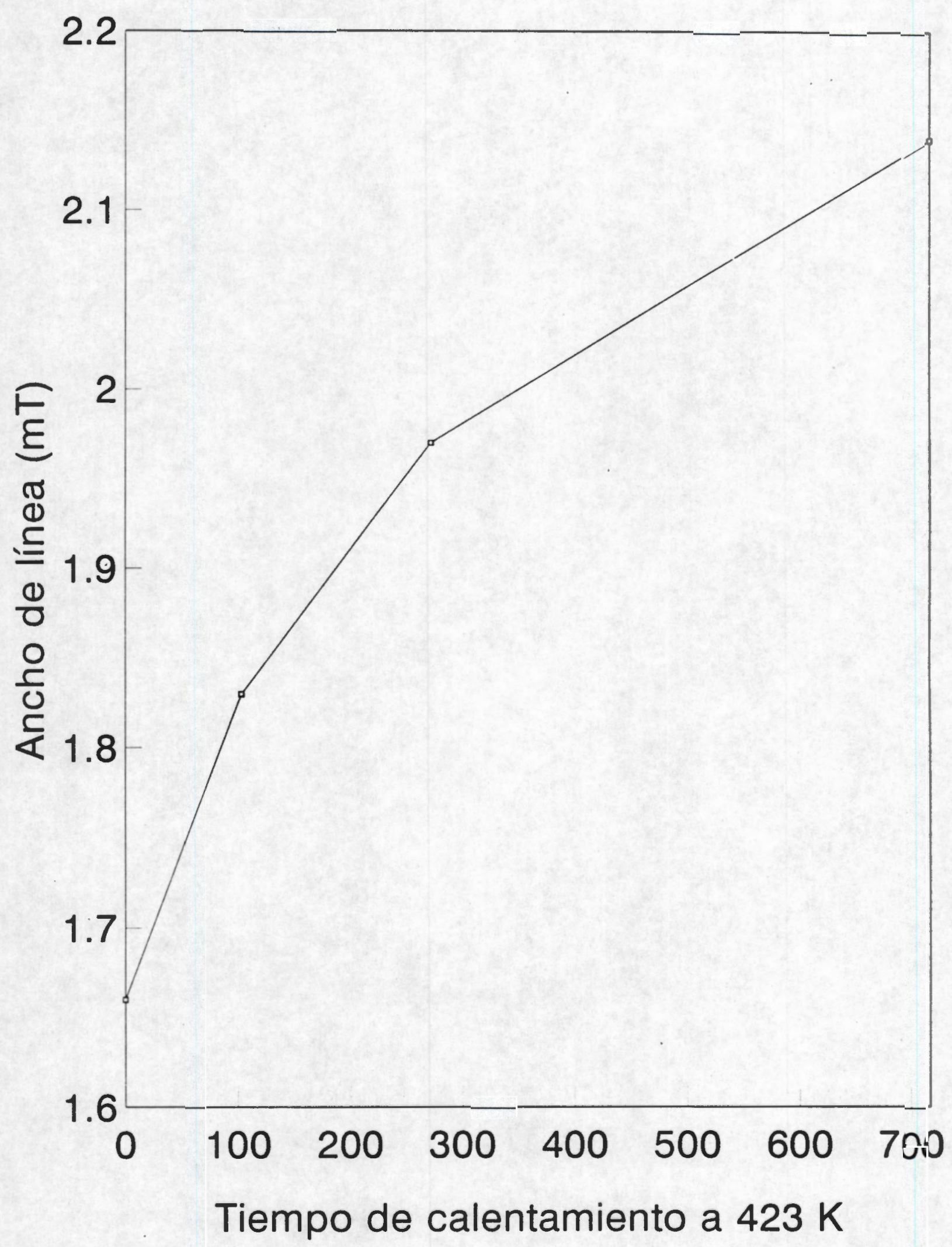

FIGURA 14. Variación del ancho de la línea central del espectro de RPE de los radicales de alanina tratada a $423 \mathrm{~K}$. 


\section{Tabla 3}

Areas relativas de los espectros de RPE de !os radicales de alanina tratados a $423 \mathrm{~K}$.

\begin{tabular}{|c|c|c|c|c|c|}
\hline $\begin{array}{c}\text { Línea } \\
\text { Min }\end{array}$ & 1 & 2 & 3 & 4 & 5 \\
\hline 0 & 1.25 & 4.00 & 6.00 & 3.28 & 0.44 \\
\hline 103 & 0.94 & 3.53 & 6.00 & 3.24 & 0.38 \\
\hline 272 & 0.74 & 3.60 & 6.00 & 3.60 & 0.46 \\
\hline 717 & 0.63 & 3.30 & 6.00 & 3.38 & 0.45 \\
\hline
\end{tabular}

sidad mayor después del tratamiento. Eso mismo ocurrió corı el tratamiento de los radicales de alanina con luz UV, Fig. 11. De igual forma este efecto puede deberse a la disminución relativa de la línea central. Por otra farte, si analiza-

Tabla 4

Semianchos de línea central de los espectros de RPE de los radicales de alanina tratados a $423 \mathrm{~K}$.

\begin{tabular}{|c|c|c|c|c|c|}
\hline $\begin{array}{c}\text { Linea } \\
\text { Min }\end{array}$ & 1 & 2 & $\begin{array}{c}3 \\
\Gamma_{V} \\
(\mathrm{mT})\end{array}$ & 4 & 5 \\
\hline 0 & --- & --- & 1.66 & --- & --- \\
\hline 103 & $-\cdots$ & $-\cdots$ & 1.83 & --- & -- \\
\hline 272 & --- & --- & 1.97 & --- & - \\
\hline 717 & --- & --- & 2.14 & $-\cdots$ & - \\
\hline
\end{tabular}

mos la intensidad de las líneas de alto campo, también marcadas con asterisco y un círculo apuntando sus flechas hacia arriba y a la derecha de la línea central, su intensidades relativas prácticamente se mantierien igual, aunque aumentan con respecto a la intensidad de la línea central, la cual disminuye por el tratamiento térmico. En este caso no se observa la desaparición de ninguna de las dos líneas de alto campo cercanas a la línea central, cumo en el caso de la Fig. 11, aunque la intensidad de la linea mas próxima a la línea central es 
siempre mayor que aquella de su derecha. Esto es, es el caso contrario al mostrado en la Fig. 11, en donde la linea mas a la derecha termina siendo mas intensa que aquella a su izquierda por efecto de la luz UV. Otros cambios notorios se indican para las lineas 2 y 4 en la Fig. 15, en doride mientras unas líneas incrementan su intensidad, otras la disminuyen; estu es, cambios de intensidad esperados para el caso en que más de una especie de radical libre se transforma por efecto de un tratamiento térmico. Nótese que la intensidad de la linea indicada con el signo mayor que, disminuye como en el caso de la Fig. 11 pero con resultados opuestos. Ahora se ve mas claramente, en ausencia de las líneas satélites, que la intensidad de la linea a su izquierda aumenta a medida que se incrementa el tiempo de calentamiento de los I adicales a $423 \mathrm{~K}$.

Para poder analizar mas de cerca estos cambios dependientes de la luz UV y calor, los radicales de alanina previamente tratados con 717 minutos a $423 \mathrm{~K}$, fueron expuestos a la luz UV. Los resultados se muestran en las Figs. 16 y 17.

En la Fig. 16 se muestran los espectros en primera derivada y en forma integrada, en donde varios cambios espectrales se pueden apreciar, como se indica con flechas apuntando hacia arriba o hacia abajo, secuun un aumento o una disminución en la intensidad de algunas lineas de resonancia. Para propósitos de comparación, estos cambios espectrales se pueden analizar de mejor manera usando los espectros deconvolucionados mostrados en la Fig. 17. Como en el caso de la Fig. 11 la intensidad de la linés marcada con un circulo aumenta por efecto de la luz UV, mientras que la intensidad de la linea a 


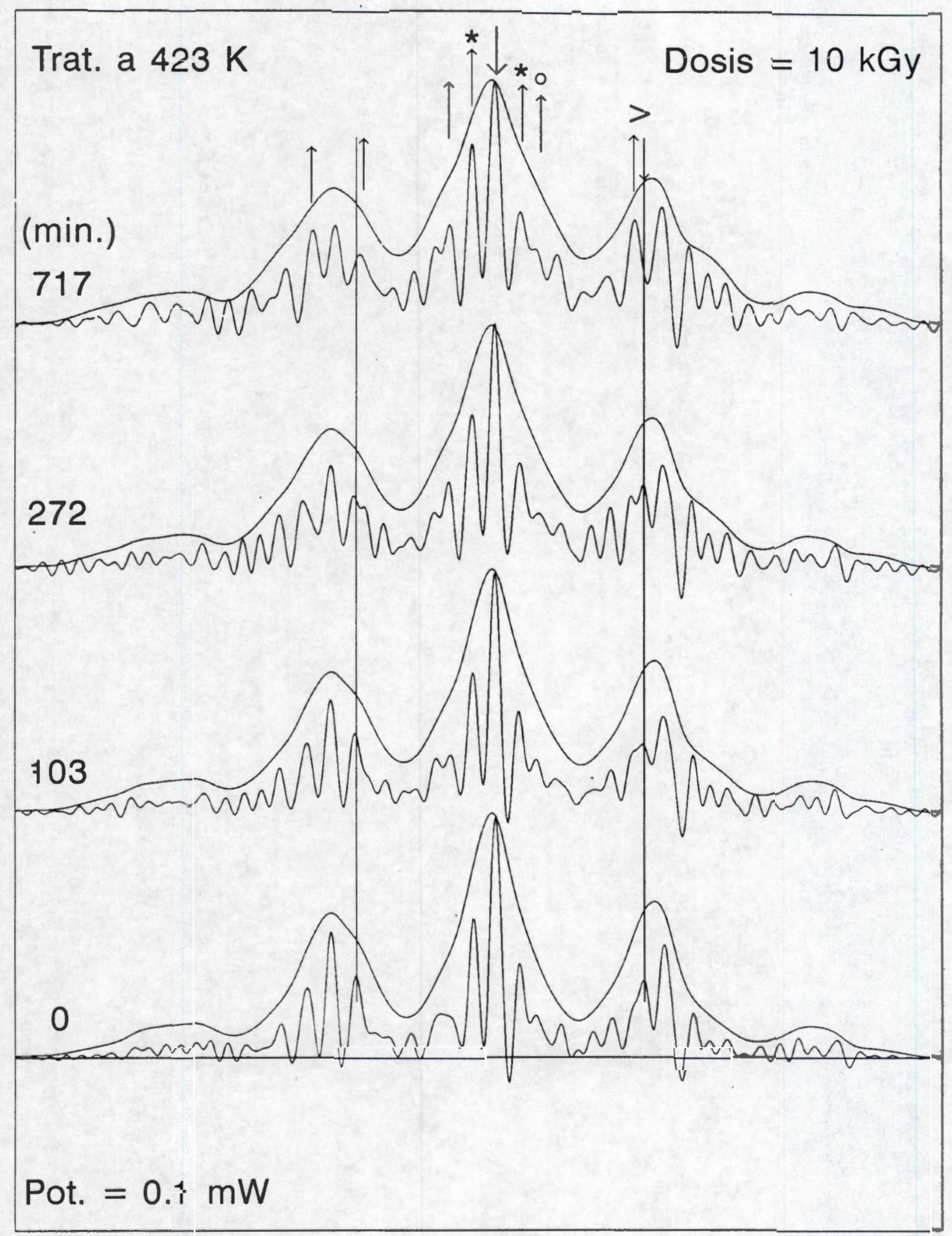

FIGURA 15. Deconvolucion espectral del tratamiento de los radicales libres a $423 \mathrm{~K}$ 
su lado izquierdo, marcada con asterisco, disminuye. Por cira parte, la línea marcada con el signo mayor que, en la línea 4, también disminuye como en el caso de la Fig. 11. Al final de ambos tratamientos las líneas que aparecen en esta región de la línea 4, prácticamente desaparecen. Esto es, pudiera pensarse que las líneas de alto campo, con respecto a la línea central del espectro y marcadas con un asterisco y un círculo y aquellas de la línea 4 , corresponden realmente a especies distintas de radicales.

Los cambios espectrales derivados de este doble tratamiento, a $423 \mathrm{~K}$ y con luz UV, se resumen en la Fig. 18, en donde solo se preser.tan los espectros terminales de cada tratamiento y se comparan con el espectro de RPE de los radicales de alanina sin haber sido tratados.

Con este tratamiento combinado se muestra mas claramente que mientras una señales desaparecen otras incrementan su intensidad, no sin mencionar que tales cambios espectrales solo son posible observarlos usando espectros resueltos en energia.

Observe, por otra parte, que el número de líneas de resor ancia cambia con respecto de aquellas que aparecen en un espectro de RPE de los radicales de alanina sin tratar. Se puede decir, sin embargo, que aunque el traslape de líneas es bastante amplio, algunas líneas se logran resolver y aún llegan a 
Trat. previo a $423 \mathrm{~K}$ por $717 \mathrm{~min}$.

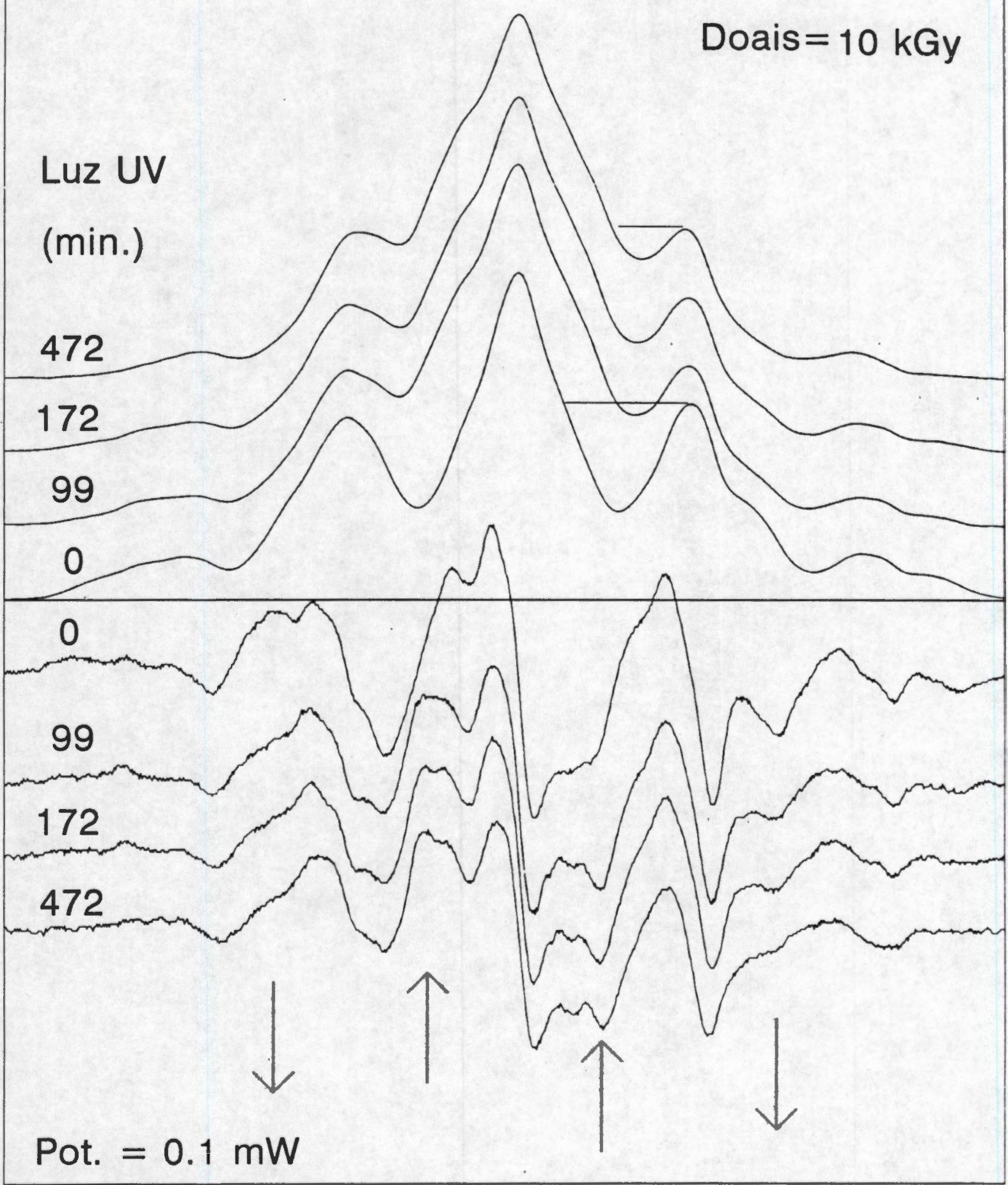

FIGURA 16. Tratamiento combinado de los radicales libres a $423 \mathrm{~K}$ y con luz UV 


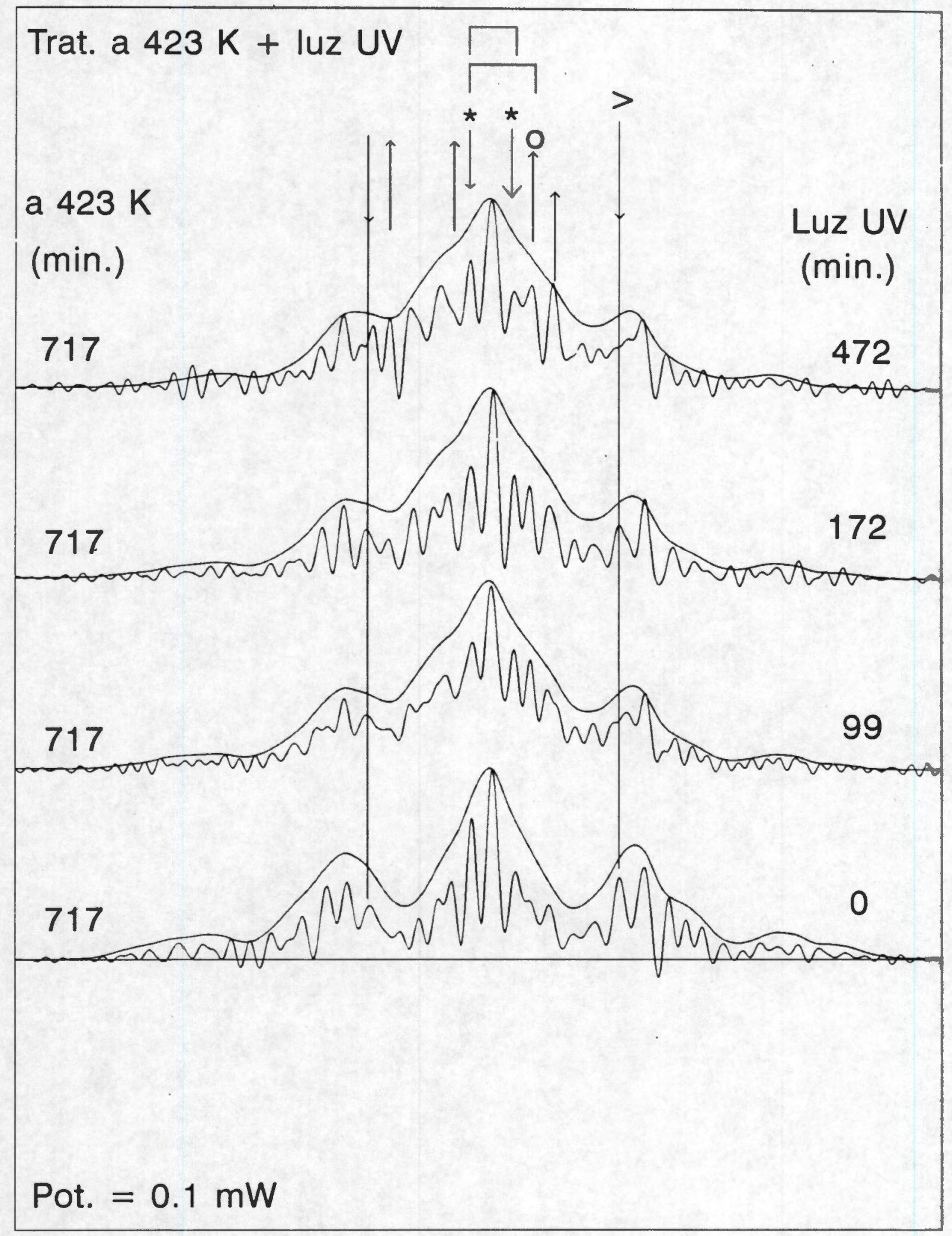

FIGURA 17. Deconvolución espectral del tratamiento combinado de radicales libres a $423 \mathrm{~K}$ y luz UV 


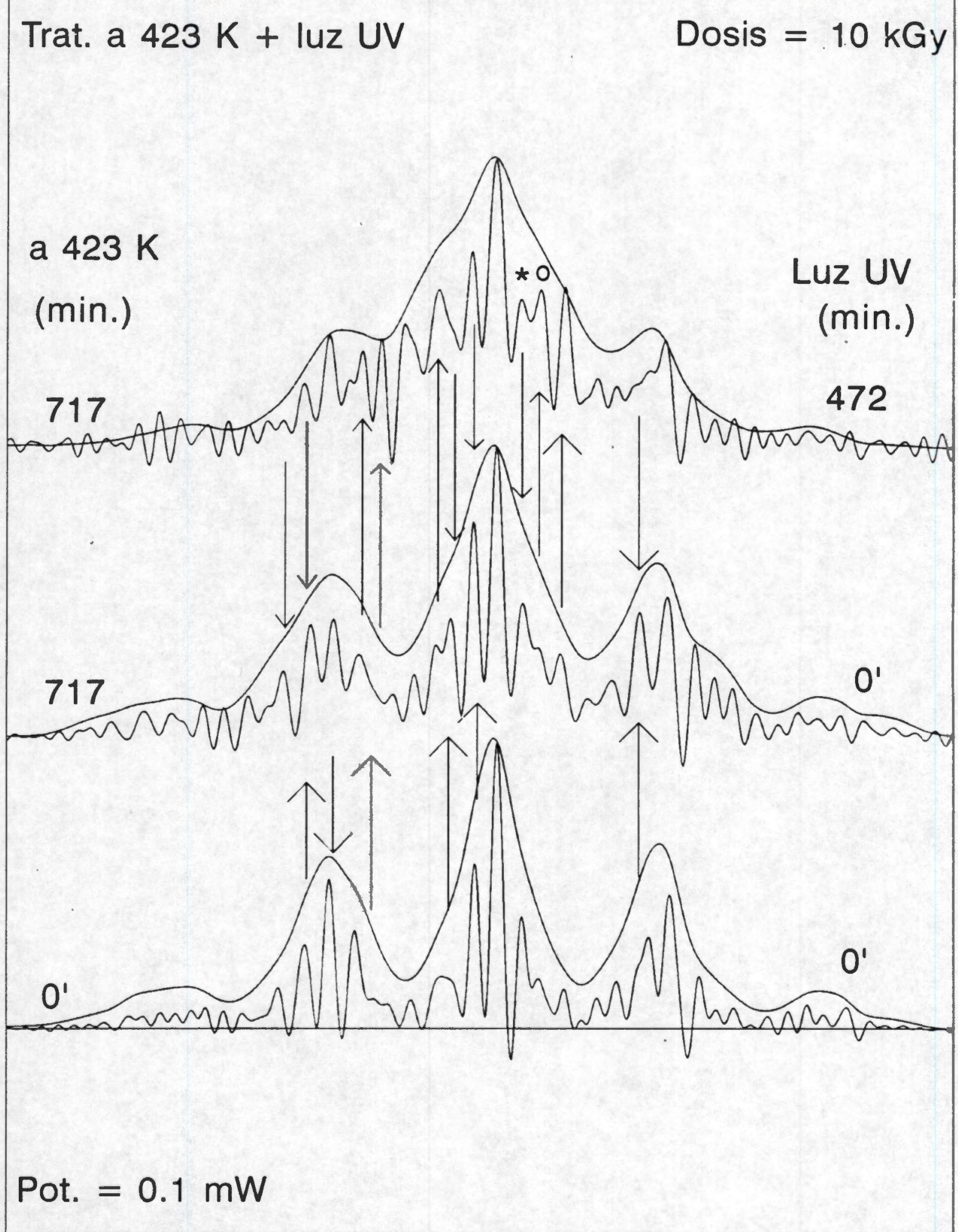

FIGURA 18. Deconvolucion espectral de los distintos tratamientos de radicales libres 
desaparecer por efecto de los tratamientos de los radicales le alanina con luz UV o temperatura. Esto hace posible confirmar la existencia de especies secundarias de radicales libres en alanina irradiada.

\section{Tratamiento térmico a $473 \mathrm{~K}$}

A continuación se presentan dos tratamientos térnicos de los radicales libres a $473 \mathrm{~K}$. La Fig. 19 muestra los dos tratamientos térmicos, uno de una muestra irradiada con $10 \mathrm{kGy}$, figura pequeña insertada, y el otro de una muestra irradiada con $100 \mathrm{kGy}$. Estos tratamientos a $473 \mathrm{~K}$ de las dos muestras irradiadas a distintas dosis no muestran la doble curva inicial que se observa cuando se trata a los radicales de alanina con luz UV, Fig. 7, o a $423 \mathrm{~K}$, ( Brustad et al., 1964). En lugar de esto aparece otra dolile curva, en donde aparecen especies residuales muy estables a esta temperatura de $473 \mathrm{~K}$. Su contribución esta entre un 10 y $20 \%$, Fig. 19. Un espectro típico de estas especies residuales es el que se muestra en las Figs. 20 y 21 . En la Fig. 21 se muestra una serie de espectros obtenidos a partir de la muestra irradiada a 100 kGy y a $413 \mathrm{~K}$ por 2601 minutos para después tratarla a $473 \mathrm{~K}$, tratamiento mostrado en la Fig. 19. Esto es, aproximadamente a los 100 minutos de un tratamiento térmico a $473 \mathrm{~K}$ ya se han eliminado las dos primeras especies que han sido estudiada anteriormente tanto con luz UV como a $423 \mathrm{~K}$. la Fig. 21 muestra que la señal máxima al centro del espectro, disminuye muy lentamente con este trâtamiento a $473 \mathrm{~K}$. Esto indica claramente, sin embargo, que los dos máximos, al centro del espectro, pertenecen a distintas especies de radicales libres. El espectro de RPE de los radicales libres al final de este tratamiento a $473 \mathrm{~K}$ puede compararse con aquel que obtiene Wieser et 


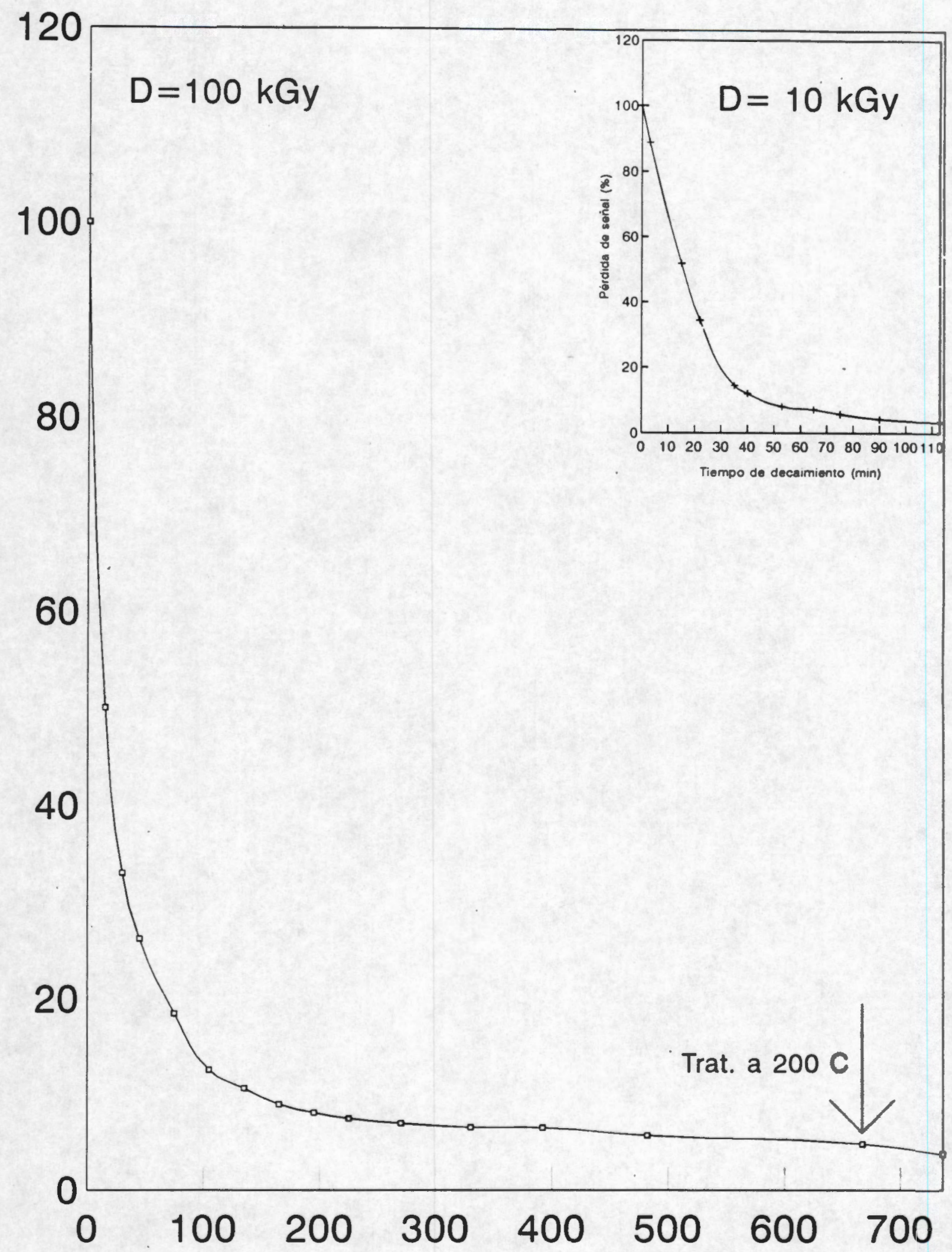

Fig. 19 Muestra con 100 kGy y previamente tratada a $140 \mathrm{C}$ y $155 \mathrm{C}$ con un tiempo total de $2601 \mathrm{~min}$. 


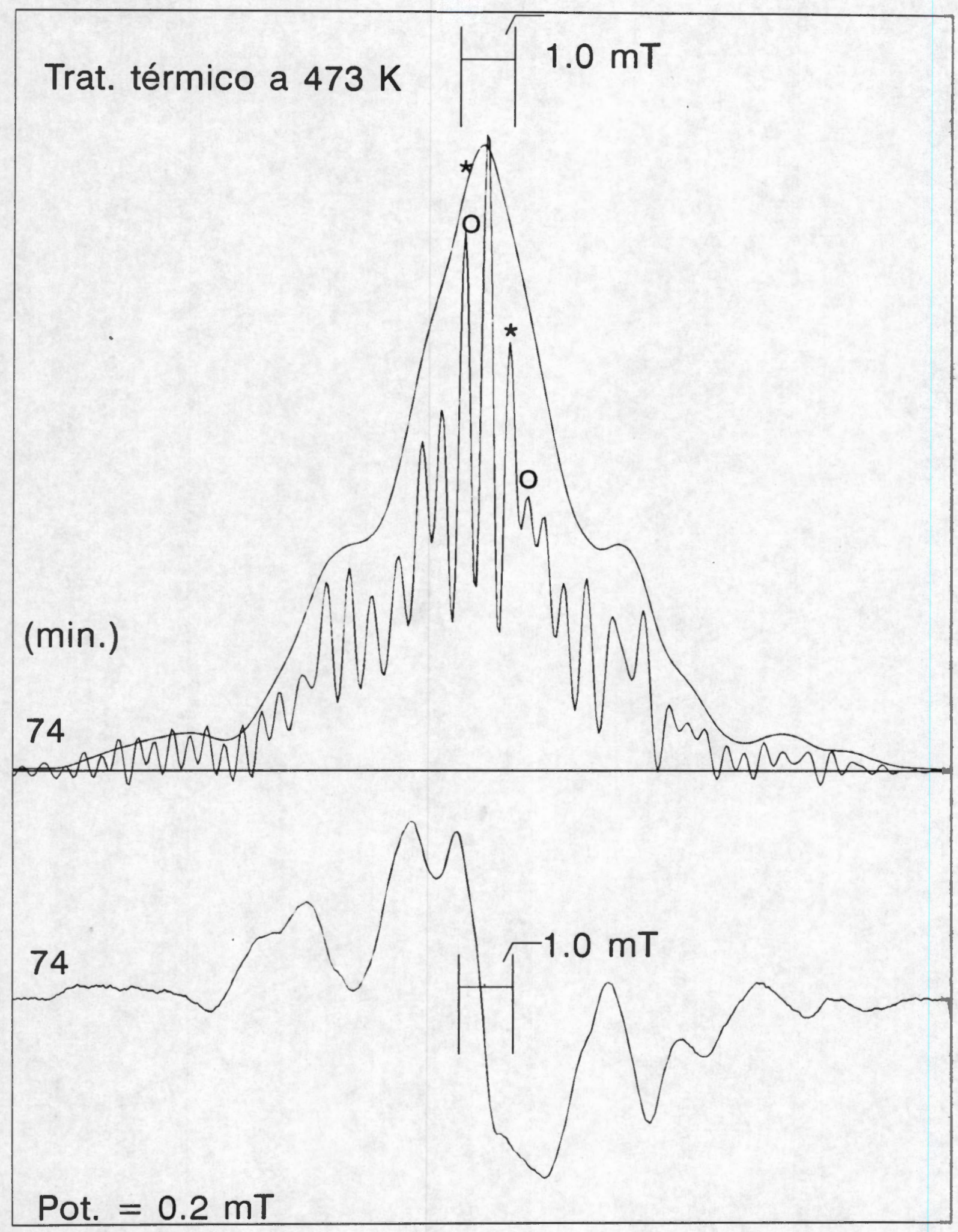

FIGURA 20. Tratamiento de los radicales libres a $473 \mathrm{~K}$ 


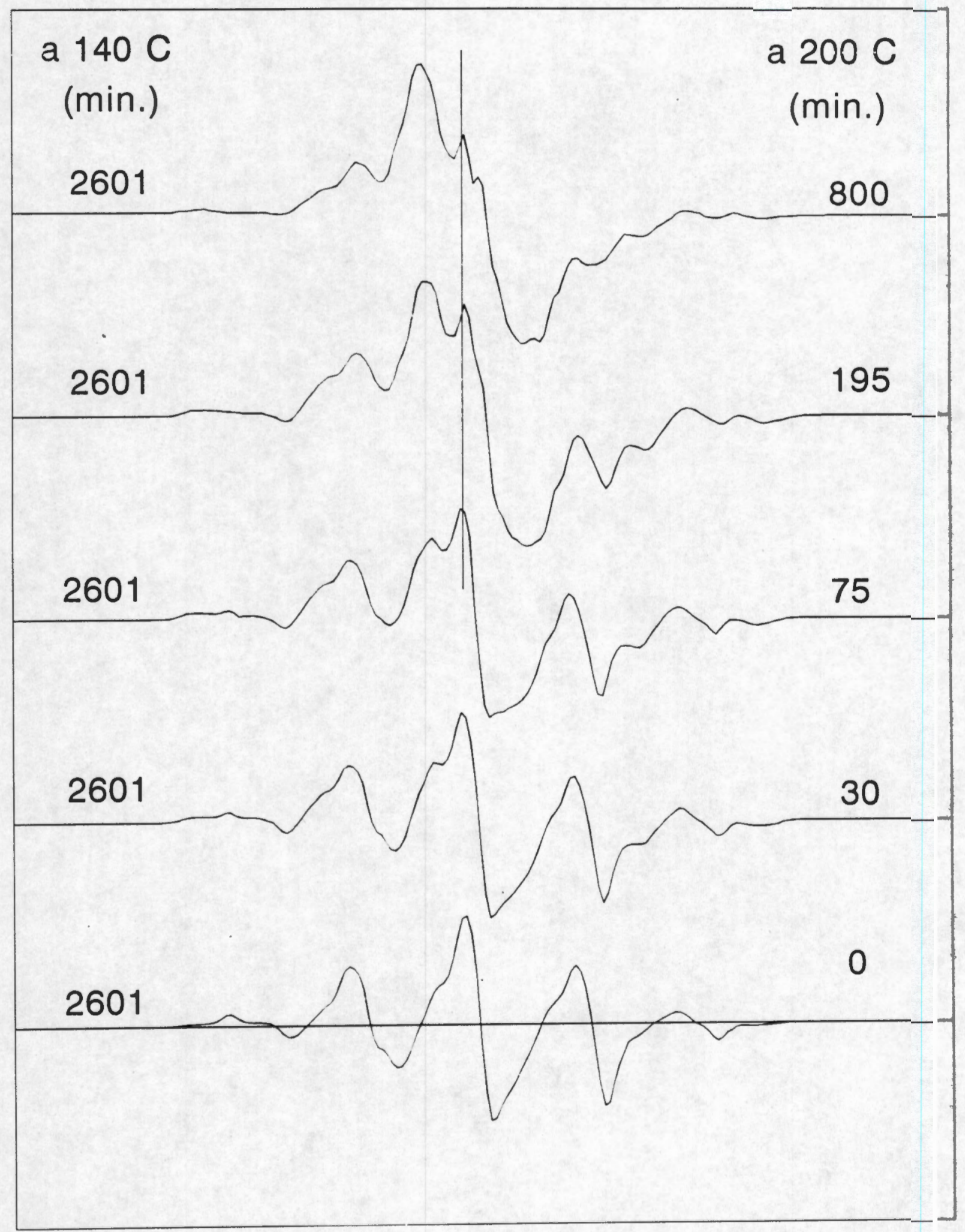

FIGURA. 21 Tratamiento a $200 \mathrm{C}$ de una muestra de alanina tratada previamenta a 140 y $150 \mathrm{C}$ por $2601 \mathrm{~min}$. Dosis $100 \mathrm{kGy}$. Irradiada en 1995 
al.(1993), después de un tratamiento de los radicales de alanina con luz UV por un lapso de tiempo de cuatro meses. Al hacer esta comparación uno se percatá que los espectros residuales son completamente distintos. Esto es, después del tratamiento de los radicales libres de alanina con luz UV se obtiene un espectro de RPE que sugiere una especie distinta de radicales libres a la que resulta después de tratar los radicales de alarina con calor a 473 K. Si de las Figs. 19 y 21 uno deduce dos especies de radicales libres, además de las ya estudiadas previamente, mas aquella sugerida por Wiesel et al., (1993), podemos concluir entonces que se forman cinco especies de radicales libres en alanina policristalina irradiada.

\section{E. Efecto de la dosis}

En esta parte del trabajo se analiza sólo brevemente el efecto de la dosis de irradiación $\gamma$ sobre la producción de los radicales de alanina. Para este análisis solo se utilizaron dosimetros de alanina a base de silicón. Se prevé que al usar el dosímetro en si, esto es, la alanina aglutinada con silicón, el silicón no afecta la producción de radicales libres (Flores et al. 1991). Como se mostrara mas adelante, el silicón afecta de algún modo a la producción de riddicales libres. Un estudio completo de este efecto, sin embargo, no se realizó en este trabajo. Esto es, el efecto del silicón en la producción de radicales libres no era esperado. Por tanto, el propósito del siguiente experimento era observar las variaciones espectrales, a través de los espectros resueltos en energía. de los diferentes

dosímetros de alanina irradiados a distintas dosis. Esto es, identificando los 
rasgos espectrales para cada una de las especies de radicales libres señalados en los estudios previos.

Así, la posibilidad de producir razones de concentración distintas de las especies de radicales de alanina previamente sugeridas por los experimentos anteriores se investiga utilizando las mismas técnicas de convolución y de deconvolución descritos en el Capitulo I y Apéndice B. Esto es, si se produjeran concentraciones distintas de cada una de las especies de radicales libres, previamente prefigurados, algunos cambios en las razones de área y en las intensidades relativas debieran estimarse y observarse.

Por otra parte, estudios previos (Vitaly et al., 1996) muestran que en las primeras horas y días, después del proceso de irradiación $\gamma$ de los dosímetros de alanina, aglutinados con polietileno, ocurren cambios de intensidad espectral que dependen de la dosis de irradiación. De esta dependencia Vitaly et al., (1996), infieren la existencia de especies intermediarias o secundarias de radicales de alanina.

Asi, la Tabla 5 muestra los resultados obtenidos de los anchos de línea y las razones de intensidad de los espectros de polvos de RPE do los radicales de alanina obtenidos a distintas dosis. Por su parte, la Fig. 22 muestra los espectros de RPE, en modo de absorción y deconvolucionados. De la íabla 5 se puede 
apreciar que no hay una notoria variación que indique algún efecto de la dosis sobre la estructura del espectro de RPE de los radicales de alanina aglutinados con silicón. Tanto los anchos de línea como las razones de área se mantienen prácticamente constantes para las dosis de 0.05 a 150 kGy.

Tabla 5. Anchos de linea y razón de área por efecto de dosis

\begin{tabular}{|c|c|c|c|c|c|}
\hline 1 & $\begin{array}{c}\text { Dosis } \\
(\mathrm{kGy})\end{array}$ & 2 & 3 & 4 & 5 \\
\hline & & & $\begin{array}{c}\Gamma_{\text {G }} \text { (Gauss) } \\
\left(\text { A }_{\text {relativa) }}\right.\end{array}$ & & \\
\hline 23.00 & 0.05 & 21.47 & 21.44 & 21.40 & 23.00 \\
$(1.03)$ & & $(4.31)$ & $(6.00)$ & $(3.92)$ & $(1.11)$ \\
\hline 25.68 & 1.0 & 15.50 & 16.36 & 15.38 & 28.88 \\
$(0.87)$ & & $(3.83)$ & $(6.00)$ & $(4.67)$ & $(3.20)$ \\
\hline 20.89 & 4.0 & 16.95 & 15.95 & 15.67 & 25.20 \\
$(0.88)$ & & $(3.80)$ & $(6.00)$ & $(4.88)$ & $(3.49)$ \\
\hline 26.32 & 14.0 & 15.40 & 16.29 & 15.42 & 25.88 \\
$(1.37)$ & & $(3.59)$ & $(6.00)$ & $(3.51)$ & $(1.34)$ \\
\hline 20.54 & 20.0 & 16.45 & 15.81 & 15.75 & 15.84 \\
$(1.08)$ & & $(3.92)$ & $(6.00)$ & $(3.76)$ & $(1.025)$ \\
\hline 24.37 & 50.0 & 15.64 & 16.24 & 15.54 & 24.10 \\
$(1.29)$ & & $(3.67)$ & $(6.00)$ & $(3.59)$ & $(126)$ \\
\hline 24.45 & 90.0 & 15.61 & 16.23 & 15.57 & 24.00 \\
$(1.29)$ & & $(3.66)$ & $(6.00)$ & $(3.61)$ & $(1.26)$ \\
\hline 21.16 & 95.0 & 16.46 & 15.88 & 15.80 & 20.33 \\
$(1.11)$ & & $(3.91)$ & $(6.00)$ & $(3.74)$ & $(1.02)$ \\
\hline 24.26 & 125.0 & 15.57 & 16.32 & 15.70 & 23.79 \\
$(1.28)$ & & $(3.65)$ & $(6.00)$ & $(3.63)$ & $(1.26)$ \\
\hline 25.00 & 145.0 & 20.55 & 20.30 & 20.03 & 25.00 \\
$(1.01)$ & & $(3.80)$ & $(6.00)$ & $(3.90)$ & $(1 .(18)$ \\
\hline 20.53 & 150.0 & 16.55 & 15.77 & 15.76 & 20.21 \\
$(1.08)$ & & $(3.96)$ & $(6.00)$ & $(3.77)$ & $(1.06)$ \\
\hline
\end{tabular}

Particularmente, los anchos de línea del espectro de los racicales de alanina obtenidos con una dosis de $0.05 \mathrm{kGy}$, son mas anchos que todos los demás. Esta 
diferencia podria deberse a la contribución del ruido instrumental del espectrómetro. El efecto del ruido instrumental se puede ver claiamente de la Fig. 1 , en donde se presentan dos espectros de los radicales de alarina obtenidos con 0.05 y 10 kGy de dosis.

Por otra parte, si uno observa los espectros deconvolucionados, Fig. 22, la estructura de líneas es también prácticamente la misma, aunque se distingan cambios ligeros en las intensidades relativas de algunas de sus iíneas. Algunas de las líneas marcadas son las mismas que varian al tratar los radicales de alanina con luz UV o con calor, pero no tanto como en esos casos. De los estudios anteriores con luz UV y con calor, uno podría pensar que pára cada dosis de irradiación se pueden producir concentraciones distintas de las dos especies de radicales libres de alanina ya inferidas, de tal suerte que el espectro deberia ser ligeramente distinto para cada dosis de irradiación. Esto no ocurre, excepto para la línea marcada en la línea dos.

Particularmente las intensidades de las líneas a la derecha y cercanas a la linea central del espectro, marcadas con asterisco y círculo no cambian prácticamente su razón de intensidades. Obsérvese que a cualquier dosis la intensidad de estas líneas son muy similares. Esto es, son los rasgos espectrales que uno obtiene para el caso en que los radicales libres son tratados con calor, aunque no aparece el hombro característico en la línea 4. Básicamente la ausencia del hombro en esta línea 4 se debe a que las lineas satélite contribuyen al espectro, pues estos 


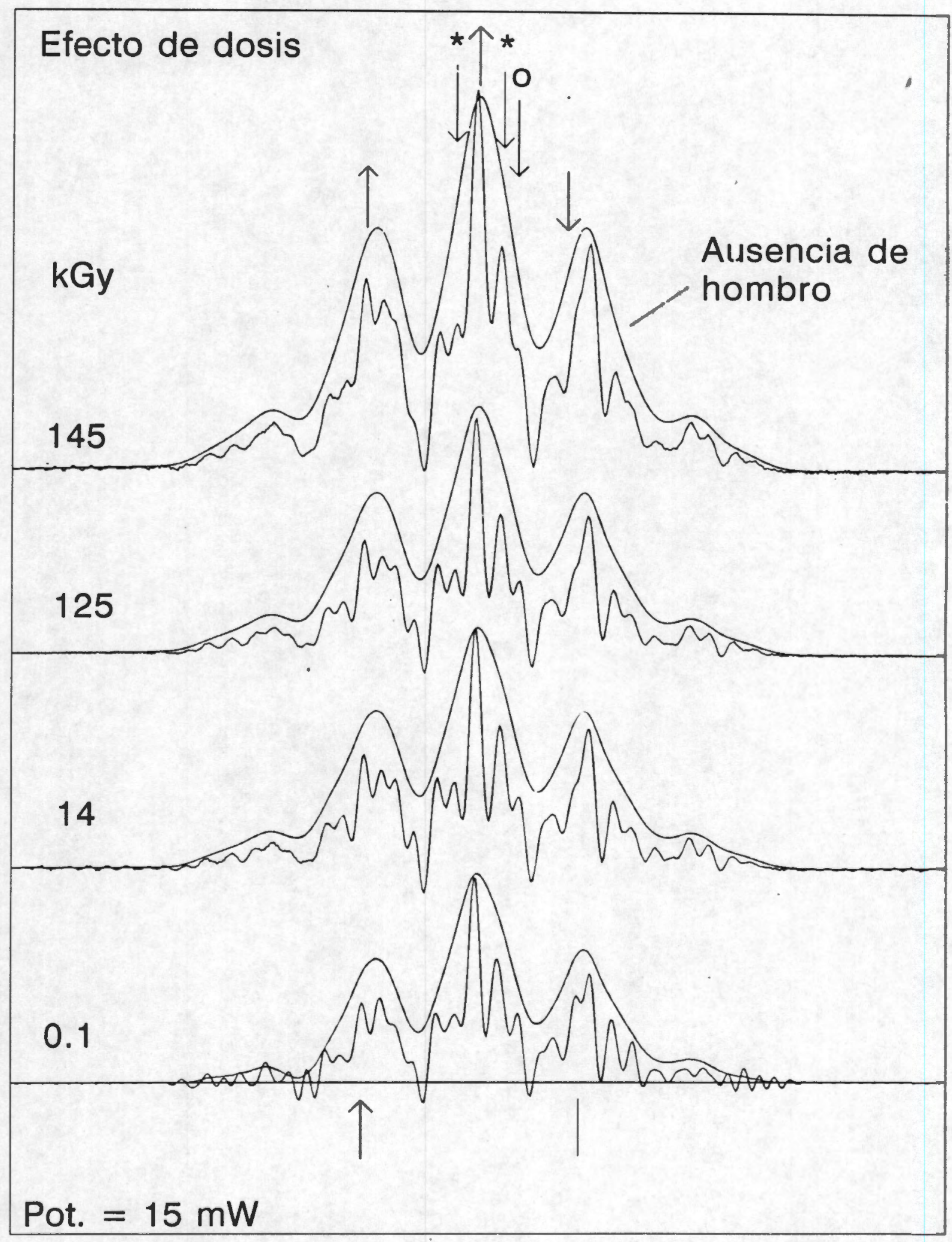

FIGURA 22. Variación espectral de los radicales libres por efecto de la dosis 
espectros fueron registrados a una potencia de $15 \mathrm{~mW}$. Adicior ralmente, si ahora observamos la intensidad de la línea situada a la izquierda de la línea central, indicada por un asterisco, su intensidad difiere de todas aquellas que se muestran en las Fig. 11, en donde los espectros fueron obtenidos con la rnisma potencia de $15 \mathrm{~mW}$ para su comparación. Es claro que el silicón produce efectos notorios en el proceso de irradiación de la alanina en su forma aglutinada. Este resultado no era esperado. Sin embargo se puede concluir a partir de la Tabla $5, y$ de los espectros deconvolucionados de la Fig. 22 que se inhibe la formación de urıa de las especies de radicales libres en alanina aglutinada. Esto es, una de las especies de radicales libres que se forma es la que decae rápidamente cor, un tratamiento a $473 \mathrm{~K}$, como en el caso de la Fig. 19, mientras que las otras dos especies de radicales libres son las que quedan después de ese tratamientc a $473 \mathrm{~K}$, Figs. 20 y 21. 


\section{CAPITULO IV}

\section{EFECTO DEL SILICON SOBRE LA PRODUCCIÓN DE RADICALES LIBRES AL IRRADIAR ALANINA CON RAYOS $\gamma$}

En la parte final del Capitulo anterior se mostró que el aglutinante del dosímetro de alanina, el silicón, presentaba cierto efecto en lo que se refiere a la producción de radicales libres. Esto es, aparentemente tres especies de radicales libres se forman cuando se irradia alanina aglutinada con silicón. En alanina pura irradiada se producen cuatro especies de radicales libres.

En razón de lo anterior; se analiza un poco más el efecto que tiene el silicón, material aglutinante del dosimetro de alanina, al producirse los radicales libres por la acción de la radiación $\gamma$. La caracterización de este efecto consistirá en analizar en forma cualitativa el relajamiento del centro paramagnéticc de los radicales libres de alanina usando el perfil de Voigt. Para ello se emplean los espectros de RPE de la alanina previamente irradiada (con y sin silicón) y posteriormente tratada y sin tratar con luz UV y con temperatura.

En la última sección del Capitulo III se determinó que los espectios de RPE de los radicales libres inducidos en alanina aglutinada con silicón y sometida a diferentes dosis de irradiación $(1,14,125,145$ kGy), Fig. 22, mostraron diferencias notorias 
con respecto de aquellos espectros de alanina pura irradiada. Por ejemplo, compárese los espectros mostrados en las Figs. 11 y 22. Un rasgo espectral importante a notar aquí es aquel en la parte mas cercana y a la izquierda de la línea central, la línea indicada con un asterisco. La diferencia entre estos espectros de las Figs. 11 y 22 son evidentes. Por otra parte, lês dos líneas mas próximas, indicadas con asterisco y un círculo, y a la derecha cie la línea central, Fig. 22, son caracteristicas de la especie que permanece después de un tratamiento térmico de los radicales libres. Compare las Figs. i5 y 22 y observe los rasgos espectrales a la derecha de la línea central indicados con asterisco y circulo. Esto es, los rasgos espectrales son muy parecidos.

Entonces, el interés de esta caracterización se debe, por una parte ${ }_{\text {; }}$ al hecho de que aủn no se tiene un dosímetro universal que supla, en el mejor de los casos, a la gran variedad de dosimetros existentes en diversos laboratorios y consistentes de DL-o L-alanina mas un aglutinante. Algunos de los aglutinantes de uso común son : el teflón, la parafina, la celulosa, el polietileno, el poliestireno, el silicón, etc. Por otra parte, no existe en la literatura un estudio sobre el efecto que tienen estos aglutinantes sobre la producción de radicales libres que se pueden producir al irradiar alanina aglutinada.

Particularmente se ha hecho notar que los diversos aglutinantes empleados son aparentemente transparentes a las radiaciones ionizantes; o lo que es lo mismo, los efectos inducidos por la radiación en estos aglutinantes son rápidamente estabilizados que no afectan grandemente ni a la producción ni á la recombinación 
o a la estabilidad de los radicales de alanina. Desde un punto de vista dosimétrico tal vez el efecto del aglutinante sobre la producción de radicales libres y su posterior estabilización no tenga mucho interés, pero como se mostró anteriormente y se verá mas adelante, se obtienen algunos resultados que tienen que ver con el entendimiento de la naturaleza de los radicales libres que se inducen al irradiar alanina, objeto principal de este trabajo.

\section{A. Alanina pura tratada con luz UV y a $423 \mathrm{~K}$}

\section{1) Alanina pura irradiada y tratada con luz UV}

En el Capitulo III se reportó la variación de las áreas relativas, Tabla 1, y del ensanchamiento de línea, Tabla 2, de los espectros de RPE de los radicales libres, producidos en alanina pura y tratados con luz UV, Fig. 11. Adiciunalmente, se hizo notar que a partir de los espectros mostrados en la Fig. 11 se podia estimar un ensanchamiento de tipo homogéneo (lorentziano) máximo, dependiendo este máximo del tiempo de exposición de luz UV sobre los radicales ibres. En la Tabla 6 , se muestran estos resultados, en donde tanto el ancho gausiano y lorentziano de la linea central del espectro de RPE de estos radicales están dados.

Por otra parte, la Fig. 23 muestra el proceso para obtener dicho máximo de ensanchamiento de tipo homogéneo, en donde se grafica el ancho de tipo homogéneo vs. el criterio de minimización, $\mathrm{Ji}^{2}$. Aqui se asume que el ancho 
lorentziano (homogéneo) es igual para cada una de la cinco líneas del espectro de polvos de RPE de los radicales de alanina. Aunque cada línea de resonancia resulta de una superposición compleja de líneas, Capítulo III, es posible asumir que cada una de las cinco líneas ensanchadas sean únicas.

Tabla 6. Efecto del ensanchamiento de la línea central del espectros de RPE de los radicales libres de alanina tratados con luz UV.

\begin{tabular}{|ccccc|}
\hline $\begin{array}{l}\text { Tiempo UV } \\
\text { (min.) }\end{array}$ & $\begin{array}{c}\Gamma_{G} \\
(\mathrm{mT})\end{array}$ & $\begin{array}{c}\Gamma_{L} \\
(\mathrm{mT})\end{array}$ & $\begin{array}{c}\Gamma_{\mathrm{V}}\left(\Gamma_{\mathrm{L}}\right) \\
(\mathrm{mT})\end{array}$ & $\begin{array}{c}\text { La razón de } \\
\text { area de la lí- } \\
\text { nea central") }\end{array}$ \\
\hline 0 & 1.59 & 1.41 & $1.59(0.20)$ & 4.60 \\
10 & 1.66 & 1.50 & $1.73(0.08)$ & 5.10 \\
20 & 1.68 & 1.51 & $1.73(0.19)$ & 5.35 \\
30 & 1.75 & 1.64 & $1.80(0.22)$ & 6.01 \\
40 & 1.58 & 1.64 & $1.83(0.18)$ & 5.60 \\
80 & 1.78 & 1.66 & $1.84(0.19)$ & 5.97 \\
140 & 1.82 & 1.71 & $1.85(0.48)$ & 6.82 \\
200 & 1.82 & 1.72 & $1.84(0.59)$ & 7.12 \\
290 & 1.84 & 1.76 & $1.86(0.68)$ & 7.78 \\
380 & 1.85 & 1.78 & $1.86(0.71)$ & 8.83 \\
470 & 1.86 & 1.78 & $1.88(0.71)$ & 8.52 \\
560 & 1.87 & 1.81 & $1.88(0.64)$ & 8.15 \\
650 & 1.87 & 1.83 & $1.95(0.71)$ & 9.33 \\
930 & 1.89 & 1.85 & $1.92(0.64)$ & 8.69 \\
1030 & 1.89 & 1.83 & $1.91(0.76)$ & 8.45 \\
1130 & 1.89 & 1.84 & $1.89(0.86)$ & 8.56 \\
1235 & 1.91 & 1.87 & $1.91(0.78)$ & 8.98 \\
1335 & 1.90 & 1.85 & $1.91(0.82)$ & 9.12 \\
1435 & 1.90 & 1.86 & $1.89(0.69)$ & 8.28 \\
1535 & 1.88 & 1.84 & $1.93(0.71)$ & 8.91 \\
1635 & 1.89 & 1.87 & $1.90(0.85)$ & 9.58 \\
1735 & 1.92 & 1.83 & $1.92(0.78)$ & 8.75 \\
2.35 & 1.92 & 1.86 & $1.94(0.83)$ & 9.36 \\
2335 & 1.91 & 1.87 & $1.92(0.81)$ & 9.86 \\
\hline
\end{tabular}

(*) El área relativa de la línea central en términos del área de la quinta línea del espectro. 


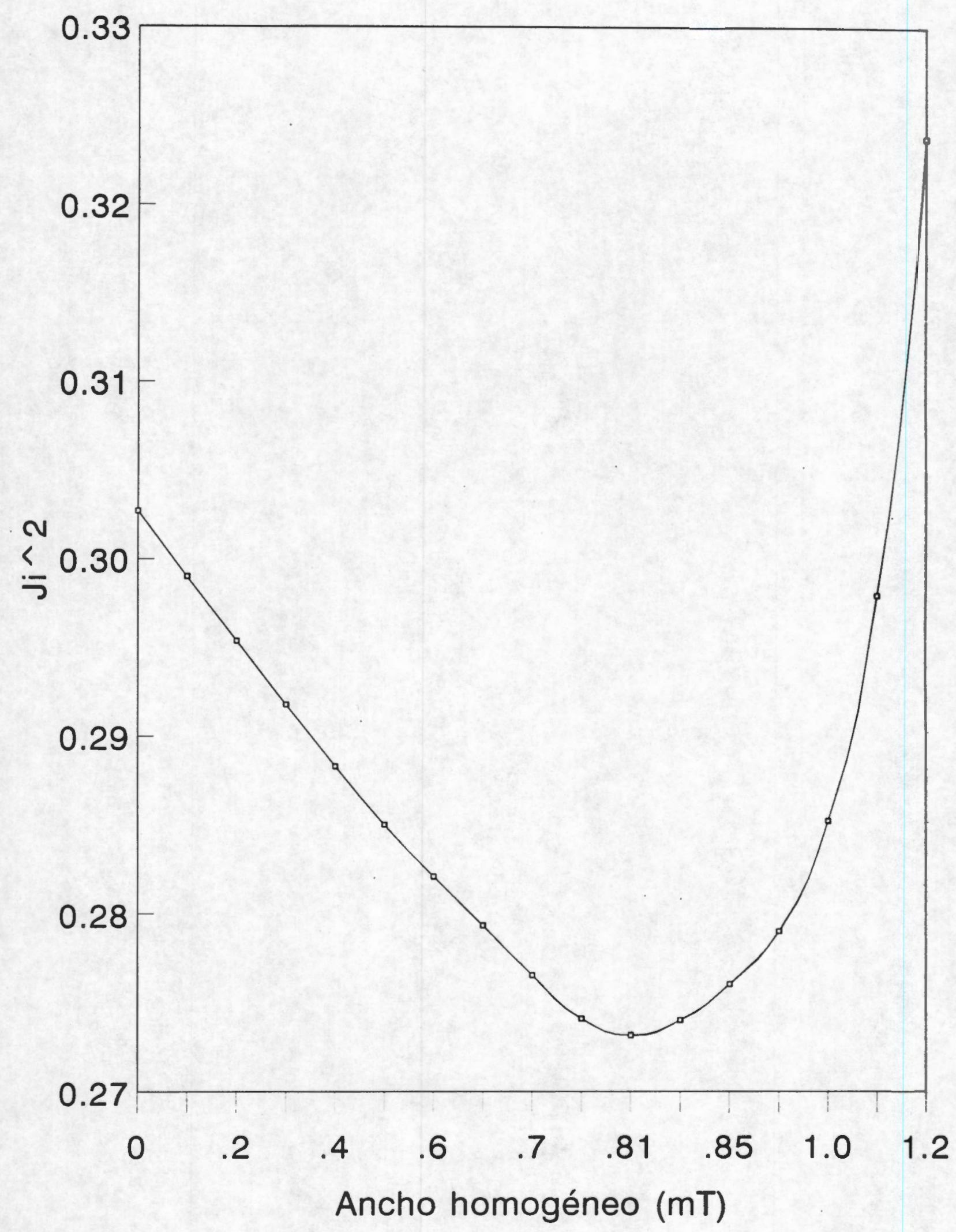

FIGURA 23. Obtención del mínimo del criterio de ajuste $(j i \wedge 2)$ para estimar un ensanchamiento de tipo homogéneo de un espectro de RPE de la alanina pura irradiada con rayos gama y tratada con luz UV. 
Esta suposición puede ser válida solo para un análisis cualitatiıo, ver Fig. 2. Así, para evaluar el ancho homogéneo, éste comenzó desde cero (caso en que las líneas son gausiana puras) y se incrementa poco a poco hasta un valor dado para ajustar a los datos con lorentziana puras, Tabla 6 . Al variar estos anchos, siempre se encuentra un mínimo en $\mathrm{Ji}^{2}$ para cierto ancho homogéneo, como el mostrado en la Fig. 23, el cual dependerá del tiempo de exposición de los radicales de alanina a la luz UV. En la cuarta columna de la Tabla 6 se muestran los valores del ensanchamiento de tipo homogéneo (entre paréntesis) estimado.

\section{2) Alanina pura irradiada y tratada a $423 \mathrm{~K}$}

En el Capitulo III también se reportó la variación de las áreas relativas, Tabla 3, y del ancho de líneas, Tabla 4, del espectro de RPE de los radicales libres inducidos en alanina pura y tratados a $423 \mathrm{~K}$. En ese Capitulo III se hizo notar que hubo una diferencia entre el efecto de la temperatura sobre los radicales de alanina con respecto de aquel con luz UV. Por ejemplo, la variación del área central del espectro de RPE de estos radicales libres tratados a $423 \mathrm{~K}$, Fig. 15, no fue tan marcada como en el caso de los radicales libres tratados con luz UV, Fig. 11, aunque el ensanchamiento espectral fue muy parecido en ambos tratamientos. Otra forma de presentación de las Tablas 3 y 4 se da en la Tabla 7 , en donde además aparece un ensanchamiento de tipo homogéneo máximo, usando el procedimiento indicado en la Fig. 24. Observe la diferencias encontradas en los anchos homogéneos como resultado de los tratamientos con l.dz UV y a $423 \mathrm{~K}$, 


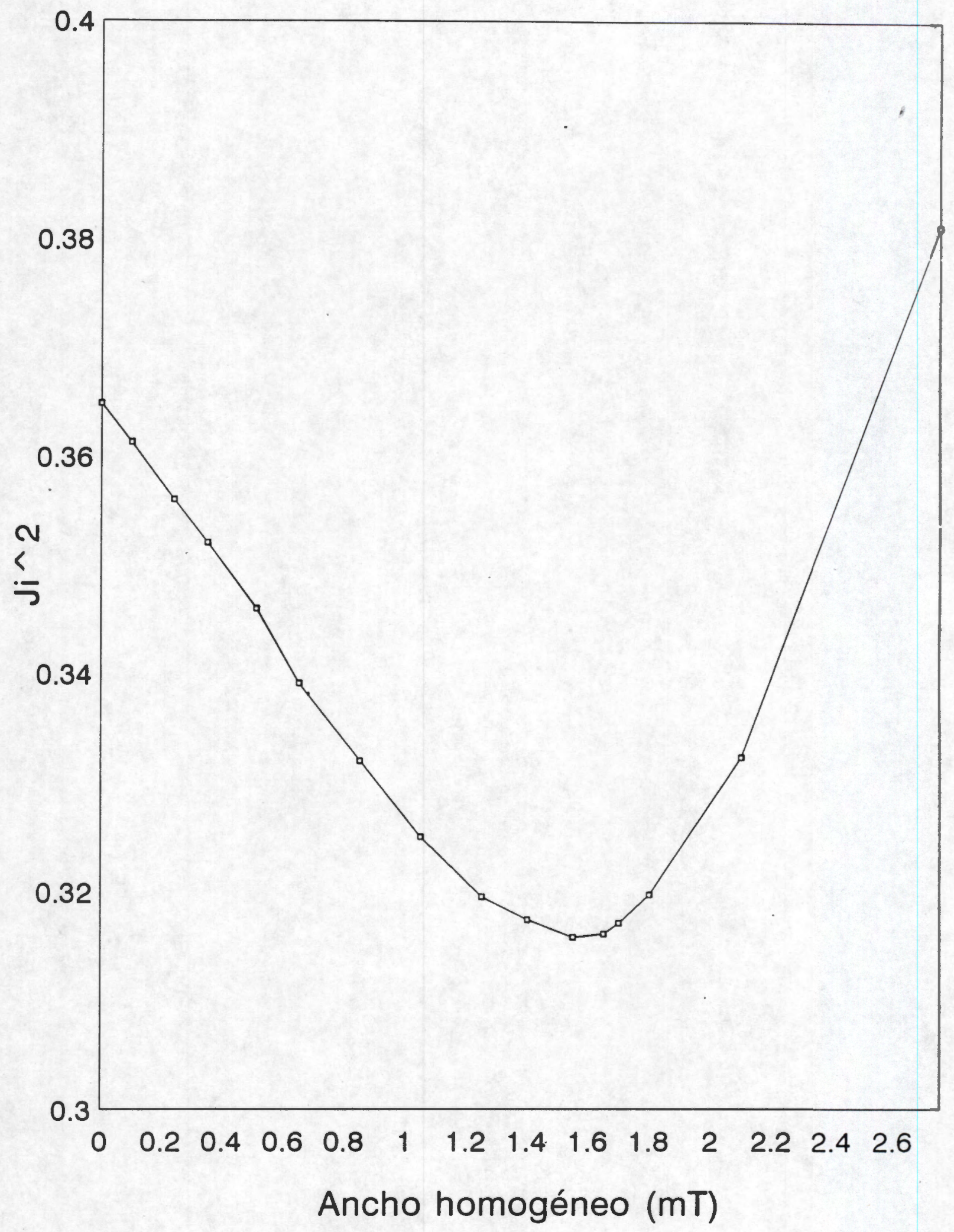

FIGURA 24. Obtención del mínimo del criterio de ajuste ( $\mathrm{Ji}^{\wedge} 2$ ) para estimar el ensanchamiento de tipo homogéneo máximo de un espectro de RPE de alanina pura e irradiada con rayos gama y posteriormente tratada con temperatura. 
Tablas 6 y 7, respectivamente, i. e. el ancho homogéneo es siempre mayor para el caso de los radicales libres tratados con temperatura que con luz UV. Esta diferencia se puede deber a que en el tratamiento con luz UV los espectros fueron registrados a $15 \mathrm{~mW}$, mientras que en el segundo caso a $0.1 \mathrm{~mW}$. Lo importante a notar aqui es que en ambos casos un ancho de tipo homogéneo se pudo estimar de los espectros de RPE resultantes de estos tratamientos usando alanina pura irradiada.

Tabla 7 . Efecto del ensanchamiento de la línea central del espectro de RPE de los radicales de alanina tratados a $423 \mathrm{~K}$.

\begin{tabular}{|ccccc|}
\hline $\begin{array}{l}\text { Tiempo UV } \\
\text { (min.) }\end{array}$ & $\begin{array}{c}\Gamma_{G} \\
(\mathrm{mT})\end{array}$ & $\begin{array}{c}\Gamma_{\mathrm{L}} \\
(\mathrm{mT})\end{array}$ & $\begin{array}{c}\Gamma_{V}\left(\Gamma_{\mathrm{L}}\right) \\
(\mathrm{mT})\end{array}$ & $\begin{array}{c}\text { La razón de } \\
\text { área de la lí- } \\
\text { nea central( }\end{array}$ \\
\hline 0 & 1.66 & 1.23 & $1.45(0.95)$ & 4.9 \\
103 & 1.83 & 1.45 & $1.65(1.25)$ & 6.4 \\
272 & 1.97 & 1.63 & $1.71(1.33)$ & 8.1 \\
717 & 2.14 & 1.88 & $1.98(1.38)$ & 9.5 \\
\hline
\end{tabular}

(*) El área relativa de la línea central en términos del área de la quinta línea del espectro.

Como se verá mas adelante, se puede analizar el efecto del aglutinante en un dosimetro de alanina, vía el análisis de anchos de linea y tratarido previamente a los radicales de alanina ya sea con luz UV o con temperatura, en donde el ensanchamiento homogéneo (o heterogéneo) estimado para alanina pura se puede usar como un dato de referencia. 


\section{B. Alanina con silicón tratada con luz UV y con temperatura}

Los resultados obtenidos de un análisis de anchos de líneas, similar al anterior, Figs. 23 y 24 , pero ahora para los espectros de RPE de los radicales libres producidos en alanina aglutinada en silicón, son los siguientes: Por una parte, la Fig. 25 muestra un resultado típico del análisis hecho para espectros de RPE de los radicales libres inducidos en alanina aglutinada con silicón, tratados (con luz UV ó temperatura) y sin tratar. Esto es, los espectros resultantes de ya sea un tratamiento de radicales con luz UV o con temperatura, o sin tratar, siempre se ajustan a gausianas puras. En estos casos no es posibie estimar algún ensanchamiento de tipo homogéneo (lorentziano). Esta diferencia, entre las Figs. 23 ó 24 y 25 es otra indicación clara de que el material aglutinante afecta de alguna manera a los radicales libres de alanina. Particularmente, el electrón libre en los radicales de alanina se relaja en forma distinta dependiendo de si se usa aglutinante o no. Cabe mencionar aquí que el silicón no prod'sce una señal de RPE que pueda ser detectada dentro de las condiciones experimentales del trabajo.

Por otra parte, aqui también se observa un ensanchamiento de líneas en los espectros de RPE de los radicales de alanina, aglutinados con silicón y tratados con luz UV. Esto se muestra en la Tabla 8. El ensanchamiento es ligeramente mayor al que se obtiene de los espectros de RPE de los radicales de alanina sin silicón, ya sea tratados con luz UV o con temperatura, Tablas $6: 7$. Obsérvese de la Tabla 8 que el área relativa de la línea central no cambia tanto al final del 


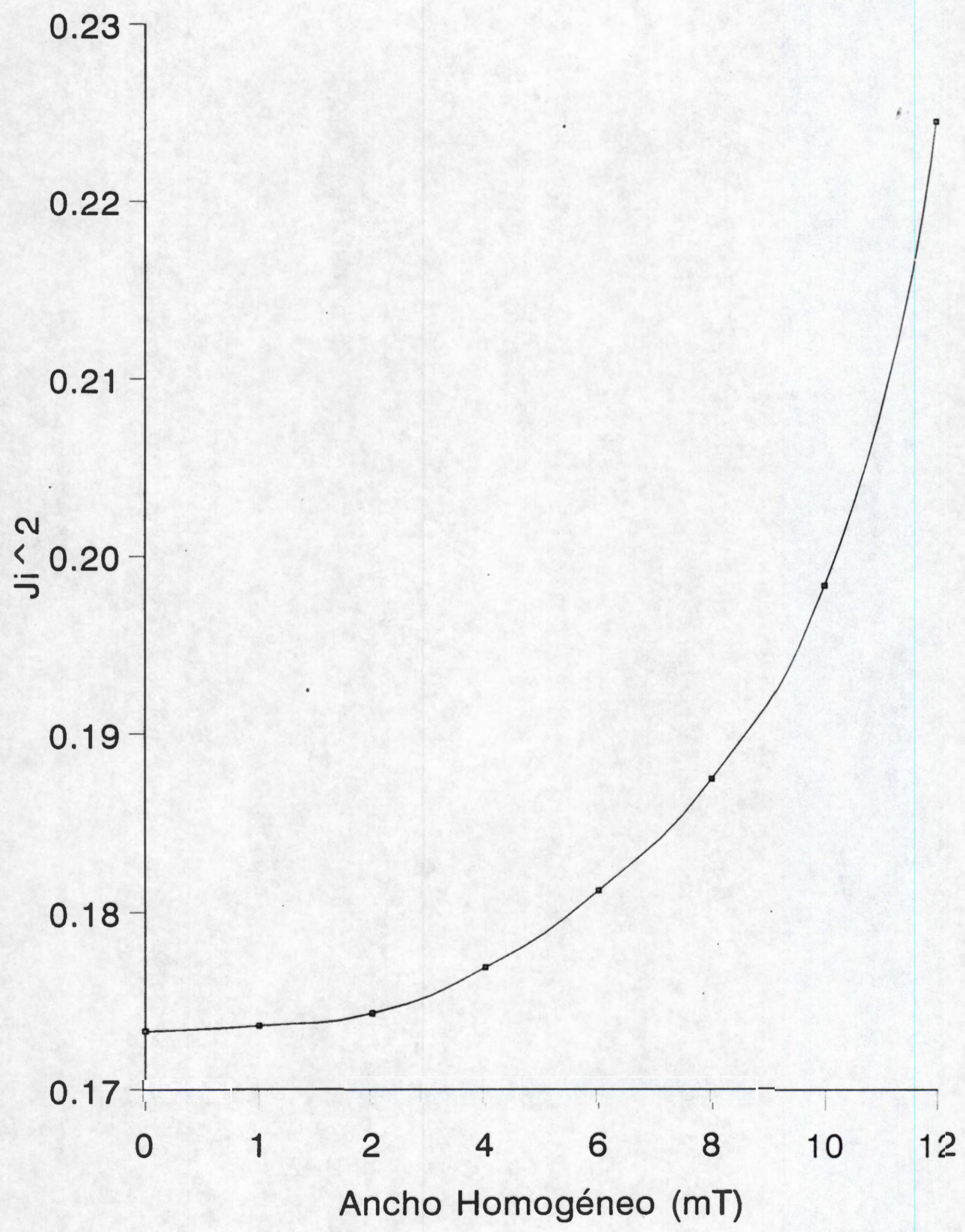

FIGURA 25. Para el caso de alanina con silicón e irradiada con rayos gama y tratada con luz UV o temperatura, no es posible estimar un ensanchamiento de tipo Lorentziano como en los casos de las Figs. 23 y 24 . El efecto del silicon sobre los radicales libres de alanina es notorio. 
tratamiento como en los tratamientos con alanina pura. Estos pequeños cambios también se aprecian a partir de las Figs. 26 a y b, en donde se presentan algunos espectros en primera derivada y en modo de absorción.

Tabla 8 . Efecto del ensanchamiento de la línea central del espectro de RPE de los radicales de alanina aglutinados con silicón y tratados con luz UV.

\begin{tabular}{|ccc|}
\hline $\begin{array}{c}\text { Tiempo UV } \\
(\text { min. })\end{array}$ & $\begin{array}{c}\Gamma_{G} \\
(\mathrm{mT})\end{array}$ & $\begin{array}{c}\text { La razón de } \\
\text { area de la li- } \\
\text { nea central }\end{array}$ \\
\hline 0 & 2.03 & 5.60 \\
300 & 2.30 & 5.25 \\
810 & 2.37 & 5.35 \\
1560 & 2.40 & 6.24 \\
\hline
\end{tabular}

${ }^{*}$ ( ) El área relativa de la línea central esta data en términos del área de la quinta linea del espectro.

Para completar este estudio, los espectros mostrados en Ta Fig. 26 fueron deconvolucionados para aumentar su resolución y ver si el aglutinante (el silicón) afecta de algún modo la producción de los radicales de alanina. Cabe señalar que tanto en el primer tratamiento de los radicales de alanina con lu> UV, Capítulo III, como en el presente caso, los espectros fueron registrados a la potencia de microondas de $15 \mathrm{~mW}$ para poder hacer comparaciones directas entre experimentos previos.

Aunque hay una variación clara en la intensidad de línea central, ver Fig. 26 b, esta no se refleja claramente a partir de los espectros deconvolucionados, Fig. 27. A partir de los espectros deconvolucionados, Fig. 27 , no se obtienen evidencias claras de cambios espectrales que indiquen la presencia de especies secundarias de radicales de alanina como las reportadas en el Capitulo III usando alanina pura 


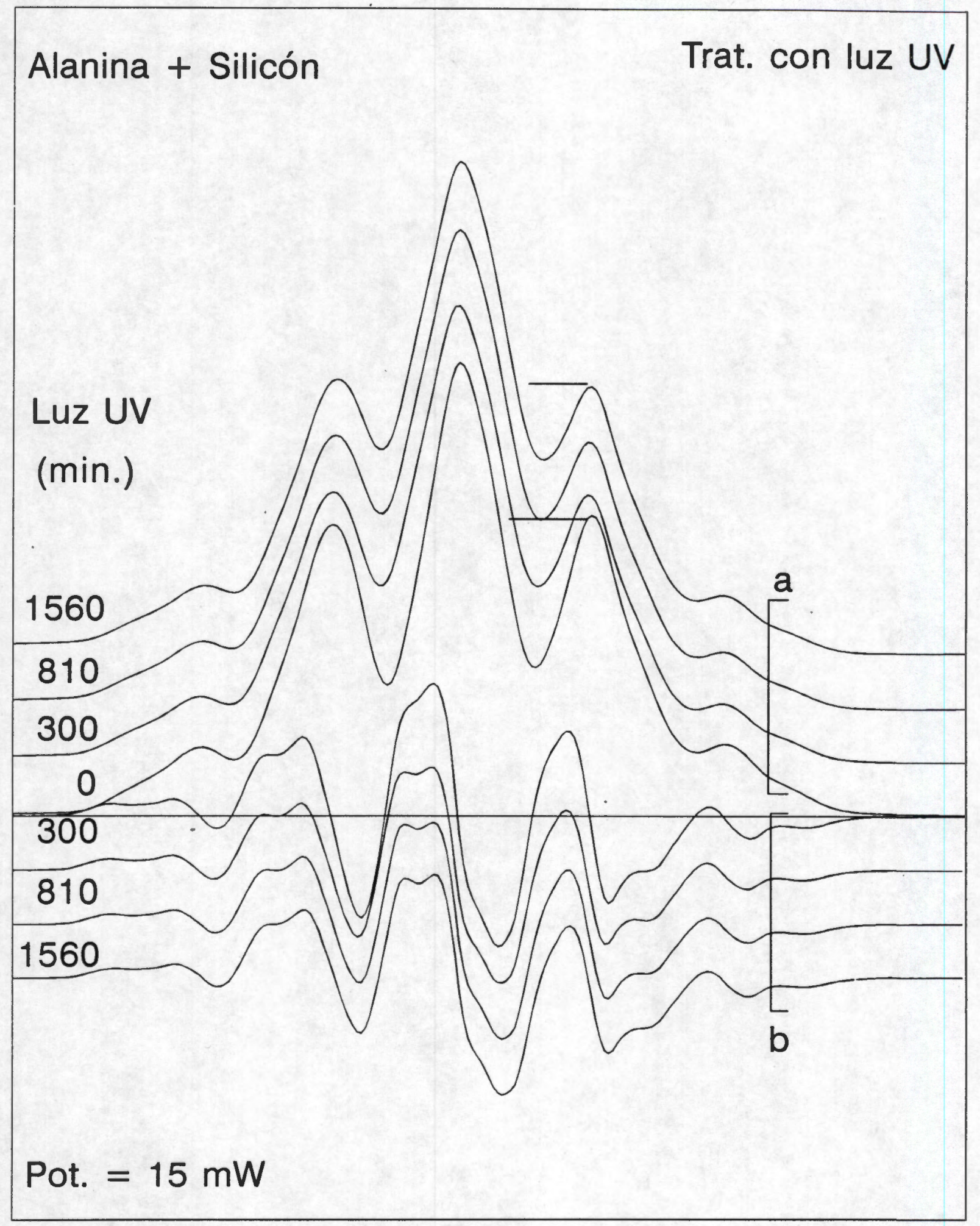

FIGURA 26. Tratamiento de los radicales de alanina aglutinados en silicón con luz UV. a) Espectros en modo absorción; b) Espectros en primera derivada. Los tiempos de exposición de luz UV están dados en la figura. 


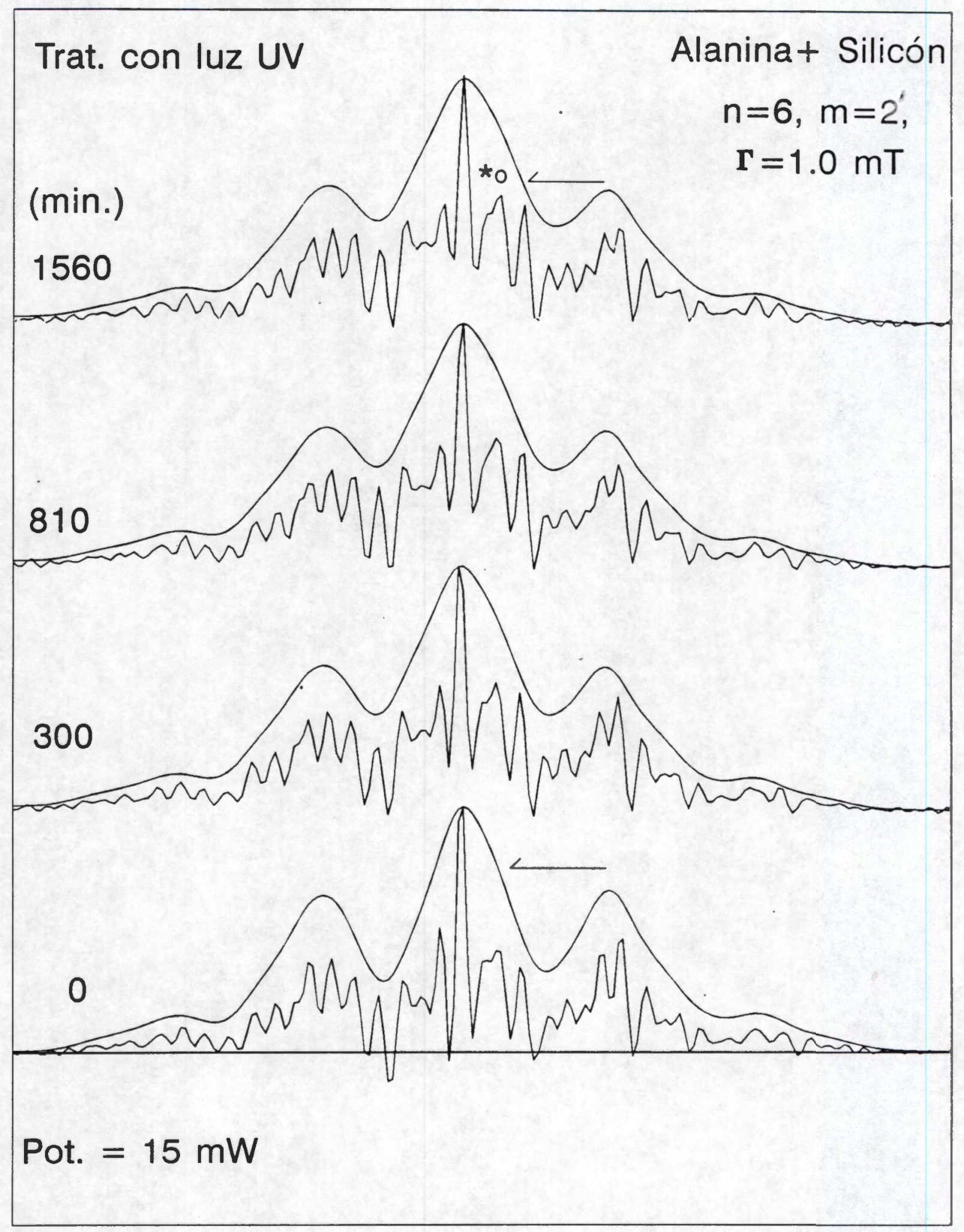

FIGURA 27. Deconvolución de los espectros de RPE de los radicales libres inducidos en alanina con silicón y tratados con luz UV. 
irradiada. Esto indica que hay un efecto considerable del silicón ` posiblemente de los otros aglutinantes, que requiere de un análisis mayor. LJ anterior resulta particularmente interesante para estudiar la naturaleza de los radicales de alanina al estudiar la posible existencia de especies secundarias. En otras palabras, cabe la posibilidad de que al usar algún otro aglutinante, se puedan obtener resultados complementarios a estos y discernir mejor el espectro de RPE de polvos de los radicales de alanina. Finalmente, se puede señalar que también hay una diferencia notable entre los espectros mostrados en las Figs. 22 y 27 en donde las intensidades de las líneas deconvolucionadas indicadas con asterisco y un círculo y cercanas a la central difieren. El espectro de la Fig. 27 es car acterístico de otra de las especies de radicales libres. Esto es, tal parece que el silicón permite la formación de cualquiera de las dos especies de radicales libres pero solamente una sola especie en gran cantidad relativa a las especies que son muy estables a $473 \mathrm{~K}$. Observe de la Fig. 27 que la lineas indicadas con asterisco y un círculo no cambian durante el tratamiento de los radicales libres con luz UV, como en el caso de la Fig. 11. Los espectros mostrados en la Fig. 27 son asencialmente los mismos, en cuanto a las intensidades relativas de las línea: resueltas. Esta diferencia por ahora no puede ser explicada claramente. Dos prisibles respuestas existen para intentar aclarar las diferencias observadas entre la.; Fig. 22 y 27 . Por una parte, el tamaño del cristal de la alanina usado en ambos dosímetros pudo diferir. Por otra parte, se podria pensar que el método de decunvolución pudiera modificar las intensidades de las líneas deconvolucionadas. Este último caso puede descartarse ya que el método en si mismo no considera cambios en intensidad al eliminar una función normalizada de un espectro ohjeto de estudio. 


\section{CAPITULO V}

\section{CONCLUSIONES}

\section{Lineas satélite}

Como resultado del presente estudio sobre la naturaleza de los radicales libres de alanina surgió una reinterpretación de las líneas satélite que pueden aparecer en el patrón de polvos de RPE de estos radicales libres. Básicamente, la señalización del presente trabajo difiere de la propuesta por Arber et al., (1991). Estos autores señalan que las líneas satélite, a las que ellos hacen referencia, deben aparecer a $0.5 \mathrm{mT}$ de la línea central. Esto no es así, incidentalmente la línea central resulta de la superposición de al menos dos líneas permitidas, debidas a especies distintas de radicales libres. Debido a esta coincidencia de traslape de lineas, la línea satélite señalada a la derecha de la línea central e indicada por Arber et al., (1991), aparece a $0.5 \mathrm{mT}$ de ella. Esto sin embargo, no ocurre para la línea satélite a la izquierda de la línea central. Su separación con respecto a la línea central es aproximadamente de $1.0 \mathrm{mT}$; esto es, la separación entra ambas líneas satélite es de $1.5 \mathrm{mT}$, como se ha hecho notar en el presente trabajo. Particularmente, las líneas satélite deben aparecer separadas por $0.5 \mathrm{mT}$ de las líneas peımitidas del doble 
cuarteto y no de aquellas líneas principales del quinteto comc. lo propone Arber et al., (1991) y secundado por Barnad et al. (1996).

En función de la nueva señalización de las líneas satélite del presente trabajo, se hizo una estimación de las distancias promedio entre el electrón libre y los protones más cercanos, usarido la ecuación [1] del. Cápitulo III. Estas estimaciones, para $\langle r(n)\rangle \operatorname{con} n=1$ y 3 protones, se aproximan a los valores reportados por Arber et al. (1991) y a aquellos de Kuroda and Miyagawa (1982). La presente estimación, por otra parte, puede ser mas transparente que la reportada por Arber et al., (1991), ya que en el cálculo de Arber no se menciona explícitamente como se obtuvo la razón de intensidades $\left(I_{p} I_{s}\right)$ ya que existe un gran traslape y ensanchamiento de líneas. En el presente caso esto fue posible de realizar al usar espectros resueltos en energia. La presente estimación de $<r(n)>$, sin embargo, no queda clara ya que si existen mas de una especie de radicales libres, la línea central del espectro surge de la superposición de líneas de resonancia debidas a especies de radicales libres distintas. Adicionalmente, Wiesel et al., (1993), propone que dichas lineas satélite no existen. En lugar de ello sugiere que esas líneas satélite son debicas a especies secundarias de radicales libres, como resultado de su experimento con luz UV. 


\section{Naturaleza de los radicales libres de alanina}

Por otra parte, cuando los radicales libres inducidos en alanina pura son sometidos a una serie de tratamientos, ya sea con luz UV o con calor a $423 \mathrm{~K}$, tales especies quimicas se comportan como si fueran dos especies de radicales libres. De las curvas de decaimiento correspondientes se pueden estimar dos constantes de decaimiento distintas. Estas podrian asociarse a dos especies de radicales libres.

En particular, tanto de los experimentos con luz UV, como con los de calor (a $423 \mathrm{~K}$ ) empleando alanina pura sin aglutinar, previamente irradiada con rayos $\gamma$, se observa, y solo a partir de los espectros resueltos en energía o deconvolucionados, que hay una variación relativa entre las intensidades de líneas con tendencias esperadas que hacen suponer la posible existencia de mas de una especie de radical libre. A partir del tratamientis de los radicales libres de alanina con luz UV y de los espectros resueltos en Energia, es posible diferenciar algunas líneas de resonancia, las mas próximas a la linea central del espectro, que podrian asociarse a diferentes especies de radicales libres en alanina pura irradiada con $10 \mathrm{kGy}$.

Como resultado del tratamiento de los radicales de alanina a $473 \mathrm{~K}$ también se pudo distinguir otro par de especies secundarias de racicales libres, que 
permanecen después de los tratamientos térmicos a $473 \mathrm{~K}$ de las muestras irradiadas con 10 y 100 kGy, que pueden asociarse a otras e.species de radical es libres de alanina aun no identificadas claramente. La existencia de estas especies, aunque de poca intensidad (10-20\% del total) producen un traslape de sus señales muy considerable de tal suerte que esto es lo que no ha permitido a varios autores reproducir el espectro mediante simulación numérica.

Por otra parte, el método de deconvolución empleado en este trabajo permite obtener espectros con una resolución bastante buena, de tal suerte que algunas líneas de resonancia se desplazan de otras, que pueden ayudar a discernir entre una o mas especies de radicales libres diferentes. Como resultado de este estudio, es posible llegar a una conclusión sobre la existencia de al menos cuatro especies de radicales libres en alanina pura irradiada.

\section{Efecto de la dosis de irradiación sobre la producción de risdicales libres}

Bajo la condiciones experimentales del presente trabajo, en donde se empleó àlanina aglutinada con silicón, solo ligeros cambios espectrales fueron detectados debido a las distintas dosis de irradiación aqui ampleadas. Como resultado del análisis hecho usando los espectros de RPE resultantes de los radicales libres obtenidos a distintas dosis no se observó una variación clara 
entre los espectros de los radicales de alanina obtenidos zon bajas y altas dosis. Un resultado importante es aquel en donde aparentemente una sola especie de radical libre se induce al irradiar alanina aglutinada con silicón, un resultado que se comenta en la siguiente sección.

\section{Efecto del silicón sobre la producción de radicales libres de alanina}

Finalmente, al estudiar las diferencias entre los radicales libres inducidos en alanina pura y aglutinada con silicón, se encontró que hay ur, efecto notorio del silicón sobre los radicales libres de alanina. Como se menciono anteriormente, solamente una sola especie de radical libre se forma cuando se irradia alanina aglutinada con silicón. En la literatura siempre se hace notar de un efecto nulo de cualquiera de los aglutinantes empleados para producir un dosimetro de alanina. Desde el punto de vista dosimétrico puede ser esto cierto, pero desde el punto de vista de la producción de distintas especies de radicales libres, no podria ser del todo cierto como se demuestra en este trabajo. Mas trabajo en esta dirección es necesario.

Adicionalmente, los anchos de líneas de los espectros de RPE de estos radicales libres inducidos en alanina aglutinada en silicón es ligeramente mayor que el ancho de línea de los espectros de RPE de los radicales de alanina sin 
aglutinar. Esto hace que la razón señal-a-ruido disminuya la cual no es muy promisorio para propósitos dosimétricos. Particularmente, $\epsilon$ sto no es óptimo cuando se desean medir dosis clínicas en donde se desea maximizar dicha razón de señal-a-ruido.

Por otra parte, es importante resaltar que el silicón aparantemente puede permitir la formación de una u otra de las especies de radicales libres de alanina inferidas en el presente trabajo. Esta conclusión surge del tratamiento de los radicales libres inducidos en alanina aglutinada en silicón con luz UV, en donde no se presenta una variación de intensidades relativas de línea como cuando esós radicales libres sin aglutinar son tratados con luz UV. Esto es, hay diferencias notorias entre uno y otro estados de los radicales libres inducidos en alanina pura y aglutinada en silicón que debiera estudiarse mas para esclarecer tanto la naturaleza de los radicales libres que se inducen al irradiar alanina policristalina como el efecto del material aglutinante. Esto es, aparentemente cuando se irradia alanina pura se obtienen mas de una especie de radical, pero cuando se irradia alanina aglutinada con silicón aparentamente solo una especie de radical libre se forma. 


\section{APÉNDICE A}

\section{ESPECTRO DE POLVOS DE RPE DE LA ALANINA IRRADIADA}

\section{A.1 El radical libre $\mathrm{CH}_{3} \mathrm{C} H R$}

El patrón de polvos de RPE de la DL- o L-alanina irradiadas es prácticamente el mismo (Ureña-Nuñez et al., 1993), aunque la L-alanina presenta una mayor sensibilidad a la radiación. La Fig. A-I muestra un patrón típico de RPE en modo absorción de los radicales libres que se inducen al irradiar alanina policristalina con radiación ionizante.

El espectro de polvos de RPE de la alanina irradiada consiste, en términos generales, de un quinteto de lineas muy ensanchadas. La razones de intensidad estimadas son muy próximas a $1: 4: 6: 4: 1$; esto es, como si un electrón intercalara con cuatro protones magnéticamente similares.

Miyagawa y Gordy ,(1960), infieren a partir de los espectrcs de RPE de un monocristal de L-alanina $\left(\mathrm{CH}_{3} \mathrm{CH}\left(\mathrm{NH}_{2}\right) \mathrm{R}\right.$, con $\left.\mathrm{R}=\mathrm{CO}_{2} \mathrm{H}\right)$ irradiado con rayos $\mathrm{X}$, obtenidos bajo distintas orientaciones entre la dirección del campo magnético externo y los ejes cristalinos, que el radical libre que se induce ; $p o r$ los rayos $X$ es 


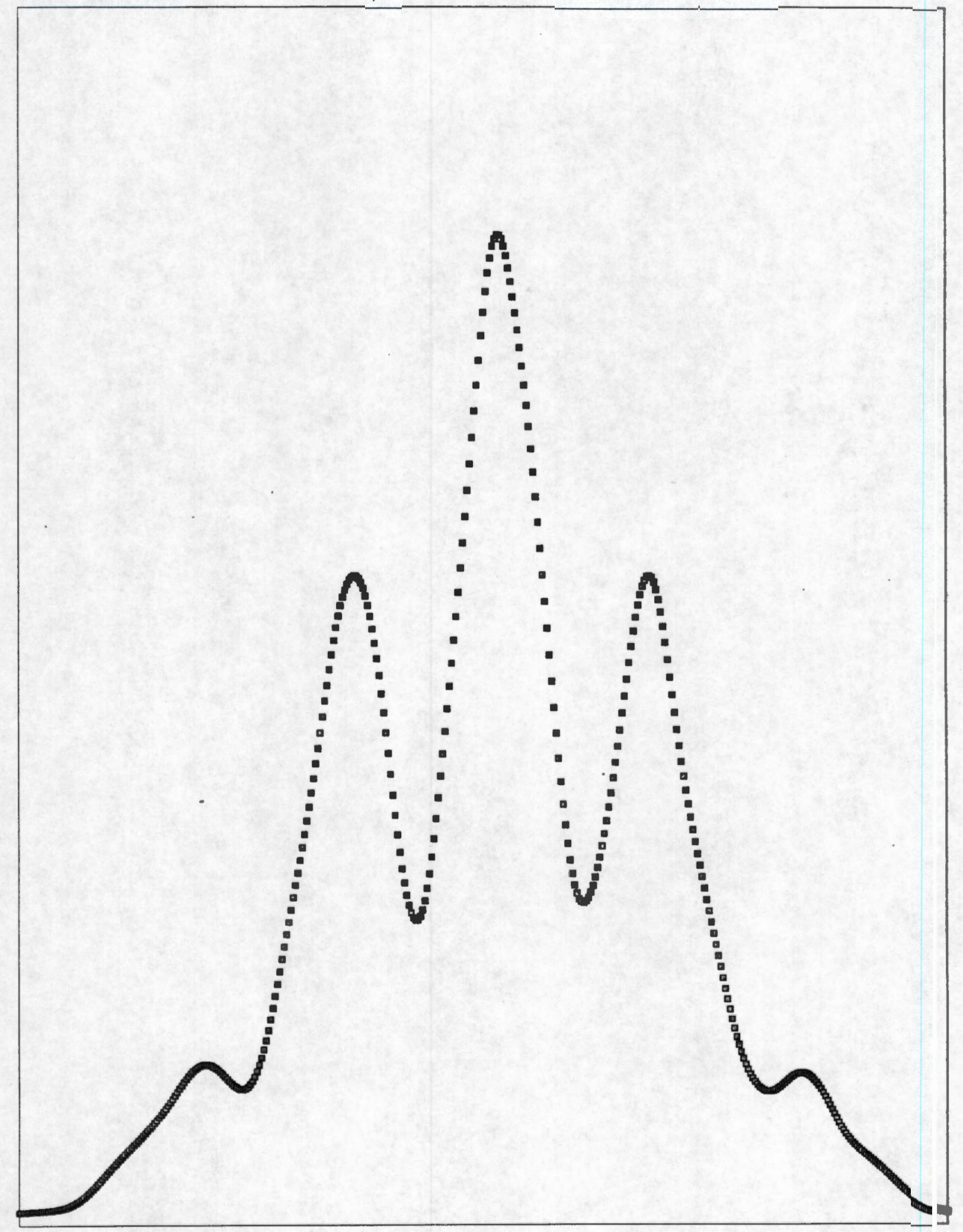

FIGURA A-I. Patrón típico de RPE de DL-alanina policristalina irradiada. 
el $\mathrm{CH}_{3} \dot{\mathrm{C}} \mathrm{HR}$. De estos estudios, los protones del grupo metilo $\left(\mathrm{CH}_{3}\right)$ y del $\mathrm{CH}$ de este radical libre, pueden o no, dependiendo de la dirección en que se les observa, comportarse magnéticamente equivalentes.

Por ejemplo, al registrar el espectro de RPE de un monociristal de alanina irradiado, alineando el eje cristalino [001] en la dirección del campo magnético aplicado, se registra un quinteto de lineas con intensidades relativas de aproximadamente $1: 4: 6: 4: 1$, y con una separación entre líneäs de $2.5 \mathrm{mT}$, Fig. A-Il a, (Miyagawa y Gordy, 1960). Por otra parte, al registrar el espectro de RPE de este mismo monocristal irradiado, pero ahora alineando el eje cristalino [100] en la dirección del campo magnético, se detecta un doule cuarteto con intensidades relativas de línea, de aproximadamente $1: 1: 3: 3: 3: 3: 1: 1$ y con una separación de líneas de aproximadamente 2.0 mT, Fig. A-II b, (Niiyagawa y Gordy, 1960). A partir de estas observaciones y demás cálculos, Miyagawa y Gordy ,(1960), proponen que la formula química de un radical libro inducido por la radiación es el $\mathrm{CH}_{3} \dot{\mathrm{C}} \mathrm{HR}$. Esto es, por efecto de la radiación ocurriria una ruptura de enlace, separándose el grupo amino $\left(\mathrm{NH}_{2}\right)$ de la alanina $\left(\mathrm{CH}_{3} \mathrm{CH}\left(\mathrm{NH}_{2}\right) \mathrm{R}\right)$ y en donde para ciertas orientaciones entre la dirección del campo magnético y los ejes cristalinos, los protones del grupo metilo y del $\mathrm{CH}$ sor, magnéticamente equivalentes por lo que resulta un quinteto de líneas como el de la Fig. A-II a. Cuando se registra el doble cuarteto de lineas, Fig. A-Il b, el protón del grupo $\mathrm{CH}$ se comporta de manera distinta a aquellos del grupo metilo. Cuiando se registra el espectro a un ángulo intermedio entre los dos ejes cristaliros [001] y [010], 


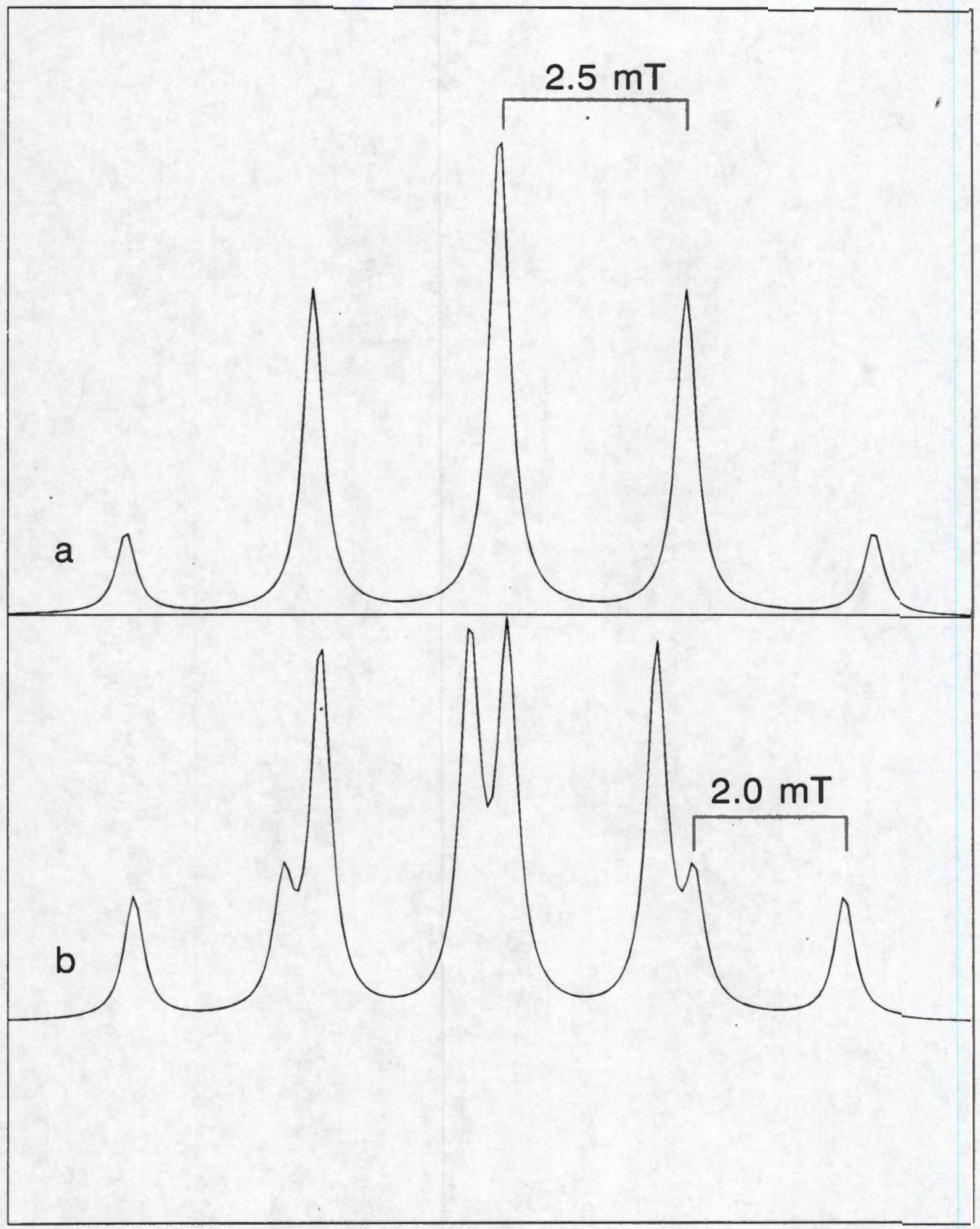

FIGURA A-II. a) Quinteto de líneas que resultan de la interacción entre el electrón libre y cuatro protones magnéticamente equivalentes. b) Doble cuarteto de líneas que resulta de la interacción entre el electrón libre y tres protones equivalentes y uno distinto. 
aparece en el espectro la superposición del quinteto y el doble cuarteto de líneas (Miyagawa y Gordy, 1960). Es de esperarse pues que el patrón de polvos consista de una superposición de estos dos patrones base. Débido a efectos de anisotropia tanto en la interacción Zeeman como hiperfina este patrón de polvos consiste de una compleja superposición de esos patrones base que ha complicado su estudio.

Para una muestra de alanina policristalina e irradiada, los efecłos de anisotropia del protón del grupo $\mathrm{CH}$ pudieran promediarse en algún grado, lo que pudiera en primera instancia simplificar la interpretación de su especiro de RPE. Sin embargo, más recientemente algunos autores (Höfer et al., 1389 ; Arber et al., 1991 ; Barnard et al., 1996), logran identificar, empleando ambas, RPE-oc y RPE$p$, líneas satélite (transiciones $\Delta m_{1}= \pm 1$ ) como una consecuencia del acoplamiento anisotrópico de electrón con el protón del grupo $\mathrm{CH}$ del radical libre $\mathrm{CH}_{3} \dot{\mathrm{C}}$ HR . Estas líneas satélites se han observado en otras substancias (Livingston et al., 1955 ; Trammell et al., 1958). Asi, el patrón de polvos de RPE cie los radicales de alanina consistiria de una superposición aún mas compleja da patrones que la descrita anteriormente; esto es, a base de solamente quintetos y cuartetos. Adicionalmente, las líneas satélite se han confundido con seinales de especies secundarias de radicales libres de alanina (Pilbrow et al., 1936) por lo que un estudio sistemático de ellas aun sigue siendo necesario.

Como se muestra en el presente trabajo esta compleja superposición de patrones se puede analizar empleando el método de deconvolución de C.abral-Prieto et al. 
(1991, 1993, 1994, 1999) para estudiar las líneas satélite $y$-la posible existencia de especies secundarias de radicales libres de alanina y/o de defectos cristalinos. En un análisis previo, el espectro de polvos de RPE de la alanina irradiada se pudo representar a partir de la superposición de quintetos, cuartetos mas un doblete, (Cabral Prieto et al., 1994). Debe mencionarse que esíe análisis a base de cuartetos, quintetos, y el doblete fue solo un ejercicio para conocer ciertos rasgos espectrales para dilucidar un poco la estructura de líneas de este patrón de polvos, pero sin utilizar ninguna base teórica mas que la de los quintetos y cuartetos que uno detecta en el patrón de un monocristal de alanina irradiado.

Para tener una imagen más analítica de el espectro de RPE de los radicales libres de alanina, se dan los hamiltonianos que describen la interacción, del electrón libre con los protones del grupo metilo $\left(\mathrm{CH}_{3}\right)$ y del $\mathrm{CH}$ del radical libre de alanina $\left(\mathrm{CH}_{3} \dot{\mathrm{C}} \mathrm{HR}\right)$, y con el campo magnético externo. En general

$$
\mathrm{H}=\left\{g_{s} \beta H+\sum\left(A_{f} I_{z}\right)_{C H_{3}}+\left[A_{f} I_{z}+A_{\mu}\left(3 \cos ^{2} \theta-1\right) I_{z}\right]_{C H}\right\} S_{z},
$$

donde el primer término representa a la interacción entre el mumento magnético del electrón y el campo magnético externo, o efecto Zeeman. El segundo y tercer términos de la expresión representan la interacción hiperfina (isotrópica y la anisotrópica), entre el electrón libre y el momento magnétiso nuclear de los protones de los grupos $\mathrm{CH}_{3}$ y $\mathrm{CH}$, respectivamente. $\theta$ mide el ángulo entre el eje 
de simetría axial del radical libre y la dirección del campo externo. Al resolver [A1] para las energías (Miyagawa et al. 1962) se obtiene:

$$
\mathrm{E}=\left\{g_{s} \beta H+\sum\left(A_{f} M_{l}\right)_{C H_{3}}+\left[A_{f} M_{l}+A_{\mu}\left(3 \cos ^{2} \theta-1\right) M_{l}\right]_{C H}\right\} M_{s} .
$$

En estas expresiones las constantes de acoplamiento dipolar, $\left(A_{\mu}\right)_{C H}$ y de Fermi, $\left(A_{1}\right)_{\mathrm{CH}}$, se pueden expresar como:

$$
\left(A_{\mu}\right)_{C H}=\rho_{c} g_{s} \beta g_{l} \beta_{l} /\left\langle r^{3}\right\rangle_{A v}
$$

y

$$
\left(A_{f}\right)_{C H}=16 \pi \beta \beta_{1}\left(\phi_{0}^{\circ} \phi\right) \rho_{C H} / 3 \text {, }
$$

donde $\rho_{c}$ representa la densidad efectiva de espín electrónico sobre el carbono de grupo $\mathrm{CH}$, la cual puede estar localizada sobre el enlace $\mathrm{CH} . g_{s}$ es el factor giromangético del electrón y $\beta$ es el magnetón de Bohr. $g$, es el factor $g$ del protón y $\beta$, su magnetón nuclear. $\left\langle r^{3}\right\rangle_{A v}$ es la separación efectiva entre $\rho_{c}$ y $\mu_{\text {. }}$. promediada ésta separación a lo largo del enlace $\mathrm{CH}$. El factor $\left(\phi_{0} \dot{\phi}^{\circ}\right)$ en $[\mathrm{A}-4]$ representa a la densidad de espín electrónico en el núcleo $\mathrm{H}$ del grupo $\mathrm{CH}$ y $\mathrm{f}_{\mathrm{cH}}$ es la densidad de tipo s en el átomo de hidrógeno del grupo $\mathrm{CH}$.

Miyagawa y Gordy, (1962), estiman los parámetros hiperfinos contenidos en estas expresiones confirmando algunos resultados experimentales usando los 
espectros obtenidos con los monocristales de $\mathrm{L}$-alanina irradiada con rayos $\mathrm{X}$. El efecto anisotrópico del protón del grupo $\mathrm{CH}$ fue también calculado por otros autores (Hrosfield et al., 1962).

Así, el patrón de polvos de RPE de la alanina irradiada consiste de una superposición de patrones (Cabral-Prieto et al., 1991, 1994) qııe puede deberse tanto al efecto anisotrópico del protón del grupo $\mathrm{CH}$ como al del efecto Zeeman ; además la presencia de especies secundarias de radicales libres y/o de defectos cristalinos no se descartan. El espectro que uno observa a la temperatura ambiente es como es el que se muestra en la Fig. A-I; esto es, un patrón de cinco líneas muy ensanchadas, separadas una de otras por aproximadamente $2.5 \mathrm{mT}$ y con razones de intensidad muy próximas a $1: 4: 6: 4: 1$. Es como si este patrón resultara de la sola interacción de un electrón con cuatro protones magnéticamente equivalentes confirmándose de esta manera la especie de radical libre propuesta por Miyagawa y Gordy., (1960).

\section{A.2 Patrón de RPE de la alanina irradiada a $77 \mathrm{~K}$}

Es interesante mencionar solo de paso, los resultados reportados en la literatura sobre experimentos a $77 \mathrm{~K}$ para estudiar la naturaleza de los radicales libres que se inducen al irradiar alanina policristalina. 

Gupo metilo
$\mathrm{CH}_{3} \dot{\mathrm{C}} \mathrm{HR}$
$\mathrm{CH}_{3} \dot{\mathrm{C}} \mathrm{HR}$

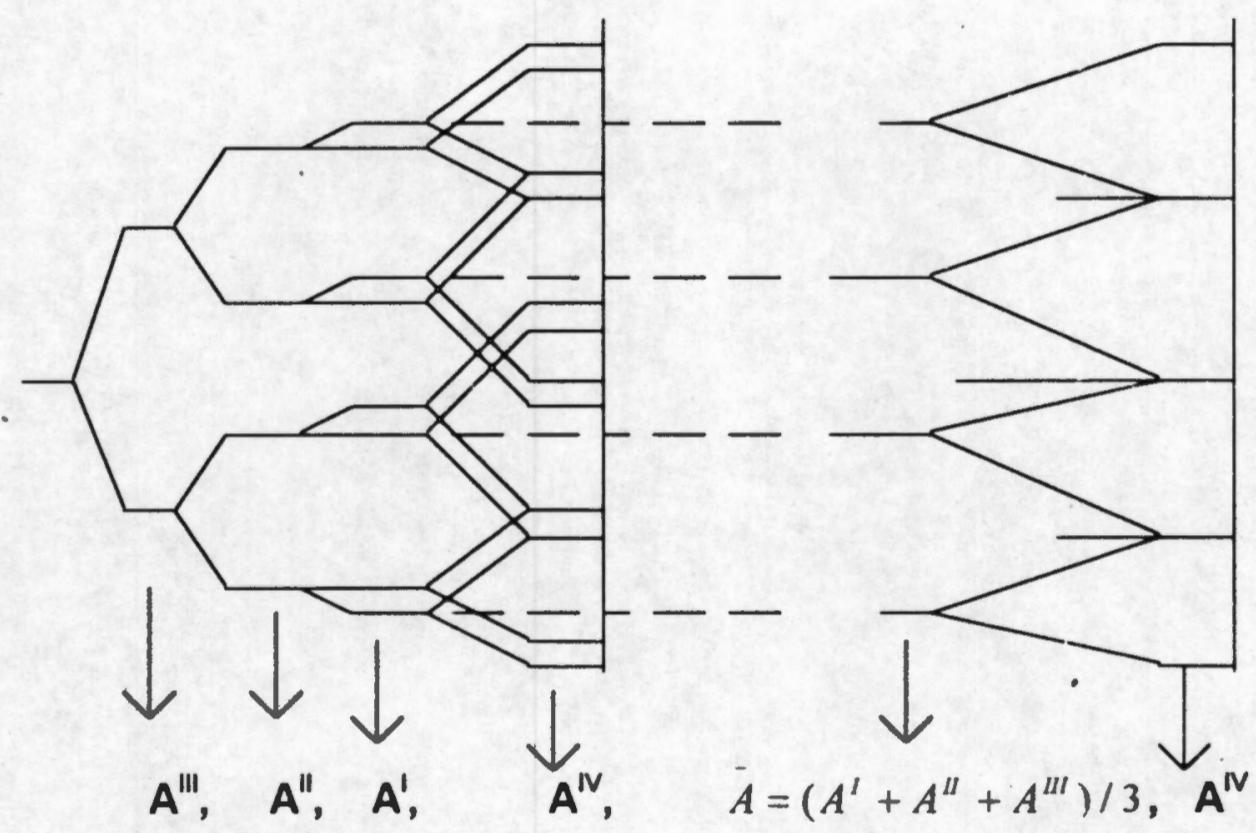

Figura A-III. Diagrama esquemático de los niveles de energía del radical libre de alanina bajo dos temperaturas distintas : a $77 \mathrm{~K}$ y a $293 \mathrm{~K}$. Las constantes de acoplamiento están indicadas según el caso de temperatura o equivalencia magnética entre protones. 
A $77 \mathrm{~K}$ la equivalencia magnética entre los protones de los grupos $\mathrm{CH}_{3}$ y del $\mathrm{CH}$ desaparece. El hamiltoniano correspondiente en su parte hiperfina para estos protones es :

$$
H=\left(A^{\prime} I_{12}+A^{\prime \prime} I_{2 z}+A^{\prime \prime \prime} I_{3 z}+A^{\prime \prime} I_{4 z}\right) S_{2}
$$

Resolviendo para la energía :

$$
E=\left(A^{\prime} M_{12}+A^{\prime \prime} M_{2 z}+A^{\prime \prime \prime} M_{3 z}+A^{\prime \prime} M_{4 z}\right) M .
$$

de donde resultan 12 transiciones como se ilustra en la Fig. A-III, donde existe una constante de acoplamiento, $A_{i}$, para cada uno de los protones. Cabe mencionar que al estudiar la naturaleza de los radicales libres de la alanina irradiada algunas mediciones a bajas temperaturas con RPE-cz, no se obtienen evidencias de especies secundarias de radicales libres en la alanina irradiada (Olsson et al., 1996), aunque de otras mediciones se muestran lo contrario (Pilbrow et al. 1996).

\section{A.3 Transiciones prohibidas en el radical libre $\mathrm{CH}_{3} \dot{C} \mathrm{HR}$.}

Las líneas que aparecen a ambos lados de la línea de reso:nancia central del quinteto de polvos de RPE de los radicales libres de alanir.a (ver Fig. 3 del Capitulo III) han sido asociadas a transiciones prohibidas $\left(\Delta \mathrm{m}_{1}= \pm 1\right)$, como 
resultado de la interacción dipolar entre el espín electrónico y los protones vecinos. En esta interacción se produce una transición o camúio simultáneo de los números cuánticos de espin nuclear y electrónico (transiciones spin-flip en inglés). El hamiltoniano que describe esta interacción puede escribirse como:

$$
H=-\mu_{e} \bullet H-\left(H+h_{e p}\right) \bullet \mu_{p}
$$

donde la e y la $a_{p}$ se refieren al electrón y al protón, $\mu$ es el operador del momento magnético del protón, $\boldsymbol{H}$ es el campo magnético aplicado (en la dirección z), y $\mathbf{h}_{\text {ep }}$ es el campo magnético del electrón en el protón en cuestión. Mas explícitamente este hamiltoniano puede escribirse como

$$
H=-g_{e} \beta_{e} H-g_{p} \beta_{p} I_{p z} H-g_{e} \beta_{e}\left\{\frac{8 \pi}{3} S_{e} \delta\left(r_{e p}\right)-\frac{1}{r_{e p}^{3}}\left[S_{e}-\frac{3\left(S_{e} \bullet r_{e p}\right) r_{e p}}{r_{e p}^{2}}\right]\right\} \bullet g_{p} \beta_{p} I_{p z}[\mathrm{~A}-10]
$$

donde $g_{\bullet}$ es la razón giromagnética del electrón, $\beta_{\bullet}$ y $\beta_{p}$ son el magnetón de Bohr y nuclear, $S$ e I son los operadores de espín en unidades de $\hbar, r_{e p}$ es el vector de distancia entre el electrón y el protón.

Las energias correspondientes al hamiltoniano de la expresión [A-9] están dadas por 


$$
E\left(M_{e}, M_{\rho}\right)=-g_{e} \beta e M_{e} H-g_{p} \beta_{p} M_{p}\left|H+h_{e p}\left(M_{e}\right)\right|
$$

en donde la separación entre la línea de resonancia princijal $\left(g_{\bullet} \beta_{a} H\right)$ y, las satélites esta dada aproximadamente por $\pm g_{p} \beta_{p} H$ siempre y cuando $h_{\text {ei, }}<H$, donde $\boldsymbol{H}$ es el campo magnético aplicado. Para átomos de hidrćgeno y usando la banda $X$ de microondas $(9 \mathrm{GHz})$, esta separación es de aproximadamente $0.5 \mathrm{mT}$ (Livingston et al. 1955; Trammell et al., 1958). Este valor coincide aproximadamente con la separación de algunas líneas de resor.ancia en espectro de polvos de RPE de los radicales de alanina (presente trabajo). Al tomar en cuenta la probabilidad de transición y la expresión [A-11] Trammell et al. (1958) llega a deducir una expresión para estimar la distancia efectiv: entre el electrón libre y el protón vecino, a través de una cálculo de la razón de iritensidades de las líneas satélite a las de las permitidas. La expresión de Trammell et al. ,(1958), es la siguiente :

$$
\langle r(n)\rangle=0.7289(g \beta / H)^{1 / 3}\left(n 2 T_{2} / T_{1}\right)^{1 / 6},
$$

donde $g_{\bullet}$ y $\beta_{\bullet}$ son el factor $g$ y magnetón de Bohr del electrcin. La razón $T_{2} / T_{1}$ representa la razón de intensidades de la señal permitida $T_{2}$ a l zeñal satélite $T_{1}$. El valor de $n$ representa al número de protones vecinos al electrón libre y $\langle\pi(n)>$ es la distancia promedio entre ese electrón y los protones $n$. 
Por otra parte, de los experimentos de saturación, y observando el aumento de la intensidad de algunas líneas de resonancia al incrementai la potencia de microondas, algunos autores (Arber et al., 199 ; Barnard et al. 1996) concluyen que esas señales son de origen prohibido.

Como se muestra en este trabajo hay cierta confusión en la identificación y señalización de estas señales satélites, (Arber et al., 1991), por lo que aqui se hace una reinterpretación de dicha señalización en el Capítulo Ill. 


\section{APÉNDICE B}

\section{DECONVOLUCIÓN DE ESPECTROS}

En este Apéndice se muestra un procedimiento para resolver en energía un espectro a partir del método aproximado de deconvolución (Cabral-Prieto et al., 1991) descrito en el Capitulo I. Para ello se escogen valores iniciales de los parámetros de deconvolución $\boldsymbol{n}, \boldsymbol{m}$ y $\Gamma_{\mathbf{G}}$, incluidos en las expresiones [16] y [17] del Capitulo I. El valor de $\Gamma_{G}$ se calcula previamente a partir de una ajuste de mínimos cuadrados sobre el espectro de RPE a resolver. Los parámetros $\boldsymbol{n}$ y $\boldsymbol{m}$ se estiman empíricamente durante el proceso de deconvolución.

En este apéndice también se hace una comparación entre este método aproximado de deconvolución con uno no aproximado de Hedberg and Ehrenberg (1968).

Debido a que el método aproximado ofrece mejores resultados para el presente estudio, el procedimiento de su deconvolución se describe primero, en donde se usa un espectro de polvos de RPE de la alanina pura irradiada. Para el caso de comparación entre métodos (aproximado y no aproximado) solıs se usarán datos simulados. 


\section{B. 1 Deconvolución usando el método aproximado}

Así, como se muestra en los Capitulos III y IV los espectros de RPE de la alanina irradiada se pueden ajustar, mediante minimos cuadrados, emplıando algún perfil. En general, los espectros de RPE de la alanina pura irradiada, se pueden ajustar al perfil de Voigt, en donde un ancho de tipo gausiano y uno ce tipo lorentziano contribuyen al espectro. Esto es, para emplear el método aproximado de deconvolución descrito en el Capítulo I, Sección B, se requiere de un análisis previo del tipo de ensanchamiento que posee un espectro dado. En este caso las líneas de todos los espectros de RPE de la alanina pura irradiada son de tipo Voigtiano, por lo que distribuciones de tipo lorentziano o gaussiano pueden eliminarse del espectro de RPE escogido y resolverlo en energía. El espectro de RPE escogido es el de la alanina pura irradiada con $10 \mathrm{kGy}$, sin ningún tratamiento térmico. La Tabla 2 del Capítulo III muestra que el ancho Voigtiano de la línea central es de aproximadamente $1.59 \mathrm{mT}$. La contribución lorentziana a dicha línea es muy pequeña $(0.02 \mathrm{mT})$. Esto es, el ensanchamiento de esta línea es prácticamente de tipo gaussiano. Asi, el ancho escogido para deconvolucionar un espectro de varias lineas debe ser representativo para cada una de esas líneas.

De acuerdo al método de deconvolución descrito en el Capítulo I, hay ciertas restricciones para el uso de los parámetros de deconvolución. Por ejemplo, el ancho de deconvolución, $\Gamma_{L} \dot{o} \Gamma_{G}$, solo puede tomar valores, igual o menor, al 
ancho medio a la mitad del pico (AMMP) de la línea que se desea deconvolucionar. En el presente caso se tiene un ancho promedio de aproximadamente $1.59 \mathrm{mT}$ para cada una de las líneas del espectro. Debido a esto se escoge el semiancho de aproximadamente $0.8 \mathrm{mT}$. En !a Fig. B-I de este Apéndice B se muestran los anchos de deconvolución empleados. Una vez estimado el ancho de deconvolución, el siguierite parámetro a determinar es el tamaño de paso, $\boldsymbol{m}$, para evaluar las derivadas pares del espectro real de acuerdo a la expresión [18] del Capitulo I. Los parámetros $m$ y $r$ que se estiman empíricamente, determinan en gran medida la calidad de un espectro deconvolucionado. Por ejemplo, si se tiene un espectro que presenta muchas fluctuaciones estadísticas (sea porque la razón de la señal-a-ruido es pequeña, o por alguna otra razón) y se escoge el valor mas pequeño para in ; esto es $\boldsymbol{m}=1$, entonces el espectro deconvolucionado también presentará fluctuaciones que obscurecen el resultado deseado. Para resolver esto, siempre se busca el mejor valor de $\boldsymbol{m}$, ( $\boldsymbol{m}=1$ solo para el caso de que el espectro sea continuo y con cero error estadistico), que en general es mayor que la unidad. En e:ste caso resultó $\boldsymbol{m}$ $=5$, Fig. B-I. Finalmente, el valor de $n$, que determina el númerc de términos de la serie a usar, ya sea de la expresión [16] o [17], del Capitulo I, también depende de la calidad de los datos experimentales. En general, para los espectros de RPE analizados en el presente trabajo se empleó un valor de $n=6$. Este valor disminuye a medida que la calidad de los datos experimentales 'ss mejor ; esto es, con pocas fluctuaciones estadisticas. 


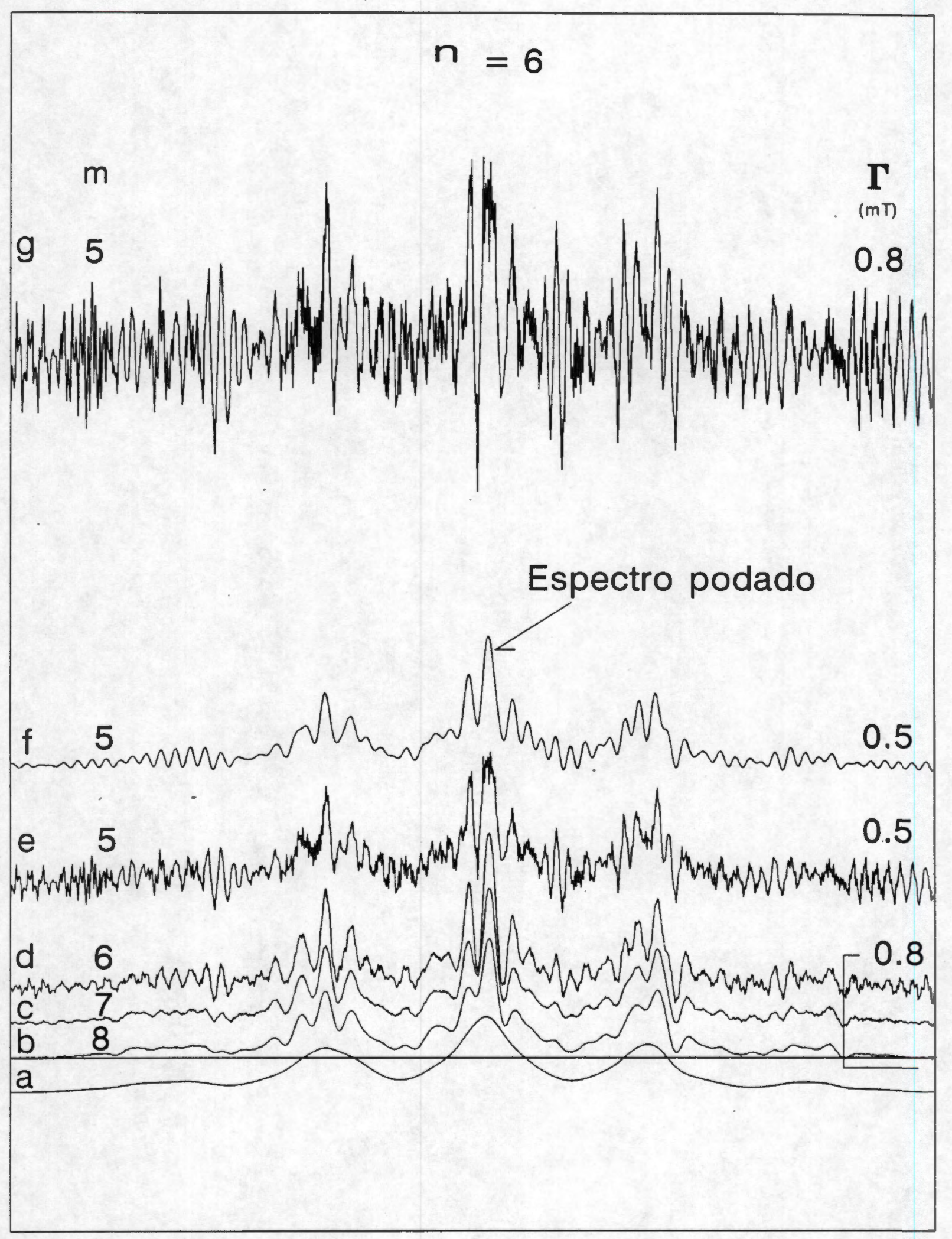

FIGURA B-I. Proceso de deconvolución para obtener un espectro resuelto. Ver texto. 


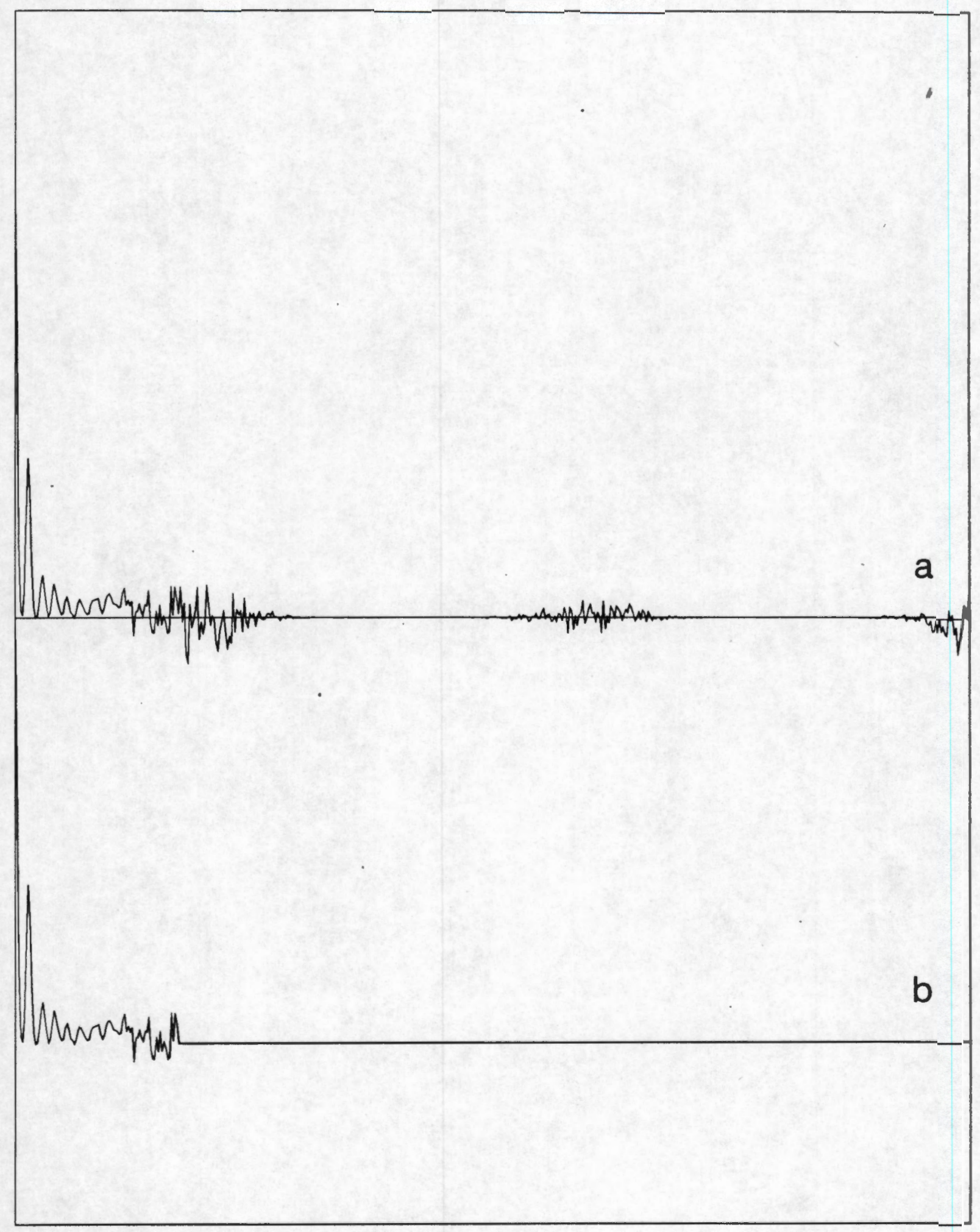

FIGURA B-II. a) Transformada de fourier del espectro deconvolucionado de la Fig. A-I-e. b) Espectro (a) truncado, empleando una función rectangular normalizada para eliminar señales de alta frecuencia. 
Estas son algunas de las reglas generales para obtener los parámetros óptimos durante un proceso de deconvolución de un espectro de RPE o de cualquier otro tipo, usando el método aproximado de deconvolución descrito en el Capítulo I. En las Figs. B-I (b, c, d y e) se muestra el efecto de variar los parámetros $\boldsymbol{m}$ y $\Gamma_{G}$, manteniendo constante el valor $n=6$ y usando la serie [16] descrita en el Capítulo I.

Como se puede observar de la figura B-I, al disminuir el valor de $\boldsymbol{m}$ (desde ocho hasta cinco) y manteniendo constante el ancho de deconvolución a $0.8 \mathrm{mT}$ y el número $n=6$, el efecto que se observa es que el espectro comienza a resolverse cada vez mas a medida que disminuye el valor de $\boldsymbol{m}$. Se tiene el caso extremo, Fig. B-1 g, de un espectro deconvolucionado usando los valores de $m=5, \Gamma_{G}=$ $0.8 \mathrm{mT}$ y $n=6$, en donde el ruido estadístico predomina sotre las señales de resonancia que se buscan. Cuando se llega a este punto, el parámetro que se varía es el ancho de deconvolución (ancho gausiano) $\Gamma_{\mathrm{G}}$ o disminuir el valor de $\boldsymbol{n}$. Aquí se optó por variar el primero. Cuando este ancho cambia de $0.8 \mathrm{mT}$ a 0.5 mT, se obtiene entonces un espectro deseable, Fig. B-I (e). Debido a que las fluctuaciones que aparecen en este espectro, Fig. I. (e), aun se confunden con las señales de resonancia buscadas, bajo estas condiciones de deconvolución ( $\boldsymbol{m}=5$, $\Gamma=0.5 \mathrm{mT}$ y $n=6$ ), el paso siguiente es transformar el espectro deconvolucionado, Fig. B-I (e), al dominio de frecuencias, usando la transformada de Fourier. Esto se muestra en la Fig. B-ll (a). En el dominio de frecuencias se eliminan las señales de alta frecuencia usando la función rectángular como se 
muestra en la Fig. B-II (b). A este procedimiento se le conoce son el nombre de método de poda de un espectro (Robert et al., 1992). Una vez p:sdado el espectro, este se regresa al espacio real, usando la transformada inversa de Fourier. De esta manera se eliminan parte de las señales de alta frecuencia o fluctußciones estadísticas que resultan del proceso de deconvolución, Fig. 3-I (e). Al realizar esto el espectro resultante prácticamente queda limpio de oscile.ciones espurias y además se obtiene un espectro mejor definido en energía, Fig. B-I (f).

\section{B. 2 Comparación entre métodos de deconvolución}

La integral de convolución de dos funciones, eq. [1] del Crapítulo I, puede expresarse como un simple producto de la funciones convolucionantes, Eq. [10] del Capítulo I :

$$
I(\alpha)=(2 \pi)^{1 / 2} G(\alpha) L(\alpha),
$$

donde $I(\alpha)$ es la transformada de Fourier del espectro observado y $G(\alpha)$ es la transfoemada de Fourier de la función de modulación (gausiana)del proceso de absorción de luz y $L(\alpha)$ es la función natural (lorentziana) del proceso de resonancia. 
Según Hedberg and Ehrenberg (1968) la función moduladora o ensanchadora puede eliminarse de B-[1] multiplicando su lado izquierdo por $H(\alpha) / G(\alpha)$. Esto es

$$
R(\alpha)=(2 \pi)^{1 / 2} I(\alpha) H(\alpha) / G(\alpha),
$$

donde $R(\alpha)$ es un espectro resuelto en energía y $H(\alpha)$ es le transformada de Fourier de cualquier función escogida por el usuario y que determina el grado de resolución de un espectro $I(\alpha)$ dado. Con el uso de esta función $H(\alpha)$ uno podria eliminar totalmente la señal de ensanchamiento o la función natural. Este caso no lo acepta el método aproximado descrito en el Capítulo I. Para el caso en que una lorentziana se elimina de un espectro la forma es la siguiente :

$$
R(\alpha)=(2 \pi)^{1 / 2} \mid(\alpha) H(\alpha) / L(\alpha) .
$$

Para probar estas expresiones B-[2 y 3] y compararlas con las descritas en el Capitulo I Eqs. [16 y 17] se usará un doblete Voigtiano ensanchado con $\Gamma_{L}=30$ unidades arbitrarias y $\Gamma_{\mathbf{G}}=1$ unidad arbitraria. La intensidad relativa entre los picos es de $1: 2$ y una separación entre ellos de 10 unidades arbitrarias. Este es un caso extremo en donde debido al ensanchamiento prácticamiante se ve un solo pico. Así, la expresión B-[3] será usada, en donde la contribución lorentziana será removida del doblete original, Fig. B-III (a). Los resultados se muestran en la Fig. B-III (b-e). El ancho usado para $\Gamma_{\mathrm{L}}$ fue de 30 unidades arbitrar. $a s$; esto es, es el mismo valor para producir el doblete. Por otra parte, los anches usados para $\Gamma_{H}$ 


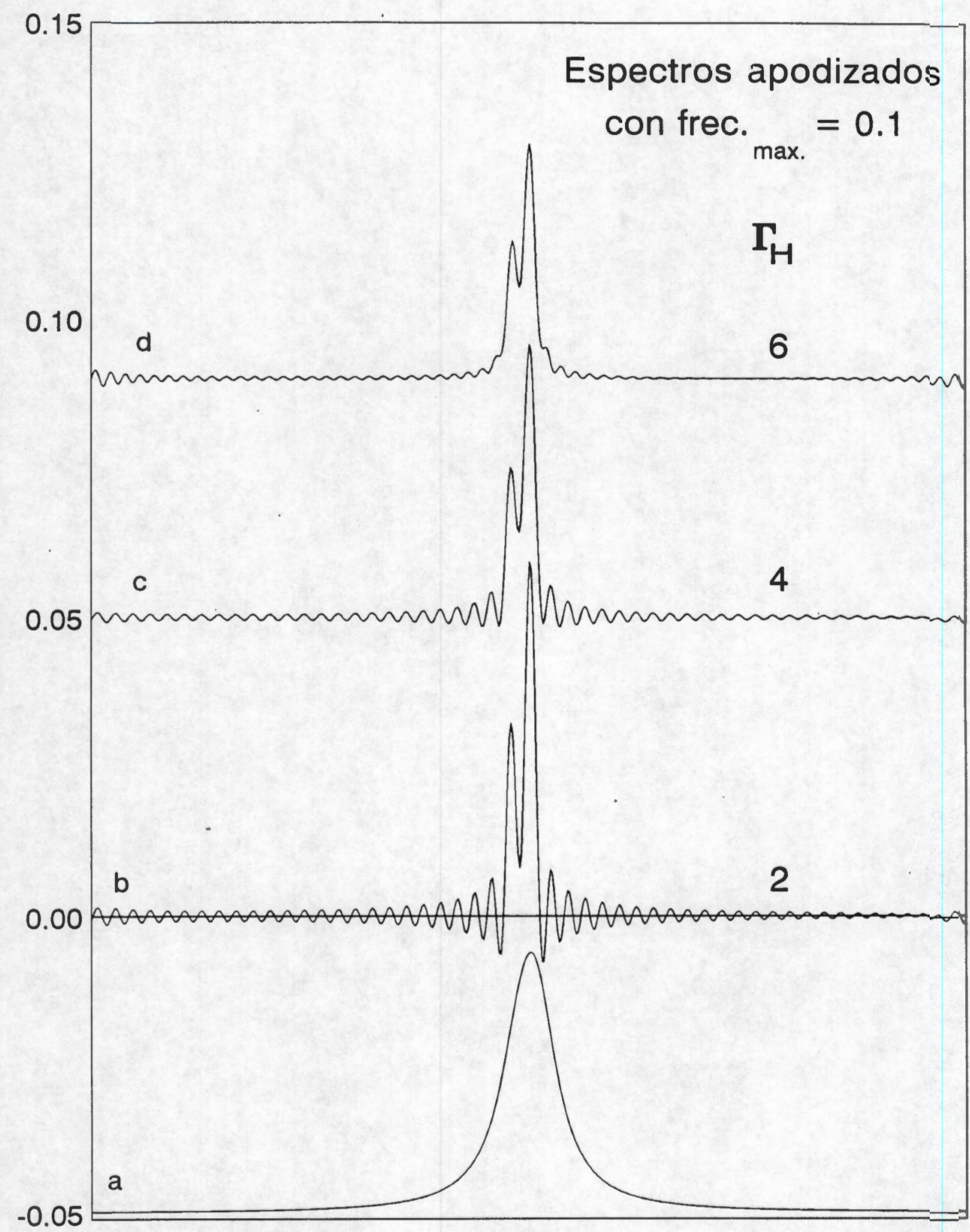

FIGURA B-III. (a) Doblete Voigtiana simulado libre de ruido. (b) $F W H M=2$, (c) $F W H M=4$, (d) FWHM $=6$ unidades arbitrarias. Los tres espectros resuletos fueron apodizados usando un corte de frecuencia maxima de 0.1 . 
fueron de 2, 4 y 6 unidades arbitrarias, Figs. B-III (b), (c) y (d), respectivamente. Los espectros así resueltos fueron apodizados usando un corte de frecuencia máxima de 0.1 y utilizando una función rectángular como se describe en la parte $\mathrm{A}$ de este apéndice B. Aunque las oscilaciones que aparecen son mínimas, estas en ningún caso desaparecen para cualquier valor de $\Gamma_{\mathbf{H}}$. Debido a que el doblete original esta libre de fluctuaciones estadisticas, las oscilaciones que aparecen en los espectros resueltos surgen de la propia representación de funciones en el espacio de Fourier. De acuerdo a Hedberg and Ehrenberg (1968) el ensanchamiento total lorentziano debiera ser removido sin ningún problema. Esto no ocurre así. Uno tiene que aumentar el ancho de la función $H(\alpha)$ a cierto valor para poder minimizar la presencia de señales oscilantes, pero sin llegar a eliminarlas completamente. Por otra parte observe que la razón cie intensidades es cercana a $1: 2$.

Estos resultados del método no aproximado serán ahora comparados con los obtenidos usando el método aproximado. Se usará el mismo doblete Voigtiano de la Fig. B-III (a).

El autor de esta trabajo de tesis ha usado exclusivamente el método aproximado para incrementar la resolución en varios tipos de espectros (Cabral-prieto et al., 1993). 
La expresión [17] del Capitulo I se usará exclusivamente. Loś resultados de su aplicación de acuerdo a la Sección A de este Apéndice B se muestran en la Fig. B-IV (a-f).

Al lado derecho de la Fig. B-IV se muestran los parámetros involucrados para obtener el doblete resulto. Particularmente, nótese que los parámetros óptimos fueron $\Gamma_{L}=25$ unidades arbitrarias, $m=1$ y $n=4$. La presencia de señales de alta frecuencia pueden ser casi totalmente eliminadas usand) la técnica de apodización. De igual forma la razón de intensidades se mantienı casi igual a 1 :2. Si se compara los resultados a través de las figuras B-IV (f) y B-III (e) se puede concluir que el método aproximada puede ofrecer mejores resultados siempre y cuando los parámetros involucrados sean elegido adecuadamerte. Esto es, con el método aproximado es posible obtener un espectro casi ausente de oscilaciones que se puedan confundir con las señales que se buscan. Esto no ocurre con el método no aproximado.

Otra prueba adicional es la que se muestra en la Fig. B-V. En esta figura se muestra una comparación entre los métodos (aproximado y no aproximado) sobre el mismo doblete Voigtiano pero con ruido, con una razón de señal-a-ruido de 20. El espectro resuelto que se obtiene cuando se usa el método aproximado es el de la Fig. B-V (c), mientras que el espectro resulto que se obtiene con el método no aproximado es el que se muestra en la Fig. B-V (d). En ambos casos los espectros fueron apodizados usando una frecuencia máxima de 0.15. A pertir de esta figuras 


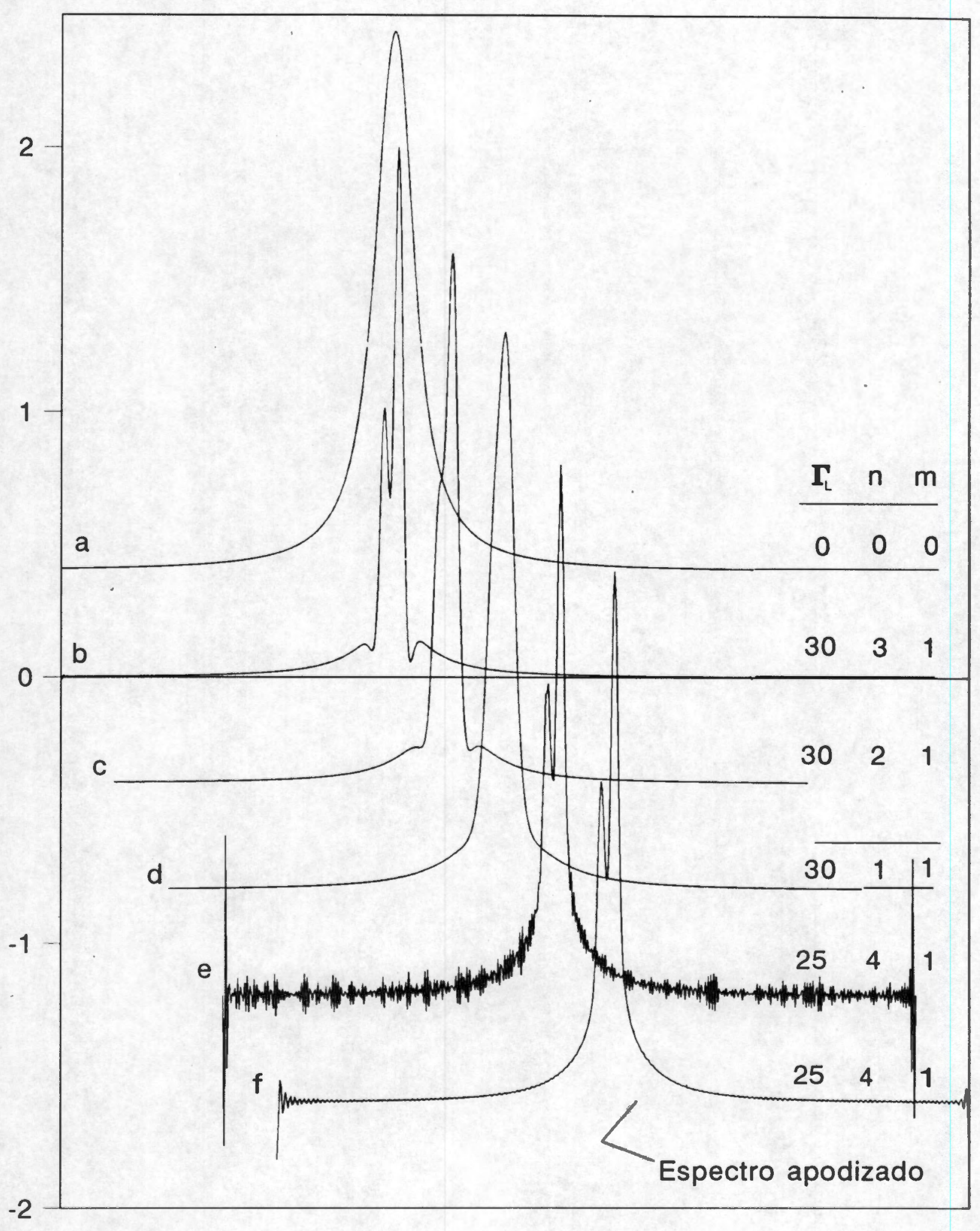

FIGURA B-IV. (a) Doblete simulado libre de ruido. (b), (c) espectros deconvolucionados con una distorción cerca del doblete. Usando los otros parámentos (d) y (e) dicha distorción es posible eliminarla. Apodizando el espectro (e) las señales de alta frecuencia son eliminadas. 


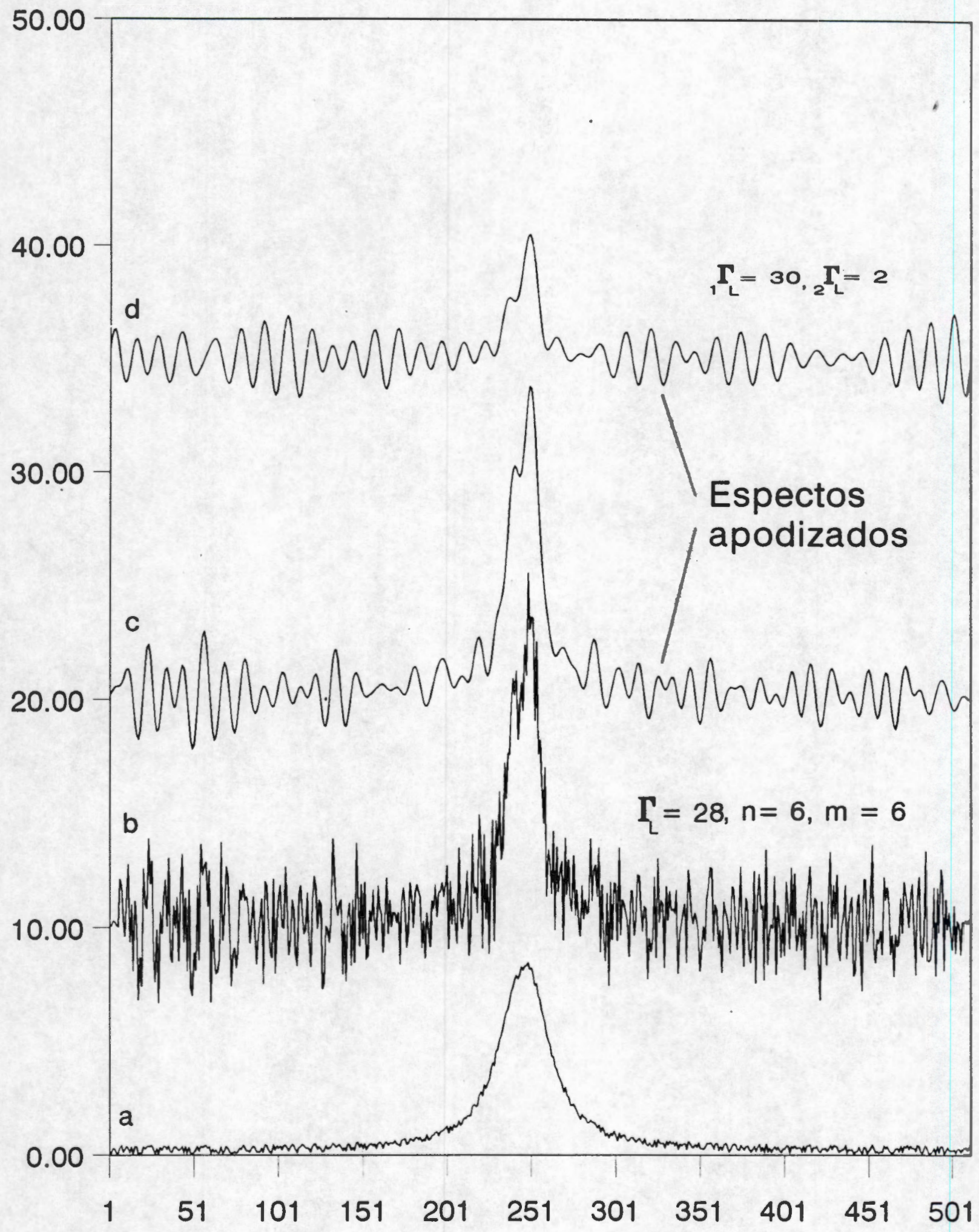

FIGURA B-V. (a) Doblete simulato con ruido. (b) Espectro resuelto con el método aproximado y (c) espectro anerior apodizado. (d) Espectro resuleto usando el método no aproximado y apodizado. Los parámetros de doconvolución están dados para cada caso. 
uno puede concluir que el método aproximado entrega una razón de señal-a-ruido mucho mejor que aquella que da el método no aproximado. Este hecho es suficiente para elegir entre uno de estos métodos. 


\section{BIBLIOGRAFIA}

A. Abragam and B. Bleaney. Electron Paramagnetic Resonance of Transition lons". Dover publications, Inc. New York, 1986.

A. Bartolotta, P. Fattibene, S. Onori, M. Pantaloni and E. Petetti. "Sources of Uncertainty in the Therapy Level Alanine Dosimetry". Appl. Radiat. Isot. 44(1/2), (1993), p. 13.

A. Horsfield, J. R. Morton and D. H. Whiffen, Mol. Phys, 4, (1961), p. 425.

A. Horsfield, J. R. Morton and D. H. Whiffen. The Electron Spin Resonance Spectrum of $\mathrm{CH}_{3} \dot{\mathrm{C}} \mathrm{CH}\left(\mathrm{CO}_{2} \mathrm{H}\right)$ Between $100 \mathrm{~K}$ and $200 \mathrm{~K}$. Mol. Phys, 5, (1962), p. 115 ;

A. Wieser, C. Lettau, U. Fill and D. F. Regulla. The Influence of Non-radiation Induced ESR Background Signal from Paraffin-alanine Probes for Dosimetry in the Radiotherapy Dose Range. Appl. Radiat. Isot., 44(1/2), (1993), p 59.

B. Rakvin. Improvement of Sensitivity in the Alanine/ESR Dosimetry. Appl. Radiat. Isot., 47(11/12), (1996), p. 525.

A. Cabral-Prieto, $H$. Jiménez-Dominguez. and $M$. Torres-Valderrama. A Deconvolution Method for Small Computers. Nucl. Instr. And Methods, B54, (1991), p. 532.

A. Cabral-Prieto, F. Ureña-Nuñez and H. Jiménez-Domínguez. The Ultraviolet Light Efect on the Alanine Radicals and Its Resolution Enhanced Electron Paramagnetic Resonance Powder Pattern. J. Cem. Phys. 101(3), (1994), 1967.

D. J. E. Ingram. Free Radicals as Studied by Electron Spin Resonance. (Butterwoth's Scientific Publications, Ltd., London, 1958.

D. W. Posener, Austr. J. Phys, 12, (1959), p. 184.

E. Oran Brigham. "The Fast Fourier Transform ". Prentice Hail, Inc, Englewood Cliffs, New Jersey, 1974.

F. Ruckerbauer, M. Sprunck and D. F. Regulla. Numerical Signal Treatment for Optimized Alanine/ESR Dosimetry in the Therapy-level Dose Range. Appl. Radiat. Isot. 47(11/12), (1996), p. 1263.

M. J. Flores, S. Galindo, Use of Alanine-Silicone Pellets for Electron Paramagnetic Resonance $\gamma$ Dosimetry, Radiat. Res. 125, (1991), pp.335-33i. 
G. T. Trammell, H. Zeldes and R. Livingston. Effect of the Environmnetal Nuclei in Electron Spin Resonance Spectroscopy. Phys. Rev. 110, (1958), 630.

H. St. Louis Robert, F. Siems William adn H. Hill Jr. Herbert. Apodization Functions in Fourier Transform Ion Mobility Spectrometry. Anal. Chem. 64, (1992), pp. 171177.

H. Zeldes and R. Livingston. Pramagnetic Resonance Study of Irradiated Glasses of Methanol and Ethanol. The Journal of Chem. Phys., 30(1), (1n59), 40.

I. Miyagawa y W. Gordy. Electron Spin Resonance of an Irradié:ted Single Crystal of Alanire: Second-order Effects in Free Radical Resonances. J. Chem. Phys. Vol 23(1), (1960), p. 255.

I. Miyagawa and $\mathrm{K}$. Itoh. Electron Spin Resonance Single $\mathrm{Cr}$ /stals of Alanina: Hindered Rotation of the Methyl Group in a Free Radical. J. Chem. Phys. 36, (1962), p. 2157.

K. Itoh and I. Miyagawa. Electron Spin Resonance Single Crystals of Alanina: Proton-deuteron Exchange Reaction of a Free Radical in the Solıd State. J. Chem. Phys. 40, (1964), p. 3328.

K. Itoh, I. Miyagawa and C. S. Chen. ESR Study of an Irraciated Crystal of Lalanine :Two new Proton-deuteron Exchange Reactions. J. Chem. Phys. 52, (1970), p. 1822.

M. S. Matheson. Radiation Chemistry in Rigid Organic Materials : The Detection of Intermediates. Proceedings of the Second United Nations International Conference on the Peaceful Uses of Atomic Energy (United Nations, Geneva, 1958), Vol. 29, p. 217

P. Höfer, K. Holczer, and D. Schmalbein. Characterization of Gamma-ray Irradiated Powder Alanine Samples by Pulsed EPR. Appl. Radiat. Isot., 40, (1989), p. 1233.

P. H. G. Sharpe, K. Rajendran and J. P. Sephton. Progress Towards an Alanine/ESR Therapy Level Reference Dosimetry Service at NPL. Appl. Radiat. Isot., 44(11/12), (1996), p. 1171.

P. O. Samskog, G. Nilson, A. Lund and T. Gillbopro. Prirnary Reactions in Irradiated Deutero $\alpha$-amino Acids Studied by Pulse Radiolysis and ESR Spectroscopy. J. Phys. Chem., 84, (1980), p.p. 2819-2823.

D. F. Regulla y U. Defner. Dosimetry by ESR Spectroscopy of Alanine. Appl. Radiat. Isot., 33, (1982), p. 1101. 
Proceedings of the $3^{\text {rd }}$ International Symposium on ESR Dosimetry and Applications. Aapl. Radiat. Isot., 44(10/12), 1989; (b) Proceedings of the $3^{\text {rd }}$ International Symposium on ESR Dosimetry and Applications. Aapl. Radiat. Isot., 44(1/2), 1993 ;(c). Proceedings of the $4^{\text {th }}$ International Symposium on ESR Dosimetry and Applications. Appl. Radiat. Isot., 47(11/12), 1996.

S. Kuroda y I. Miyagawa. ENDOR Study of an Irradiated Crystal of L-alanine : Environment of the Stable $\mathrm{CH}_{3} \mathrm{CHCO}-$ radical. J. Chem. Phys, 76(8), (1982). p.3933.

T. Brustad and J. Dyrset. The Effect of Heat an UV-light on X-ray Induced ESR Center in $\alpha$-alanine. Acta Chem. Scand. 18, (1964), p. 1559.

K. Matsuki and I. Miyagawa. ENDOR Study of an Irradiated Crystal of L-alanine : Structure and the Environment of the Unstable $\mathrm{CH}_{3} \mathrm{CHCO}_{2}^{-}$. J. Chem. Phys, 76(8), (1982), p.3945.

J. R. Morton and A. Horsfield. Electron Spin Resonance Spectrum and Structure of $\mathrm{CH}_{3} \dot{\mathrm{C}} \mathrm{CH}\left(\mathrm{CO}_{2} \mathrm{H}\right)$. J. Chem Phys. 35, (1961), p. 1142.

F. Ureña-Nuñez, A. Cabral-Prieto, H. Jiménez-Domínquez, $S$. Galindo and $P$. Bosch, EPR Structure of the Gamma-irdiated Alanine Spectruin. Appl. Radiat. Isot. 44(1/2), (993), 53.

K. Van Laere, J. I. Buysse, and P. Berkvens, Spectrophotometric and Electrochemical Readout Procedures Compared to ESR Spectrisscopy of Alanine. Int. J. Appl. Radiat. Isot., 40, (1989), p. 885.

W. Gautchi, SIAM J. Numer. Anal., 7, (1970), p. 187.

W. Voigt, S. B., Bayer Acad. Wiss., (1912), p. 603.

W. W. Bradshaw, D. G. Cadena,JR. , G. W. Crawfors and H: A. W. Spetzler. The Use of Alanine as a Solid Dosimeter. Radiation Research, 17, (1962), p. 11.

Y. N. Vitaly and M. F. Desrosiers. Complex Time Dependence of the EPR Signal of Irradiated L- $\alpha$-alanine. Appl. Radiat. Isot. 47(8), (1996), 789. 
